\title{
Mass spectrometry imaging for plant biology: a review
}

\author{
Berin A. Boughton • Dinaiz Thinagaran • \\ Daniel Sarabia $\cdot$ Antony Bacic $\cdot$ Ute Roessner
}
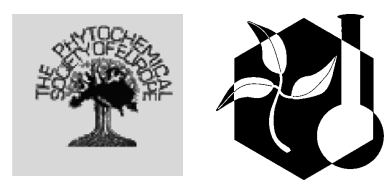

Received: 18 May 2015/Accepted: 25 September 2015/Published online: 13 October 2015

(C) The Author(s) 2015. This article is published with open access at Springerlink.com

\begin{abstract}
Mass spectrometry imaging (MSI) is a developing technique to measure the spatio-temporal distribution of many biomolecules in tissues. Over the preceding decade, MSI has been adopted by plant biologists and applied in a broad range of areas, including primary metabolism, natural products, plant defense, plant responses to abiotic and biotic stress, plant lipids and the developing field of spatial metabolomics. This review covers recent advances in plant-based MSI, general aspects of instrumentation, analytical approaches, sample preparation and the current trends in respective plant research.
\end{abstract}

Keywords Biochemistry - Lateral resolution . Natural products $\cdot$ Spatial mapping $\cdot$ Spatial metabolomics

B. A. Boughton $(\bowtie)$

Metabolomics Australia, School of BioSciences, The University of Melbourne, Parkville, VIC 3010, Australia e-mail: baboug@unimelb.edu.au

D. Thinagaran · D. Sarabia · A. Bacic - U. Roessner School of BioSciences, The University of Melbourne, Parkville, VIC 3010, Australia

A. Bacic

ARC Centre of Excellence in Plant Cell Walls, School of BioSciences, University of Melbourne, Parkville, VIC 3010, Australia

A. Bacic

Bio21 Molecular Science and Biotechnology Institute, University of Melbourne, Parkville, VIC 3010, Australia

\begin{tabular}{|c|c|}
\hline Abbreviations & \\
\hline 3D-MSI & $\begin{array}{l}\text { Three-dimensional mass } \\
\text { spectrometry imaging }\end{array}$ \\
\hline 9-AA & 9-Aminoacridine \\
\hline AP-MALDI & $\begin{array}{l}\text { Atmospheric-pressure matrix- } \\
\text { assisted laser desorption ionization }\end{array}$ \\
\hline AP-SMALDI & $\begin{array}{l}\text { Atmospheric-pressure high- } \\
\text { resolution scanning-microprobe- } \\
\text { MALDI }\end{array}$ \\
\hline $\begin{array}{l}\text { CHCA (or } \\
\text { HCCA) }\end{array}$ & $\alpha$-Cyano-4-hydroxycinnamic acid \\
\hline DAN & 1,5-Diaminonaphthalene \\
\hline$\Delta m$ & Mass difference \\
\hline DESI & Desorption electrospray ionization \\
\hline DHB & 2,5-Dihydroxybenzoic acid \\
\hline DIOS & Desorption ionization on silica \\
\hline DMAN & 1,8-Bis(dimethylamino)naphthalene \\
\hline ESI & Electrospray ionization \\
\hline FFPE & Formalin-fixed paraffin-embedded \\
\hline fNPs & Functional iron nanoparticles \\
\hline FT & Fourier transform \\
\hline FT-ICR & $\begin{array}{l}\text { Fourier transform ion cyclotron } \\
\text { resonance }\end{array}$ \\
\hline FT-IR & Fourier transform infrared \\
\hline FWHM & Full width at half maximum \\
\hline $\mathrm{HCA}$ & Hierarchical cluster analysis \\
\hline ICP & Inductively coupled plasma \\
\hline IR-MALDI & $\begin{array}{l}\text { Infrared matrix-assisted laser } \\
\text { desorption ionization }\end{array}$ \\
\hline ITO & Indium tin oxide \\
\hline
\end{tabular}




$\begin{array}{ll}\text { kMSI } & \text { Kinetic mass spectrometry imaging } \\ \text { LA-ICP } & \begin{array}{l}\text { Laser ablation inductively coupled } \\ \text { plasma }\end{array} \\ \text { LAESI } & \text { Laser ablation electrospray ionization } \\ \text { LDI } & \text { Laser desorption ionization } \\ \text { LESA } & \text { Liquid extraction surface analysis } \\ \text { LTP } & \text { Low temperature plasma } \\ m & \text { Nominal mass } \\ \text { MALDI } & \text { Matrix-assisted laser desorption } \\ & \text { ionization } \\ \text { MRI } & \text { Magnetic resonance imaging } \\ \text { MS } & \text { Mass spectrometry } \\ \text { MS } & \text { Multistage tandem mass } \\ \text { MSI } & \text { spectrometry } \\ \text { MS/MS } & \text { Mass spectrometry imaging } \\ m / z & \text { Tandem mass spectrometry } \\ \text { nanoDESI } & \text { Mass-to-charge ratio } \\ & \text { Nanospray desorption electrospray } \\ \text { nano-LC-ESI } & \text { ionization } \\ & \text { Nanoliter liquid chromatography } \\ \text { electrospray ionization }\end{array}$

\section{Introduction}

A resurgence in surface-based analytical technologies and application of molecular imaging techniques is enabling new spatial and temporal exploration of metabolic processes in plant biology. Spatial analysis of plant tissues, including determination of the locations of production, storage and site/s of action of plant natural products, provides fundamental and unique insights into plant biology. A number of different molecular imaging technologies and modalities are employed, with each possessing distinct advantages and disadvantages. Mass spectrometry imaging (MSI) is gaining in popularity and is emerging as one of the leading technologies. Over the past decade MSI has been adopted for the investigation of plant biology, including mechanisms of plant responses to stresses both abiotic and biotic, plant defense mechanisms, beneficial symbiotic relationships, and fundamental ecophysiologically important processes including nitrogen fixation and nutrient cycling. Many reviewers have published excellent comprehensive reviews of MSI which have mostly focused on biomedical applications (Addie et al. 2015; Aichler and Walch 2015; Chaurand 2012; Chughtai and Heeren 2010; Ellis et al. 2014a; Gode and Volmer 2013; Jungmann and Heeren 2012; Miura et al. 2012; Norris and Caprioli 2013; Rompp and Spengler 2013; Seeley and Caprioli 2012; Shariatgorji et al. 2014; Spengler 2015; Svatoš 2010; Wu et al. 2013); more recently a number have provided coverage of imaging of plant metabolites (Aichler and Walch 2015; Bjarnholt et al. 2014; Fujimura and Miura 2014; Horn and Chapman 2014; Kaspar et al. 2011; Sparvero et al. 2012; Spengler 2015; Sumner et al. 2015). The intention of this review is to provide an introduction to MSI used for plantbased research, including an overview of the technology with a detailed review of recent developments (2013-2015), a period that has seen rapid advances. We also highlight the new technologies that have the potential to impact on "systems-based" approaches to advance knowledge of relevance to plant biology and biotechnology.

The 'omics' technologies, genomics, transcriptomics, proteomics and metabolomics (and others), have provided insights into plant biochemistry, physiology and biology and are at the forefront of discovery in modern Systems Biology (Sumner et al. 2015). Advanced genomics capabilities have enabled the rapid and comprehensive determination and assembly of a number of plant genomes. However, the prediction and annotation of the functions of individual genes remain notoriously difficult (Claros 
et al. 2012; Korte and Farlow 2013). Alongside the greater ability to identify the number of gene loci in plants, the concomitant desire to elucidate the function of these genes has led to the development of the fields of transcriptomics, proteomics and metabolomics. The products measured within the transcriptome, proteome and metabolome are all dynamic and are both spatially and temporally resolved within the organism relative to the 'static' genome, demonstrating a need for both spatial and temporal analytical techniques. The transcriptome represents the complement of RNA transcripts produced from the genome which varies from cell to cell or between tissue types and with development; the proteome represents the total protein complement translated from the genome which is highly localized, one gene often encoding proteins with diverse functions distinguished by the large array of post-translational modifications (PTMs) that modulate function and activity. Finally, the metabolome is comprised of the complement of small molecules or metabolites representing the end products of both anabolic and catabolic cellular processes. There is an estimated 200,000 metabolites in Plantae, with only 100,000 that have been isolated and identified (Fiehn 2002). Considerable work is still needed to identify the full range of natural products and the novel biosynthetic pathways employed to generate them. The metabolome is generally the first to be affected by changing conditions and measurement provides a rapid and direct determination of the phenotype or current state of an organism, providing a detailed snapshot of the complement of small molecules that can be mapped back onto metabolic pathways. The metabolome can provide more detailed information relative to individually measuring the genome, transcriptome or proteome. The distribution of metabolites and proteins within an organism is spatio-temporally resolved, and MSI offers the ability to measure both in a spatially resolved manner and at high resolution.

Plants are inherently compartmentalized into specialized groups of cells (tissues and organs) and cells into subcellular organelles/compartments, where specific biochemical processes take place, supporting life, and leading to the synthesis of a range of molecules including metabolites, phytochemicals and natural products. The biosynthesis and storage of plant metabolites are highly regulated and spatiotemporally resolved; they are endogenously expressed or produced in response to specific stimuli including both abiotic and biotic stresses. The biosynthesis of natural products occurs within sub-populations of cells from which intermediates, precursors and end-point products are either transported to their site of action or locations of storage via translocation between cells or via the vasculature through the phloem and xylem. In particular, toxic or defensive metabolites are sequestered in highly specialized compartments protecting the normal cellular processes of the plant. For example the specialized oil glands of the Eucalyptus species store terpene essential oils and toxic formylated phloroglucinols that act to protect the plant against herbivores and as potent antibiotics. Other specialized structures include glandular trichomes (Lamiaceae) that store essential oils or individual secretory cells, such as those found in the tissues of ginger (Zingiberaceae) and nutmeg (Myristicaceae). Plants also produce an array of signaling molecules that are generated rapidly in highly localized and transient manners or at specific time points in their life cycle.

Both spatial and temporal approaches are necessary to unveil underlying biology in higher-order systems. Spatial analysis has been conducted using a number of different techniques which can be broadly categorized into two approaches: (1) in vitro isolation and extraction of individual tissue/cell types and (2) in situ, including in vivo, analysis using an imaging approach. The suite of technologies available for in situ imaging in plants is enormously powerful and varied; taking advantage of different physical and chemical properties to provide insight into the underlying biology. Approaches such as histochemical staining and immunolabeling coupled to optical, fluorescence or electron microscopies, employed to examine underlying tissue morphology and the spatial distribution of biomolecules, are modern-day stalwarts, but are relatively limited due to targeting of select classes of biomolecules. More recently, as the capabilities of analytical instrumentation have dramatically improved, other spectral techniques have been employed, including Fourier Transform Infrared Spectroscopy (FT-IR), synchrotron X-ray fluorescence imaging (XRF) of metal distribution in plant tissues, and nuclear imaging such as Magnetic Resonance Imaging (MRI) spectroscopy (imaging water in tissues) and Positron Emission Tomography (imaging the distribution of ${ }^{11} \mathrm{C}$ and ${ }^{18} \mathrm{~F}$ isotopes in tissues).

Modern Mass Spectrometry (MS) has seen major technical advances over the past decade that have 
increased the scope, applicability and adoption of the technology in a vast array of research areas (Spengler 2015). New instrumentation provides molecular specificity and high sensitivity, and has the ability to measure a broad range of analytes at high mass resolving power with high mass accuracy across wide mass ranges. MS measures individual chemicals as ions with unique mass-to-charge $(\mathrm{m} / \mathrm{z})$ ratios. When high mass resolution MS is used, the molecular formula can be identified and in tandem mass spectrometry (MS/MS) allows (generally) unambiguous identification from unique fragmentation patterns by comparison with authentic standards. Although the concept of using MS for imaging was introduced in 1962 utilizing Secondary Ion Mass Spectrometry (SIMS) (Castaing and Slodzian 1962), it was not until the mid-90's, with the introduction of soft ionization techniques, in particular Matrix-Assisted Laser Desorption Ionization (MALDI), and application to biomedical imaging by Spengler and Kaufmann (1994) and Caprioli et al. (1997), that MSI began to be applied to the biosciences for imaging of biomolecules, including peptides and proteins. MSI has significantly advanced, providing both high lateral (spatial) and high mass resolution capabilities using a variety of different ion sources and approaches. MSI has found extensive use in molecular pathology and histology, where the technique is used to map the spatial distribution of proteins and small molecules including drugs, lipids and endogenous metabolites within tissues (Aichler and Walch 2015; Spengler 2015). MSI has been demonstrated to have a number of advantages including a label-free analysis and the simultaneous multiplex measurement of hundreds to possibly thousands of analytes in a single imaging experiment, providing rich high-density multi-dimensional data. When MSI is combined with advanced software and data analysis techniques, it allows the virtual micro-dissection and interrogation of the molecular make-up of individual tissues. Further advances in spatial resolution have placed MSI at the forefront of single-cell metabolomics (Korte et al. 2015; Thiery-Lavenant et al. 2013). The ability to monitor the metabolism of an individual specialized cell within a tissue provides unique insights into the biology of the organism and the interaction between cell types.

For the plant biologist, MSI holds much promise for spatio-temporal analysis of plant tissues, and since
2005, the technology has been applied to measure the spatial distributions of plant metabolites allowing exploration of the functional roles of plant metabolites, including the identification of precursors or related metabolites, the exploration of localized responses to stress, and the identification of novel metabolic pathways. In comparison to mammalian tissue imaging, where the number of journal publications increased into the thousands, the number of plant-based articles totals less than 100, however, the total number of publications has been steadily increasing (Fig. 1; Table 3) (a literature search was conducted using general search terms including Imaging Mass Spectrometry, Mass Spectrometric Imaging, Mass Spectrometry Imaging and Plant Imaging, results were then filtered for plant based articles). A dramatic acceleration (doubling) in the rate of

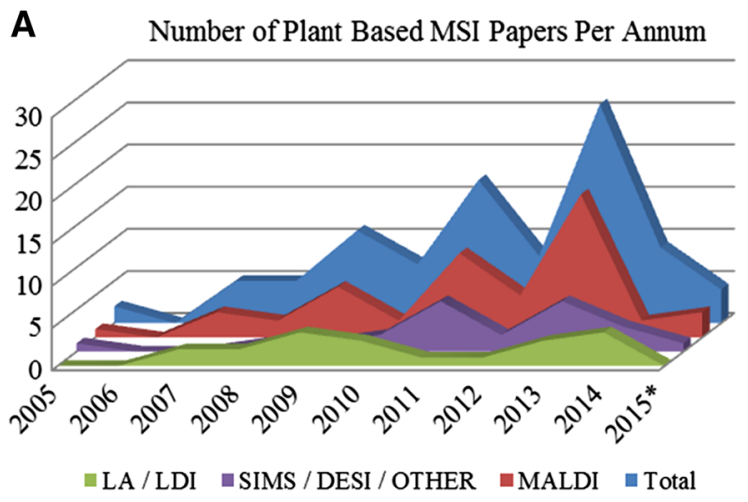

B

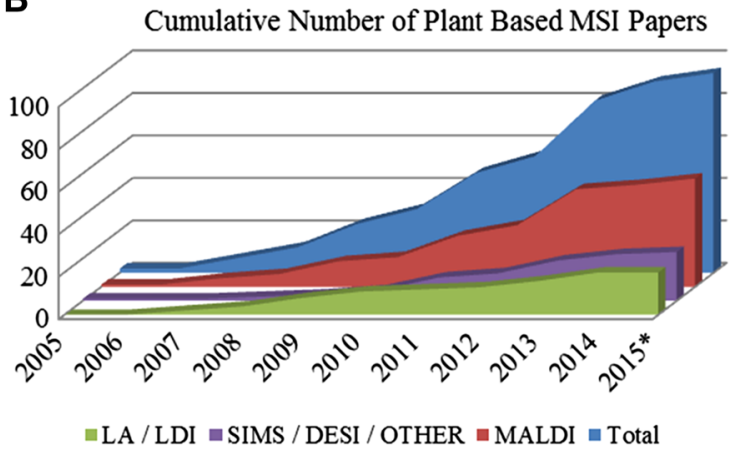

Fig. 1 A Number of plant-based MSI papers per annum and B cumulative number of plant-based MSI papers by ionization source showing: green laser ablation methods (LA-ICP, LAESI) and laser desorption ionization, purple SIMS, DESI and other alternative ionization sources, red MALDI source based MSI papers, blue total number of papers. The cumulative number of plant-based papers by ionization source demonstrates the dominance of MALDI-type sources 


\section{Microprobe Approach}

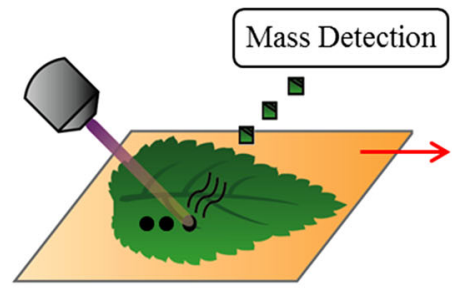

Sample discrete $\mathrm{x}, \mathrm{y}$ locations

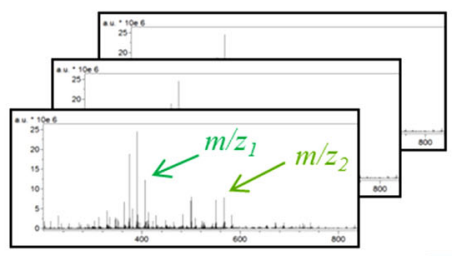

Individual Mass Spectra per $\mathrm{x}, \mathrm{y}$ location

\section{Microscope Approach}

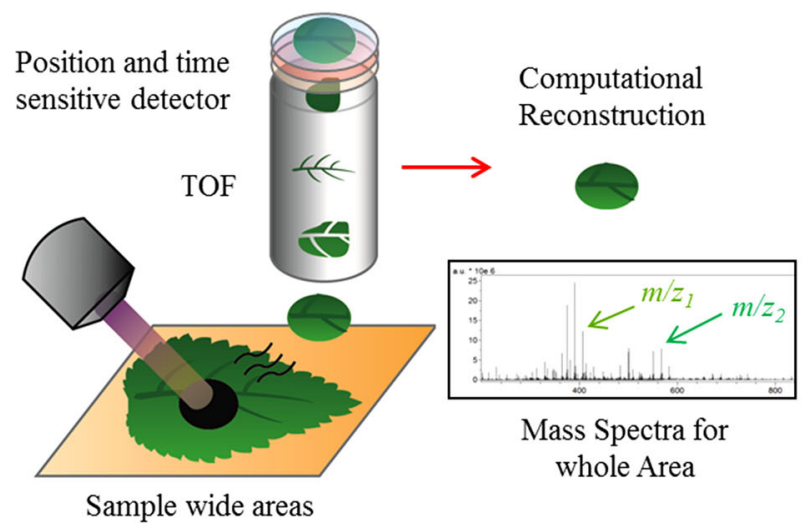

Fig. 2 Basics of mass spectrometry imaging for MALDI ionization showing 1 microprobe approach: discrete $\mathrm{x}, \mathrm{y}$ locations on tissue are sampled forming ions, the $\mathrm{m} / \mathrm{z}$ of ions is measured, then resulting mass spectra for each $\mathrm{x}, \mathrm{y}$ location are computationally reconstructed to form a complete dataset; 2 microscope approach: wide areas of tissue are sampled using a broadly focused laser, resulting ions are detected using a position and time sensitive mass time-of-flight (TOF) detector,

publication over the past 3 years indicates that the technology has reached a certain degree of maturity, and the approach has enough penetration and acceptance to become of utility to plant scientists.

\section{Basic concepts of mass spectrometry imaging}

A basic MSI experiment can be broken down into four steps: (1) sample selection and preparation, (2) desorption and ionization, (3) mass analysis and (4) image registration and data analysis. Careful control of each of the elements is essential to enable generation of high-quality images. In particular, sample selection, storage and preparation have a disproportionate impact on the final results; if any element in the chain
Computational Reconstruction for whole tissue

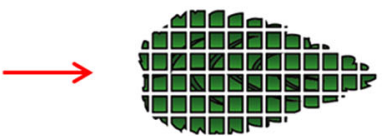

In silico microdissection and image analysis

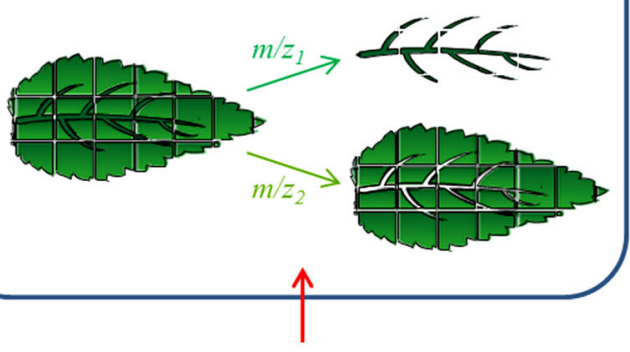

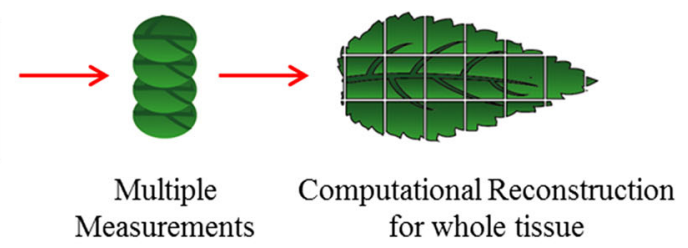

allowing determination of both $\mathrm{m} / \mathrm{z}$ and the discrete spatial distribution of ions within the sample area. To cover very large areas of tissue multiple measurements may be conducted across the whole tissue section with data computationally reconstructed to form a complete dataset. Image analysis is conducted in silico on datasets, individual ions may be plotted for their distribution or statistical analysis conducted to determine colocalization of ions

is sub-optimal, then poor results will be obtained. Fundamentally, the MSI process involves placing a suitable tissue section into an ion source, ionizing the sample and collecting a series of mass spectra. This series of individual mass spectra is collected in a twodimensional (2D) array across the tissue section or the surface of a tissue using one of a range of different ion sources and mass analyzers (Figs. 2, 3; Table 1). For each spatial co-ordinate the corresponding mass spectra collected represent the amounts of ionizable molecules present as a function of their mass-tocharge $\operatorname{ratios}(\mathrm{m} / \mathrm{z})$. The resulting spectra are correlated with a high resolution optical image of the tissue taken either before MSI or post-MSI analysis after histochemical staining to enable identification of the cell types in the tissues. Each spectrum is assigned as 
A

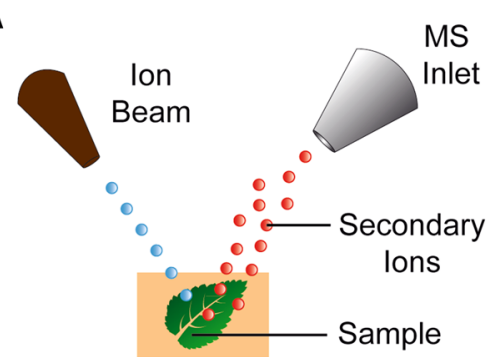

D

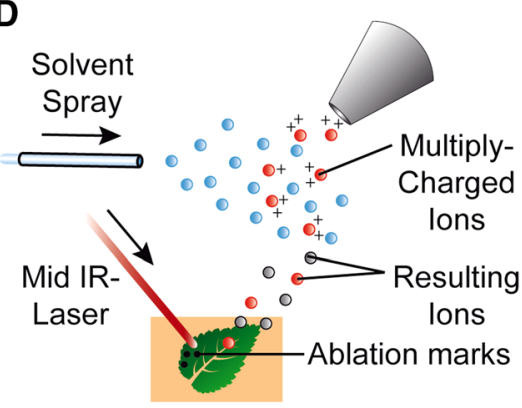

G

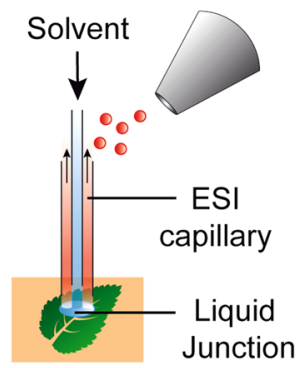

B

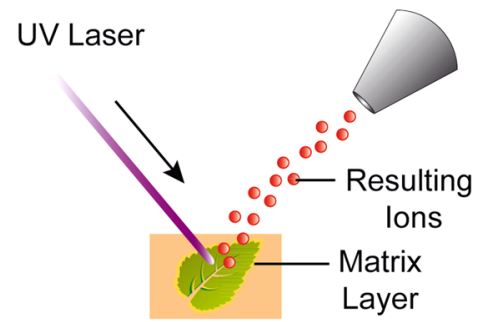

E

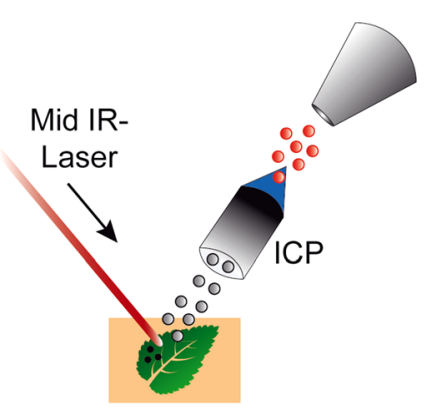

H

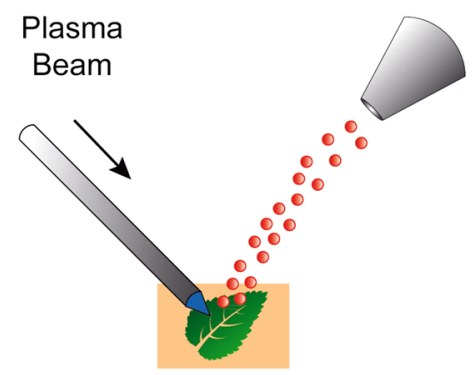

C

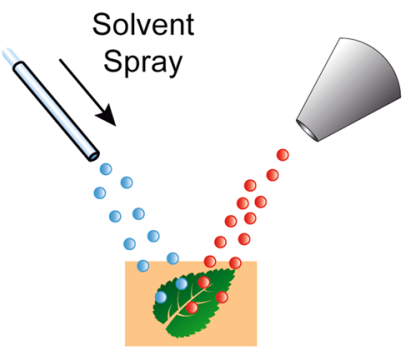

$\mathbf{F}$

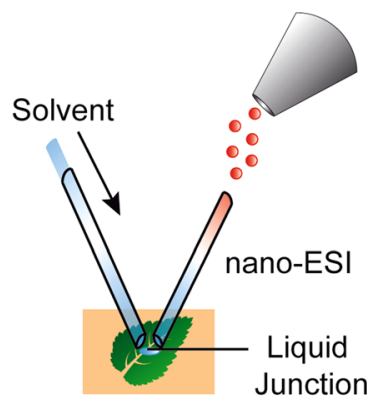

I

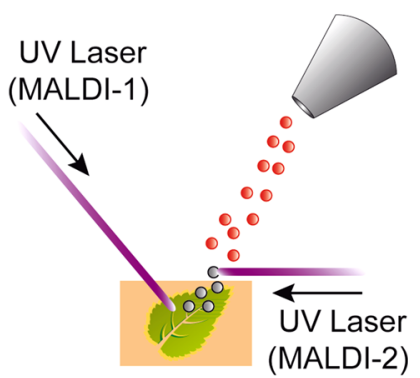

Fig. 3 Principals of different ionization sources used for MSI imaging of plant tissues with leaf displayed, for many approaches a tissue section is used to access internal metabolites. A Secondary ion mass spectrometry (SIMS) showing primary ion beam impacting surface and generating secondary ions, B matrix assisted laser desorption ionization (MALDI) with UV laser photons absorbed by matrix layer causing desorption and ionization, $\mathbf{C}$ desorption electrospray ionization (DESI) showing electrospray stream and desorbed ions, D laser ablation electrospray ionization (LA-ESI) showing ablation plume and secondary ESI stream generating multiply charged ions, E laser ablation inductively couple plasma showing

an individual pixel for image generation and by plotting the intensity value of a respective ion as an intensity map across a 2D array. The resultant reconstructed ion image represents the spatial distribution of the corresponding molecule(s), which can then be compared to the optical image of the tissue. Three-dimensional (3D) approaches are also possible where serial 2D arrays from sequential tissue sections ablation (LA-ICP) plume transferred through ICP to generate ions, $\mathbf{F}$ nano-desorption electrospray ionization (nano-DESI) demonstrating micro-extraction and liquid junction followed by nano-ESI, G liquid extraction surface analysis (LESA) showing localized extraction and ionization through ESI capillary, H low temperature plasma showing plasma beam ionizing surface metabolites, I MALDI-2 showing primary MALDI source coupled to secondary MALDI laser inducing secondary ionization in the ablation plume. $M S$ mass spectrometer, $U V$ ultraviolet, $I R$ infrared, ESI electrospray ionization, ICP inductively coupled plasma [modified from (Addie et al. 2015)]

(or depth profiling) from the one tissue sample are measured and then a $3 \mathrm{D}$ volume is reconstructed computationally to generate a 3D ion map. Two different acquisition approaches are used to conduct an MSI experiment, either a microprobe or microscope approach (Soltwisch et al. 2014) (Fig. 1). A microprobe approach is by far the most common, where sequential individual spectra are collected and then 
Table 1 List of ion sources used for (plant based) MSI including ionization technique; pressure regime: high vacuum $(\mathrm{HV})$, intermediate pressure to high vacuum (IP-HV) and ambient pressure; preparation steps required for MSI, applications and achievable lateral resolutions

\begin{tabular}{|c|c|c|c|c|c|}
\hline Method & Ionization technique & $\begin{array}{l}\text { Pressure } \\
\text { regime }\end{array}$ & Preparation steps & Applications & Lateral resolution \\
\hline SIMS & $\begin{array}{l}\text { Primary Ion Beam } \\
\text { Gas Cluster }\end{array}$ & $\mathrm{HV}$ & $\begin{array}{l}\text { Tissue section and drying. For matrix } \\
\text { enhanced SIMS additional } \\
\text { application of matrix }\end{array}$ & $\begin{array}{l}\text { Cellular biology, lipids } \\
\text { and lipid fragments, } \\
\text { elements, small } \\
\text { fragments of large } \\
\text { biomolecules }\end{array}$ & $50 \mathrm{~nm}-5 \mu \mathrm{m}$ \\
\hline MALDI & $\begin{array}{l}\text { Matrix, UV Laser } \\
\text { (Nd:YAG } 355 \mathrm{~nm} \text {, } \\
\text { Nitrogen } \\
\quad 337.1 \mathrm{~nm}) \\
\text { IR-Laser } \\
\quad(2800-3100 \mathrm{~nm})\end{array}$ & IP-HV & $\begin{array}{l}\text { Tissue section, drying and } \\
\text { application of matrix }\end{array}$ & $\begin{array}{l}\text { Small molecule } \\
\text { metabolites, lipids, } \\
\text { proteins and peptides, } \\
\text { non-covalent } \\
\text { complexes }\end{array}$ & $\begin{array}{l}\mathrm{UV}=10-50 \mu \mathrm{m} \\
\mathrm{IR}=100-200 \mu \mathrm{m}\end{array}$ \\
\hline LDI & UV or IR Laser & IP-HV & Tissue section and drying & $\begin{array}{l}\text { Small molecule } \\
\text { metabolites, lipids }\end{array}$ & $\geq 10 \mu \mathrm{m}$ \\
\hline $\begin{array}{l}\text { AP- } \\
\text { MALDI }\end{array}$ & $\begin{array}{l}\text { As for UV/IR } \\
\text { MALDI }\end{array}$ & Ambient & As for UV/IR MALDI & $\begin{array}{l}\text { Small molecule } \\
\text { metabolites, lipids }\end{array}$ & $\geq 10 \mu \mathrm{m}$ \\
\hline DESI & ESI Stream & Ambient & $\begin{array}{l}\text { None for external surfaces; section } \\
\text { and mount for internal tissues, } \\
\text { imprint onto PTFE }\end{array}$ & $\begin{array}{l}\text { Small molecule } \\
\text { metabolites, lipids }\end{array}$ & $50-200 \mu \mathrm{m}$ \\
\hline $\begin{array}{l}\text { nano- } \\
\text { DESI }\end{array}$ & $\begin{array}{l}\text { nano-Capillary } \\
\text { coupled to } \\
\text { nano-ESI source }\end{array}$ & Ambient & $\begin{array}{l}\text { No sample pre-treatment, section if } \\
\text { needed }\end{array}$ & $\begin{array}{l}\text { Analysis of complex } \\
\text { mixtures of soluble } \\
\text { organic and biological } \\
\text { molecules on } \\
\text { substrates }\end{array}$ & $20 \mu \mathrm{m}$ \\
\hline LA-ESI & $\begin{array}{l}\text { Desorption using IR } \\
\text { Laser } \\
(2800-3100 \mathrm{~nm}) \\
\text { coupled to ESI } \\
\text { source }\end{array}$ & Ambient & $\begin{array}{l}\text { Section if needed, mount sections on } \\
\text { flat surface, prevent condensation } \\
\text { by using a chamber filled with inert } \\
\text { gas }\end{array}$ & $\begin{array}{l}\text { Small molecule } \\
\text { metabolites, lipids }\end{array}$ & $300-500 \mu \mathrm{m}$ \\
\hline LA-ICP & $\begin{array}{l}\text { IR Laser desorption } \\
\text { ionization by } \\
\text { Inductively } \\
\text { Coupled Plasma }\end{array}$ & Ambient & Section if needed & $\begin{array}{l}\text { Elemental and isotopic } \\
\text { analysis, in situ } \\
\text { analysis of trace } \\
\text { elements }\end{array}$ & $\geq 10 \mu \mathrm{m}$ \\
\hline DIOS & $\begin{array}{l}\text { IR/UV Laser } \\
\text { Desorption }\end{array}$ & Ambient & $\begin{array}{l}\text { No matrix, sample deposition on } \\
\text { spots no less than } 1 \mathrm{~mm} \text { in } \\
\text { diameter, molecules trapped on a } \\
\text { porous silicon surface }\end{array}$ & $\begin{array}{l}\text { Small molecule } \\
\text { metabolites, lipids, }\end{array}$ & $\geq 20 \mu \mathrm{m}$ \\
\hline NIMS & $\begin{array}{l}\text { IR/UV Laser } \\
\text { Desorption }\end{array}$ & Ambient & Tissue section or imprint, no matrix & $\begin{array}{l}\text { Small molecule } \\
\text { metabolites, lipids, } \\
\text { proteins and peptides }\end{array}$ & $\geq 20 \mu \mathrm{m}$ \\
\hline $\begin{array}{l}\text { LESA- } \\
\text { MS }\end{array}$ & $\begin{array}{l}\text { Liquid extraction } \\
\text { coupled to } \\
\text { nanoESI }\end{array}$ & Ambient & $\begin{array}{l}\text { None for external surfaces, section } \\
\text { and mount for internal tissues }\end{array}$ & $\begin{array}{l}\text { Micro-liquid extraction } \\
\text { of biomolecules }\end{array}$ & $1-2 \mathrm{~mm}$ \\
\hline
\end{tabular}

combined into a single dataset; currently all commercial instruments operate in this manner. The microscope approach is an experimental approach in development that uses a spatial micro-channel plate detector (Timepix) which is made up of an array of individual detectors that can spatially resolve ions over a larger area in a single sampling event (Ellis et al. 2014b). 
The spatial resolution of an MSI experiment is a key parameter and is highly dependent on the type of ion source and sample preparation conditions employed. For 2D MSI, the term spatial resolution is commonly substituted for the more accurate term of lateral resolution, which is the ability to distinguish two different features that are located side-by-side. In practice, the lateral resolution is not generally reported or determined, and when spatial resolution is reported, it is usually used to refer to the density of pixels in the acquired 2D array that make up the resultant reconstructed image. Typically, image resolution is reported as function of the 2D array of pixels spaced at preset distances, e.g. in a $50 \mu \mathrm{m} \times 50 \mu \mathrm{m}$ array. However, spatial resolution is not only a combination of the elements involved in defining 2D lateral resolution, but also incorporates depth resolution which is only relevant in 3D MSI experiments. The achievable spatial resolution of any MSI experiment is derived from a combination of different parameters including (1) the sampling area or 'spot size', which is a function of both the size and shape of the primary desorption event (e.g. laser pulse, primary ion beam or droplet size), (2) the step size or raster size, which is the distance between sampling events, (3) the pixel size and density of pixels which define lateral binning of MS data into digital elements, which when combined determine the lateral resolution or ability to distinguish two features. For microprobe laser- or beambased techniques the absolute lateral resolution can be increased beyond the physical limit of the spot size by the practice of oversampling, where the area of ablation is incrementally moved in smaller steps than the overall area of the sampling spot. Lateral resolution within the microscope approach is preset and is determined by the spatial arrangement of the individual detectors of the micro-channel plate, including both size and spacing.

\section{Ionization techniques}

MSI first relies on the ability to form ions, which are then transferred under vacuum and measured by the mass analyzer (Table 1; Fig. 3). The processes of forming ions can affect both the sensitivity and selectivity, and are dependent upon the sample type and the type of ionization source employed. The past three to 5 years have seen an explosion in different types of ion sources available, particularly specialized sources for ambient ionization conditions (Monge et al. 2013). Although not all have been explored in plant MSI, there exists much promise for their future application. Currently, in the field of plant-based MSI, the dominant ion source and approach is MALDI, due to a range of commercial instruments that display high spatial resolutions, ease of use and broad range of applicability to a variety of biological applications. A review of the literature shows that MALDI accounts for more than half of the articles published and has dominated particularly in more recent years (2014-2015; see Fig. 2). An alternative matrix-free approach using Laser Desorption Ionization (LDI) is the next-most commonly used, with roughly 10-15\% of total publications. Finally, around a third of all publications use alternative ion sources, including SIMS, Desorption Electrospray Ionization (DESI) and coupled sources including Laser Ablation Electrospray Ionization (LAESI). Of the alternative sources, DESI and SIMS have generated the most number of publications (see Fig. 2).

\section{Secondary ion mass spectrometry (SIMS)}

SIMS was first introduced in 1962 for imaging of inorganic elements, it was not until the 1970's that SIMS was applied to biological imaging and utilizes a high energy pulsed primary ion beam $\left(\mathrm{Ga}^{+},{ }^{133} \mathrm{Cs}^{+}\right.$, $\mathrm{Au}^{+}, \mathrm{Be}^{3+},{ }^{40} \mathrm{Ar}^{+}, \mathrm{C}_{60}{ }^{+}$) or gas clusters accelerated at high energy (15-25 keV) focused onto a sample surface (Fig. 3A) (Castaing and Slodzian 1962; Galle 1970; Lefevre 1975; Morrison and Slodzian 1975). Impact of the ion beam causes emission of secondary ions at each pixel to produce spatial distribution of metabolites (Fletcher et al. 2011a; Imai et al. 2005; Saito et al. 2008, 2012; Zhou et al. 2011). Modern advances in SIMS and nano-SIMS instrumentation are allowing high lateral resolutions of $<100 \mathrm{~nm}$ and 3D depth profiling of samples. However, SIMS has a number of drawbacks for biological MSI, including the requirement for high vacuum, essential to prevent secondary ion collision with background gases, leading to a requirement that samples and analytes must be vacuum-stable. SIMS is a harsh ionization technique that, due to the large amount of energy transferred during impact of the primary ion beam, leads to significant fragmentation of analytes and potential decreases in chemical specificity. Downstream 
difficulties lie in identifying unique fragment ions for individual analytes from complex biological matrices where similar fragments may be observed from related or similar molecules.

Matrix-assisted laser desorption ionization (MALDI)

MALDI is the most common MSI technique and is a soft ionization technique that enables direct measurement of molecular ions (Fig. 3B) (Caprioli et al. 1997). MALDI relies upon a secondary matrix to absorb the relatively harsh laser ablation energy. In most cases the matrix is a small organic chemical that aids both desorption of analytes from the solid to gas phase and promotes ionization within the ablation plume (Dreisewerd 2003). Using this approach, little to no fragmentation of individual analytes is observed. Depending upon the instrument configuration, MALDI instruments are capable of measuring large mass ranges, $>100 \mathrm{kDa}$, enabling measurement of a broad range of biological molecules. MALDI may use a number of different laser sources, either in the Ultraviolet (UV) or Infrared (IR) range, with differing wavelengths including Nitrogen UV laser (337.1 nm wavelength), Neodynium-doped yttrium aluminium garnet UV laser (Nd:YAG, $355 \mathrm{~nm}$ wavelength) and tunable infrared lasers to promote desorption (Park and Murray 2012). Laser Desorption Ionization (LDI) is a matrix-free technique that relies upon volatilization of molecules by direct absorption of laser energy. This represents a more energetic approach, relative to MALDI, that can lead to significant in-source ion fragmentation of chemicals present. Ion yields for LDI are estimated in the range of $1 \%$ of MALDI, and sensitivity can be impacted due to lower yields (Hölscher et al. 2014; Holscher et al. 2009; ThieryLavenant et al. 2013).

\section{Ambient ionization techniques}

Ambient ionization techniques are growing in popularity due to the ability to measure directly off sample surfaces with very little preparation. Atmospheric Pressure Matrix-Assisted Laser Desorption Ionization (AP-MALDI) or AP High Resolution Scanning Microprobe-MALDI (AP-SMALDI) are ambientpressure variants of the MALDI technique with high lateral resolution (spot sizes $12 \mu \mathrm{m}$ ). They typically use a nitrogen laser at AP to enable desorption and ionization (Koestler et al. 2008). The higher source pressures decrease in-source fragmentation of analytes due to collisional cooling with neutral gases within the source. The AP source also imparts a number of other advantages (relative to MALDI), including allowing direct mounting of samples, preventing vaporization and sublimation of volatile matrices and analytes within the source over time, thereby allowing measurement of samples for a longer period and resulting in images with larger pixel number and density.

\section{Desorption electrospray ionization (DESI)}

The DESI method directs charged droplets to the surface of samples via a spray capillary, the ESI stream impacts the surface extracting and ionizing analytes (Fig. 3C) (Ifa et al. 2007; Wiseman et al. 2006; Zoltán et al. 2004). The ions are desorbed into the gas phase and then transferred via an atmospheric ion transfer line into the MS, thereby enabling measurement of ions. The sampling area of a DESI source is large, with lateral resolutions of $250 \mu \mathrm{m}$ achievable under standard conditions. With great care, lateral resolutions of $50 \mu \mathrm{m}$ have been achieved. A variant of DESI uses imprinting of sample analytes onto a surface, such as a PTFE membrane, paper or Thin Layer Chromatography plate, by directly pressing the sample onto the surface, thus transferring analytes which can then be imaged using a normal DESI approach (Muller et al. 2011; Thunig et al. 2011). Nanospray-Desorption Electrospray Ionization (nano-DESI) MSI utilizes a self-aspirating nanospray capillary that is translocated across a sample surface, with lateral resolutions of $100-150 \mu \mathrm{m}$ achievable (Fig. 3F) (Lanekoff et al. 2013; Laskin et al. 2012b). The arrangement directly transports desorbed surface analytes to a nanospray-ESI source, where ionization occurs. This arrangement prevents the simultaneous desorption and ionization event and leads to improved sampling efficiency (Roach et al. 2010). Both DESI and nano-DESI do not require intensive sample preparation steps nor require high-vacuum conditions for ionization, allowing direct spatial analysis of plant surfaces (Roach et al. 2010; Zoltán et al. 2004).

Laser ablation techniques

Laser Ablation techniques also operate under AP, including Laser Ablation Electrospray Ionization 
(LAESI) and Laser Ablation Inductively Coupled Plasma (LA-ICP) ionization. LAESI couples midinfrared laser ablation of a sample surface, to generate a plume of predominantly neutral particles and molecules, to electrospray ionization (ESI) where charged droplets from the ESI ionize gas within the ablation plume (Fig. 3D) (Nemes and Vertes 2007). The ionization technique allows the generation of multiply charged ions, which can offer a number of analytical advantages for protein and peptide MSI. LAESI had previously been used for lateral imaging (300-350 $\mu \mathrm{m}$ resolution) and depth profiling (30-40 $\mu \mathrm{m}$ resolution) in plants; combination of these provides insight of 3D imaging (Nemes et al. 2008; 2009; Nemes and Vertes 2007). LA-ICP-MS is frequently used for 2D and 3D imaging of elements and isotopes in biological samples (Fig. 3E) (Becker 2013). The sample surface is ablated using a UV laser producing an ablation plume, which is then passed through inductively coupled argon plasma (ICP) at $8000 \mathrm{~K}$, generating elemental ions for MS analysis. LA-ICP-MS is highly sensitive and capable of detecting elements and isotopes of low concentrations ( $\mathrm{mg} / \mathrm{g}$ to $\mathrm{ng} / \mathrm{g}$ range) without any sample preparation (Sussulini et al. 2013).

Desorption ionization on silica (DIOS) and nanostructure-initiator MS (NIMS)

Desorption Ionization On Silicon (DIOS) and Nanostructure-Initiator Mass Spectrometry (NIMS) use a silicon substrate to which sample analytes have been deposited or transferred directly by pressing against the surface of the sample. NIMS uses customized porous silicon surfaces (10-20 nm pores) with trapped nanostructure initiators in the pores which aid desorption and ionization (Fig. 8) (Woo et al. 2008). Laser irradiation desorbs analytes for MS analyses (Woo et al. 2008). For NIMS, the initiators are not ionized during the desorption process, leading to an improved signal-to-noise ratio with decreased interference when analyzing low-mass metabolites (in comparison to MALDI). A similar method, Nanostructured Laser Desorption Ionization (NALDI), uses a metal target coated with either nanostructures or nanowires which is pressed against a sample surface, transferring analytes to the target (Tata et al. 2014). A matrixfree laser desorption approach is then used, with desorption and ionization promoted by the nanowires.
Liquid extraction surface analysis MS (LESA-MS)

LESA-MS is a combination of solid sample surface micro-liquid extraction and nano-electrospray MS (Fig. 3G) (Eikel et al. 2011; Kertesz and Van Berkel 2010; Tomlinson et al. 2014). Extraction solvents (acetonitrile, methanol, water:formic acid) are dispensed onto the surface of a sample extracting localized analytes, a liquid micro-junction is maintained allowing aspiration and subsequent nanosprayionization (Kertesz and Van Berkel 2010). Although spatial resolution is poor (in the $\mathrm{mm}$ range), due to the large area covered by the solvent, this approach offers the ability to extract a broad range of analytes and, when coupled to separation using nano-LC-ESI-MS, offers much potential to conduct highly localized orthogonal separations, which will increase both the sensitivity and the depth of coverage.

\section{Other ionization sources}

Instruments are frequently being 'mixed and matched' to produce either hybrid or multimodal configurations, improving spatial resolution and an ability to measure a wider range of compounds in the process. Recently, the dual MALDI/ESI source of a Bruker SolariX instrument was coupled to a LESA source, resulting in multimodal MALDI and LESA analysis being conducted on the same tissues (Tomlinson et al. 2014). Shimadzu have commercialized a dual optical microscope and MALDI-TOF, enabling multimodal optical and MSI imaging within the same instrument. A Laser Ablation Atmospheric Pressure Chemical Ionization (LA-APCI) multimodal optical and MSI imaging instrument was recently reported that consists of a commercial laser micro-dissection system used to isolate individual cells, which had been coupled to a modified APCI source for secondary ionization of ablated material (Lorenz et al. 2013). This hybrid instrument was capable of providing high lateral resolution $(13 \mu \mathrm{m})$. There has also been a MALDI/ SIMS hybrid MS developed by mounting a $20 \mathrm{kV} \mathrm{C} 60$ ion gun onto an existing MALDI ion source that was able to achieve a lateral resolution of $10 \mu \mathrm{m}$ in mammalian neurons (Lanni et al. 2014). Very recently, a number of new sources were reported that have been optimized for MSI in plants, including a Low-Temperature Plasma probe (Fig. 3H) (Maldonado-Torres et al. 2014) and a hybrid MALDI-2 source 
(Fig. 3I) (Soltwisch et al. 2015), which incorporates a second wavelength-tunable post-ionization laser that initiates secondary ionization in the primary ablation plume, which has been shown to increase ionization events by several orders of magnitude over standard MALDI sources.

\section{Mass analysis}

The mass analyzer is the core component of a MS, enabling determination of $\mathrm{m} / \mathrm{z}$ of an ion. The type of mass analyzer used also has a direct impact on the ability to conduct MSI experiments (Table 2). There are three common mass analyzers used on MSI instruments, (1) unit resolution analyzers including quadrupole and ion-trap technologies, typically a linear ion trap; high resolution analyzers including, (2) Time-of-Flight (TOF) and (3) Fourier Transform (FT) encompassing both Orbitrap and FT Ion Cyclotron Resonance (FT-ICR) instruments. For metabolites there is clearly a need for accurate-mass and high mass-resolving instruments and/or the use of tandem mass spectrometry (MS/MS) to be able to distinguish different metabolites in tissues when conducting MSI experiments. Low mass-resolution instruments can lead to misidentification or misinterpretation due to inability to resolve nominally isobaric peaks (peaks very close in mass that cannot be distinguished in the acquired mass spectrum). Hybrid instruments that combine one or more different mass analyzers offer many advantages; typically a mass selective quadrupole coupled to a collision cell will be operated with a higher mass resolution analyzer such as a TOF or FT. Common arrangements include quadrupole ion-trap-TOF, Qq-TOF, Qq-FT-ICR and Q-Orbitrap systems. A number of instruments incorporate Linear Ion Traps (LIT), imparting a number of advantages including increased sensitivity due to ability to trap specific ions and increase the population of selected ions.

Spectral resolution as a function of both sensitivity in detection and the ability to resolve different ions from each other, of the acquired mass spectra, is dependent upon both the type of mass analyzer and detector used. High-sensitivity detectors now allow the detection and amplification of very small numbers of ions, even a single ion, thus allowing measurement across wide concentration ranges, increasing the total possible number of ions observed. High mass-resolution instruments are required to distinguish very small mass differences, also increasing the total possible number of ions observed. The ability of a MS to distinguish one mass peak from an ion close in mass is described by both mass resolution and resolving power (RP). Mass resolution is defined as the degree of separation between two adjacent ions observed in the mass spectrum $(\Delta m)$ at Full Width Half Mass (FWHM) of the peak. Resolving power is the inverse of mass resolution and is defined as the nominal mass $(m)$ divided by the difference in masses $(\Delta m)$. Higher mass-resolution allows easier identification of contributing ions to the mass spectrum, and higher massresolving power is essential for high mass-accuracy,

Table 2 List of common mass analyzers and instrument configurations detailing: mass resolving power, approximate mass range, tandem MS/MS capabilities and acquisition speed

\begin{tabular}{lllll}
\hline Mass analyzer/configuration & Mass resolving power & $m / z$ range & MS/MS & Acquisition speed \\
\hline Ion Trap & $\sim 1000$ & $50-4000$ & Yes & Medium \\
TOF & $2500-40,000$ & $20-500,000$ & No & Fast \\
TOF/TOF & $>20,000$ & $20-500,000$ & Yes & Fast \\
IT-TOF & 10,000 & $50-20,000$ & Yes & Fast \\
IT-Orbitrap & $>100,000$ & $40-4000$ & Yes & Slow \\
Q-Orbitrap & $>100,000$ & $50-6000$ & Yes & Medium \\
FT-ICR & $>200,000$ & $10-10,000$ & Yes & Slow \\
Ion Mobility Q-TOF & $13,000 / 40,000$ & Up to 40,000 & Yes & Fast \\
\hline
\end{tabular}

TOF time of flight, TOF/TOF tandem TOF, IT ion trap, FT-ICR Fourier transform ion cyclotron resonance, $Q$-TOF quadrupole time of flight 
whereby a higher RP allows more accurate identification of center-of-peak and determination of mass error. Low mass error is essential for unambiguous assignment of molecular formula, aiding in identification. Mass error is defined as the difference between the observed and theoretical mass of a given ion. For modern high-resolution mass spectrometers, $<10$ parts per million (ppm) mass error is common for TOF instruments, and $<2$ ppm mass error is common for FT instruments (FT-ICR and Orbitraps). The high massresolution available from FT instruments provides further advantages for MALDI-MSI, allowing resolution of interferences from matrix signals in the low mass-range.

Measurements conducted on low mass resolution instruments are typically operated in a targeted tandem MS approach to provide molecular selectivity, where specific fragment ions of a single analytes are monitored thereby providing both molecular specificity and increased sensitivity. For MSI measurements, higher-resolution detectors provide the ability to unambiguously resolve a peak from the complex spectra, which are generated with profiling-type techniques. Accurate mass instrumentation provides the ability to conduct profiling-type, untargeted measurements where high-resolution analyzers can distinguish nominally isobaric peaks. There are three different types of high-resolution analyzers in common use, including high mass resolution TOF with achievable resolution up to 60,000 (typically 10-50,000), ultra-high mass resolution FT detectors, including the Orbitrap (achievable resolution $>200,000)$ and Ion Cyclotron Resonance detectors with resolutions $>500,000$.

Ion mobility spectrometry, when coupled to MS, is a hybrid approach that first separates ions by their mobility in a carrier gas on a millisecond timescale, followed by detection with a MS (Jackson et al. 2014b; Stauber et al. 2010). The hyphenated approach offers the ability to separate ions with similar $\mathrm{m} / \mathrm{z}$ but different shapes, providing the added benefits of an orthogonal separation phase within the single acquisition instrument. Benefits include better signal-tonoise $(\mathrm{S} / \mathrm{N})$ ratio and the potential to separate isomers according to their shape and charge. There are a number of reported MSI applications imaging lipids in a variety of mammalian tissues (Jackson et al. 2014b; Stauber et al. 2010). The approach is yet to be applied to plants.

\section{Multimodal imaging}

Within the molecular imaging field, the use of different types of imaging modalities to examine a single biological question is common. However, the different datasets are typically treated as separate entities. An emerging theme is multi-modal imaging, which involves combing two or more imaging modalities; a common approach is to generate a histochemically stained section of tissue, either a serial section or in some cases the same piece of tissue on which an MSI measurement has been conducted. Co-registration of high-resolution optical images from histochemical staining with the acquired MSI data provides more in-depth information (tissue/cell type distribution), aiding sample interpretation. Another combination is that of MALDI and SIMS, which has been used extensively in plant and animal MSI imaging (Chughtai et al. 2012; Hanrieder et al. 2014; Ogrinc Potočnik et al. 2014; Seaman et al. 2014), where the former has been used to generate lowerresolution images across a wide area, and SIMS for very-high-resolution imaging of a smaller sub-section of the tissue. The modality need not be another MSI technique or optical imaging approach; other modalities including MRI, FT-IR and XRF could be employed to examine the underlying biology. Previously, MSI was combined with high-resolution magnetic resonance spectroscopic imaging (MRSI) to examine choline metabolites and cations in tumor cells (Amstalden van Hove et al. 2010). Recently, a hybrid predictive technique called Image Fusion has been reported (Fig. 4). The approach uses the combination of information containing high spatial resolution but low chemical specificity, such as images generated from optical microscopy at high magnification, coupled to lower-spatial resolution but high chemical specificity information, such as MSI data, to computationally predict the distribution of chemicals in the tissue sections. The approach has a number of advantages and in principal can be applied to and fuse a variety of different imaging modalities (Van de Plas et al. 2015).

\section{Advantages and limitations of MSI}

MSI has a number of advantages over other imaging modalities, which are directly derived from the 
Fig. 4 Demonstrates the image fusion approach combing two different image modalities at differing lateral resolutions. By using information contained in the higher lateral resolution image the distribution of a lipid can be predicted. Example of IMSmicroscopy fusion. An ion image measured in mouse brain, describing the distribution of $\mathrm{m} / \mathrm{z} 778.5$ [identified as lipid (PE(P40:4)] at $100 \mu \mathrm{m}$ spatial resolution (top right), is integrated with an $\mathrm{H} \& \mathrm{E}$ microscopy image measured from the same tissue sample at $10 \mu \mathrm{m}$ resolution (top left), by combing the information from both image types, the image fusion process can predict the ion distribution of $\mathrm{m} / \mathrm{z}$ 778.5 at $10 \mu \mathrm{m}$ resolution (bottom). Reprinted by permission from 1629 Macmillan Publishers Ltd: Nature Methods, (Van de Plas et al., 2015) 12(4):36672, Copyright (C) 2015
Microscopy

H\&E image

(10- $\mu \mathrm{m}$ resolution)
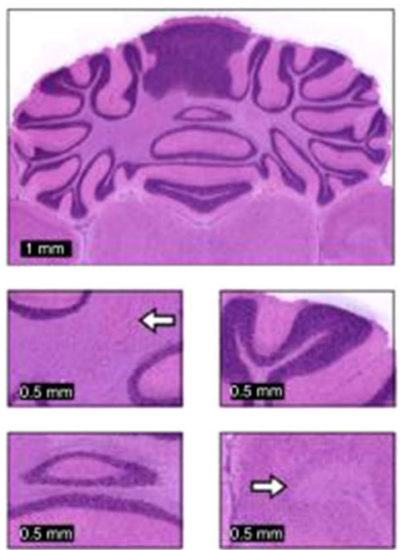
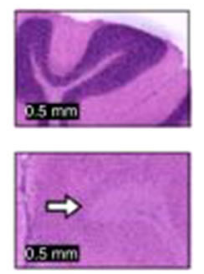

IMS

lon image for $\mathrm{m} / \mathrm{z} 778.5$ (100- $\mu \mathrm{m}$ resolution)
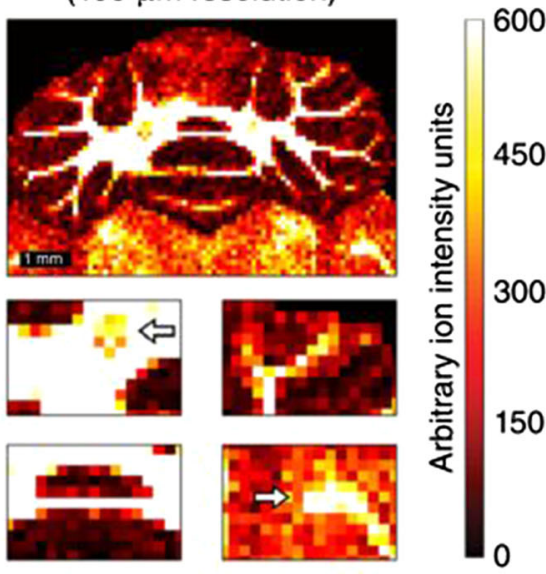

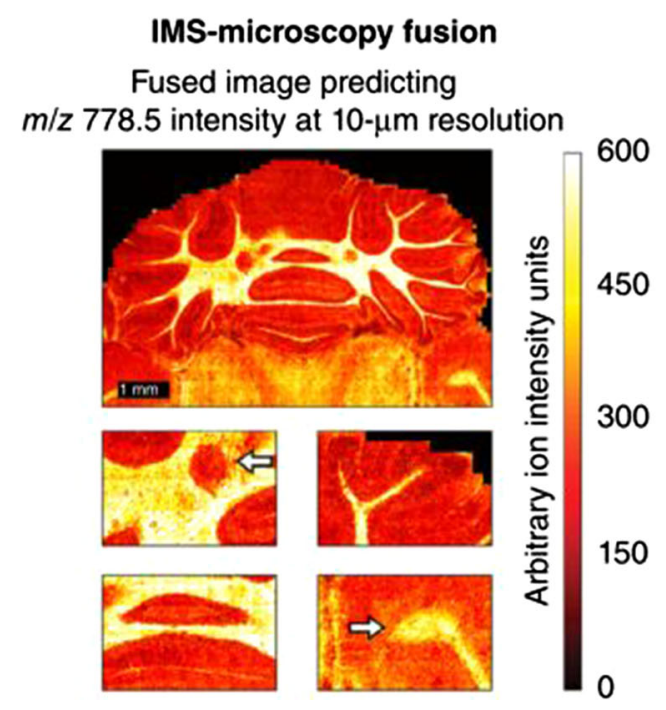

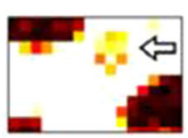
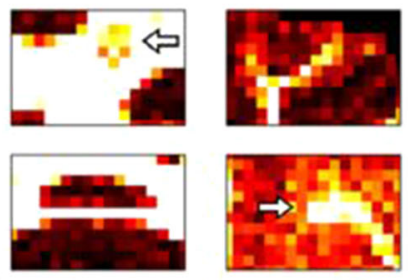

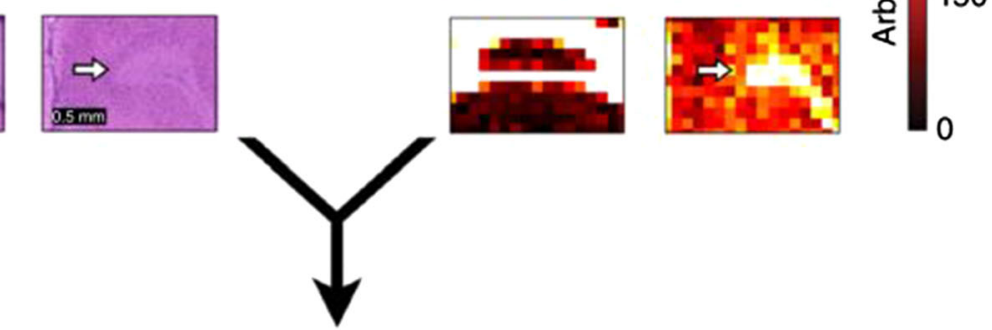

IMS-microscopy fusion

Fis in image predicting capabilities of modern mass spectrometers. MSI provides high molecular selectivity, high sensitivity and rapid multiplexed acquisition of many ionizable compounds in a single measurement. MSI can provide very high lateral resolutions for imaging, giving the ability to distinguish the molecular nature of fine morphological features of tissues. In practice, lateral resolutions of $50 \mathrm{~nm}$ for nano-SIMS, $10-50 \mu \mathrm{m}$ for MALDI instruments with front-side illumination geometry, $1 \mu \mathrm{m}$ for transmission geometry MALDI instruments and between 15 and $250 \mu \mathrm{m}$ for nanoDESI and DESI type ion sources can be achieved. Many of the approaches allow lateral resolutions of around the size of a mammalian cell $(\sim 10$ to $30 \mu \mathrm{m})$ or subcellular resolution for large plant cells $(\sim 10$ to $100 \mu \mathrm{m})$. Advanced electron multipliers and ion detectors impart the capability to measure very low numbers of ions, providing extremely high sensitivity for individual ions. When MSI is coupled to accurate mass analyzers, MSI has a unique ability to distinguish 
many compounds at once in a profiling-type experiment. This would not be possible with a low-resolution instrument, however, the same instruments operated in MS/MS mode can provide very high selectivity and sensitivity using SRM/MRM or ion trapping techniques. The application of ion mobility separation to MSI experiments holds promise for the analysis of isomers and closely related metabolites, particularly large lipid molecules, peptides and proteins. However, the benefits of ion mobility for small molecule analysis are still being assessed. The capacity of modern MSI instruments and software allows rapid collection of data that can allow high-throughput analysis and screening approaches.

There are a number of limitations of MSI, including the ion suppression and space charging effects for ion trap-type instruments (LIT, LIT-TOF, FT-ICR, Orbitrap). When operating MSI instruments at very high spatial resolutions, there is a significant trade-off with sensitivity, as the total number of ions decreases with the sampling area, and thus the overall sensitivity for individual ions will be compromised. MSI experiments are less sensitive than analyses that utilize an orthogonal separation prior to measurement and detection; this is directly due to the extremely complex biological matrix of the tissues where vast concentration ranges of chemical entities are present with differing chemistries and molecular sizes (e.g. proteins, lipids, organic acids, amino acids, carbohydrates, inorganic ions etc.). The generation of competing ions from chemicals with vastly different desorption and ionization efficiencies from the same sampling area leads to an ion suppression effect, where ions that may be preferred or those that are present in higher abundance dominate over low-abundance or poorly ionizable molecules. For MALDI experiments, the presence of high-abundance low-weight ions generated directly from the matrix leads to significant interfering signals. MSI is generally an ex vivo technique that relies upon harvesting appropriate tissue samples from biological organisms for analysis. This is in contrast to in vivo imaging modalities (MRI, PET, X-ray, XRF) that do not require tissue harvesting. During sample harvesting, preparation and analysis, there are many potential pitfalls that must be avoided to obtain useful images; any sample preparation steps or techniques have the potential to contaminate the tissue section with exogenous material that may affect reproducibility, ionization and image quality, and that may complicate the data analysis. Finally, the most significant bottleneck of MSI experiments remains the lack of robust and efficient data analysis pipelines, particularly for analysis of ultra-high resolution FT data. The recent adoption of common data output standards, the ongoing development of software, and a move towards common standards will likely address many aspects of these problems in the very near future (see below).

\section{Sample preparation}

Prior to analysis, tissues must be collected and stored. The steps taken during both tissue collection and storage are critical for successful MSI analysis and often vary depending upon the analyte of interest. Most experiments will have a distinct timing missmatch between sample collection and analysis, requiring the storage of samples for a period of time. Typically, to protect delicate tissues, structures and small metabolites, a gentle freezing approach is recommended, including freezing in the atmosphere over liquid nitrogen or in cold carbon dioxide atmosphere over dry-ice, alternatively samples may be dipped into isopentane:liquid nitrogen or isopentane:dry-ice slurries. Tissue stabilization methods for proteins include heat stabilization and microwaving (Goodwin et al. 2008, 2010, 2012). For previously fixed tissue samples, there are a number of sample preparation protocols that have been developed for Formalin-Fixed Paraffin-Embedded (FFPE) mammalian tissue specifically for MSI analysis (Powers et al. 2014). Although these methods have not yet been tested for plant samples, the developed protocols are likely to be directly applicable to formalin-fixed plant tissues, noting that the fixation approach is only suitable for examination of metal distribution, proteins, peptides and other polymeric biomolecules in tissues, due to the fixation process typically leading to the extraction and degradation of small molecules. Further tissue preparation steps for this process are lengthy due to the need to conduct antigen retrieval steps. For most MSI analyses, tissue samples are typically flash-frozen to quench metabolism and retain the spatial distribution of analytes. Care must be taken to retain the tissue morphology during the freezing process and to preserve an accurate representation of the native tissue; soft tissues may deform and take the 
shape of the container (tube or tray) within which they are frozen. Once frozen, tissues and analytes are generally stable for months to years when stored at $-80{ }^{\circ} \mathrm{C}$. Embedding tissues within an external matrix is a common approach and is often required to ensure that suitable sections are generated from fragile frozen plant tissues which have a distinct tendency to fracture and crumble. A number of different embedding media have been successfully demonstrated, including agarose (Marques et al. 2014), gelatin (Gemperline and Li 2014a; Horn et al. 2013b, 2014; Korte and Lee 2014; Korte et al. 2015; Ye et al. 2013) and aqueous carboxymethyl-cellulose solutions (1-5\%) (Bencivenni et al. 2014; Yoshimura et al. 2012b). In general, the easier the frozen matrix is to section or the closer the properties of the matrix are to the tissue being sectioned, the easier it will be to generate suitable sections of tissue for analysis. Thicker plant tissue sections (of 20-50 $\mu \mathrm{m}$ ) than for mammalian tissues $(5-25 \mu \mathrm{m})$ are recommended to limit fracturing and crumbling. Standard histological workflows utilize Optimal Cutting Temperature (OCT) compound [a solution containing $\sim 4 \%$ poly-ethylene glycols (PEG)] as an embedding medium, but this is strongly discouraged for MSI research due to absorption into the tissue and smearing of OCT across the tissue surface during cryo-sectioning, which has been shown to directly lead to ion suppression effects and loss of analyte signals (Schwartz et al. 2003).

Depending on the analysis method and instrument used, tissues must be prepared differently for imaging purposes, and a number of factors must be considered. External surfaces can be readily analyzed by mounting tissues directly to sample stages using double-sided tape, but for the measurement of internal distributions of metabolites tissues must first be sectioned at an appropriate thickness to expose the underlying tissue. In particular, the type of analytes and their stability and turnover must be considered. To retain metabolite distributions and concentrations, tissues are flash frozen during harvesting and sectioned or prepared at a later time point. Both the sample height and morphology may have a large effect upon the number of ions generated (due to laser focusing) and, for linear TOF instruments (LDI and MALDI), mass accuracy and resolution (due to changes in flight path length). Instruments where the detector is decoupled from the source, such as LIT, FT-ICR and Orbitrap instruments, are not reliant upon the sample thickness and are only limited by the physical configuration of the sample stage.

While cryo-sectioning is the most commonly used method for sample preparation to access internal metabolites, there are other alternatives for tissue sectioning. For ambient ionization techniques such as LTP-MS, AP-IR-MALDI-MS, DESI-MS and LAESIMS, the tissue thickness is reliant upon the sample stage configuration used for MS measurement. Manual tissue sectioning is practiced using a knife blade, vibratome or microtome with thickness of $200 \mu \mathrm{m}$ upward to $4 \mathrm{~mm}$ without freezing ( $\mathrm{Li}$ et al. 2007; Maldonado-Torres et al. 2014; Tata et al. 2015; Vaikkinen et al. 2013). In addition, a hollow punch has been used to produce grapevine leaf discs (Becker et al. 2014). Tissue samples are normally frozen to preserve their native metabolic state and prevent the loss of metabolites with short half-lives. While DESI mainly analyses freshly frozen tissues, fresh nonfrozen tissues are used in many other methods. Very recently, a fracturing approach has been demonstrated for accessing the internal cell layers of rice leaf (Klein et al. 2015). For surface metabolite analysis, samples are used directly for MS analysis without pretreatment. However, analysis of high-molecularweight plant cell surface/wall components, such as cutin, suberin, acetylated arabinoxylan and betaglucans, requires in situ chemical (e.g. alkaline hydrolysis) or enzymatic (lichenase and xylanase) digestions, in order to depolymerise the polymers prior to MS analysis (Velickovic et al. 2014; Veličković et al. 2014).

For ionization techniques and stages that are under high vacuum, e.g. in SIMS and MALDI-TOF instruments, the instrument configuration typically requires a number of extra steps during sample preparation. For these techniques, tissue thickness is typically $8-50 \mu \mathrm{m}$, but can be up to $1.5 \mathrm{~mm}$. Once mounted to the sample carrier, the tissues are typically dehydrated under vacuum prior to either matrix deposition or direct analysis. Prior dehydration avoids any shrinkage of tissues leading to changes in sample morphology within the instrument. In MALDI-MS using TOF detection, where a voltage is applied to the sample stage, samples are usually mounted either on glass slides coated with conductive indium tin oxide (ITO), or on re-useable metal sample stages (steel or gold-coated steel). Samples are either directly freezethaw mounted to the surface or adhered using 
conductive double-sided tape (Burrell et al. 2007). Freeze-thaw mounting is generally performed by transferring the cut tissue section to the top of the sample holder (slide, plate), then gently warming the holder from the underside using body heat. The tissue section quickly thaws and adheres to the surface of the holder. Once mounted, the sections are warmed and transferred to a vacuum desiccation chamber and dried under reduced pressure for at least $15 \mathrm{~min}$ before any further steps are conducted. Tissue sections may degrade rapidly and must either be stored under vacuum or, for longer periods, at $-80{ }^{\circ} \mathrm{C}$ (Patterson et al. 2014). For MALDI-MSI, application of the matrix has been shown to stabilize analytes within the tissue to oxidation and degradation processes.

Other ionization sources that do not require a voltage to be applied to the sample carrier, such as APSMALDI-MS, LAESI-MS, LAAPPI-MS, LTP-MS and SIMS, generally use normal glass slides (disposable), metal or silicon surfaces. To prevent inaccurate analysis of uneven samples, imprinting techniques are common, especially in DESI-MS, using either paper, TLC or PTFE substrates (Ifa et al. 2011; Lane et al. 2009; Li et al. 2011; Muller et al. 2011; Thunig et al. 2011), although glass slides (Andras et al. 2012) and tapes (Tata et al. 2015) have also been reported. Similarly, detection of trace elements via LA-ICP-MS requires samples to be fixed onto acetate double-sided adhesive tape, before placing them into an ablation chamber (da Silva and Arruda 2013).

Tissue washing

A commonly accepted principle of MSI analysis is to conduct the minimal amount of sample preparation steps, to avoid metabolite degradation and retain the distribution of analytes. However, a number of tissue washing steps can be conducted to either increase the sensitivity for certain analytes or to remove background salts to decrease salt adducts (Angel et al. 2012; Seeley et al. 2008; van Hove et al. 2011). Mounted sections can be carefully dipped into washing solutions and then dried, before further processing such as enzymatic digestion or application of matrix. These steps have been successfully employed to increase the ionization of selected metabolites (including lipids, proteins and peptides) in mammalian systems, but have not yet been demonstrated in plant systems.
MALDI matrix application and in situ protein digestion strategies

MALDI and Matrix-Enhanced SIMS techniques rely upon an exogenous matrix, consisting typically of either small organic molecules or inorganic UV absorbent nano-particles, which must be applied by one of a number of different techniques. Further, the achievable lateral resolution is dependent upon the size of the matrix crystals, which is in turn dependent upon the application technique employed. There are a number of approaches used to apply a MALDI matrix that can be separated into two different strategies, involving either dry deposition or wet deposition and extraction. The first, dry deposition strategy, deposits the matrix without any solvents to the top surface of a tissue section by one of two common techniques, employing hand-shaking of dry fine crystals of matrix onto the sample through a sieve or the use of a sublimation apparatus. A sublimation approach for deposition of matrix provides very uniform coatings with very small crystal sizes (typically in the range of $1-5 \mu \mathrm{m}$ ), allowing imaging with high spatial resolution. It is becoming one of the preferred approaches for small-molecule and lipid imaging (Hankin et al. 2007).

Wet deposition strategies have also had significant attention, and there are many different techniques available for specific analyte classes. Wet deposition is one of the most common techniques for matrix deposition for MALDI-MSI analysis and is essential to conduct in situ protein digests. To conduct an in situ protein digestion, a protease, generally trypsin or $\alpha$ chymotrypsin, is deposited in a buffered solution. Once uniform application of enzyme has been achieved, the sample is incubated in a humid atmosphere for a period of time, to allow localized digestion before drying and matrix application for MALDI-MSI. As yet, no in situ protein digestion strategies have been reported in plant-based MSI. Matrix is first dissolved in a suitable solvent, then small droplets are applied to the surface of the tissue to be imaged, micro-extraction of endogenous molecules takes place at the solvent-tissue interface and, as the solvent dries, analytes co-crystallize with the dissolved matrix. The achievable lateral resolution of a wet deposition technique is predominantly dependent upon the droplet size maintained during matrix deposition. There are several different techniques 
reported in the literature, including home-made solutions and a range of commercially available instruments, ranging from manual airbrushing (where success is highly dependent upon the operator) to more controlled robotic spraying (HTX Imaging TMSprayer, HTX Technologies LLC, Carrboro, NC, USA; SunChrom SunCollect and SunCollect II plus+, SunChrom GmbH, Friedrichsdorf, Germany), automatic droplet deposition through piezoelectric vibration (ImagePrep, Bruker, Bremen, Germany), inkjet printing (ChIP 1000, Shimadzu Corp., Japan) with standard inkjet printers (Baluya et al. 2007), robotic spotting (Labcyte Portrait 630 Spotter-no longer available) and automatic protein digestion robots (SunChrom SunDigest, SunCollect II plus+, SunChrom). Once deposition conditions have been optimized for specific solvents, matrix and concentration, number of passes or spray cycles, temperatures and drying, it is possible to achieve very small crystal sizes of 5-20+ $\mu \mathrm{m}$ (in the longest dimension), allowing high-resolution imaging. A combination approach of initial dry deposition using sublimation followed by in situ 'rehydration/recrystallization' by vapor exchange provides excellent results for protein and peptide imaging (Norris and Caprioli 2013).

\section{Matrices for MALDI analysis}

There are a large number of matrices that are either in common use or have been recently reported in the literature for MALDI, including the main stalwarts 2,5-dihydroxybenzoic acid (DHB) (Becker et al. 2014), 2,5-dihydroxyacetophenone (DHAP) (Meriaux et al. 2010), sinapinic acid (SA) (Anderson et al. 2015; Fraser et al. 2007), and $\alpha$-cyano-4-hydroxycinnamic acid (CHCA) (Debois et al. 2014; Franceschi et al. 2012; Gemperline and Li 2014b), which are typically used for positive mode MALDI analysis. 9-aminoacridine (9-AA) (Korte and Lee 2014; Shroff et al. 2015), 1,8-bis-dimethylaminonaphthalene (DMAN) (Horn et al. 2012; Ye et al. 2013) and 1,5-diaminonaphthalene (DAN) (Becker et al. 2014; Korte and Lee 2014; Korte et al. 2015) were reported for negative mode analyses. 2-aminoethyl- $\mathrm{N}$-2-aminonaphthalene has also been reported as a suitable matrix (Cha et al. 2008). Recent use of the plant metabolites quercetin and morin (Wang et al. 2013), which are structural isomers, as matrices for both positive- and negativemode analysis has demonstrated vastly increased detection of phospholipids in mammalian tissues when using high-resolution FT-ICR-MS. The use of plant-based flavonols as a MALDI matrix will require careful assessment for each system being imaged, including the method for deposition (wet vs. dry) and the analytes being targeted, to avoid any complications. Indeed, it is the natural abundance of endogenous flavonols in high concentrations in plants, together with other UV-absorbing metabolites, that allows UV-LDI approaches to be employed in these systems. In these cases, the plants' own metabolites are acting as an endogenous MALDI matrix (Holscher et al. 2009). Some caution must be employed if the distribution of UV-absorbing molecules in the plant tissues is not uniform, since then the ion yield from each raster may be different, likely yielding misleading results.

More recently, DAN has been adopted for plantbased imaging, which requires very low laser energy and very small crystal size (Korte and Lee 2014). DAN has been used for MSI imaging in both positive and negative modes at very high spatial resolution. (However, caution is required when using DAN as it is suspected to be a carcinogen.) Further, DAN is also chemically reactive with the ability to form gas phase radicals, to induce in-source decay and to conduct gas phase reductions of disulphide bonds (Molin et al. 2011; Yang et al. 2009). The use of an ambientpressure MALDI source allows the use of volatile matrices, including liquid ion matrices and also water in the form of ice for IR-MALDI within frozen tissues (Robichaud et al. 2014). Nanoparticles and colloids have been reported as suitable matrices for MALDIMSI, including the use of silver and gold nanoparticles for the imaging of waxes and phospholipids (Dufresne et al. 2013; Jackson et al. 2007, 2014a; Muller et al. 2015; Wu et al. 2009). Furthermore, functional iron nano-particles (fNPs) have been demonstrated in mammalian tissues (Taira et al. 2008). More recently, silica particles have been reported as a suitable matrix for the analysis of lignin oligomers in Eucalyptus species, and colloidal graphite in a Graphite-Assisted LDI approach (GALDI) for imaging plant metabolites (Cha and Yeung 2007). In the case of small-molecule matrices, these can be readily removed post-MSI acquisition, washed with a suitable solvent such as ethanol or aqueous solutions, and then subjected to histochemical staining (Norris and Caprioli 2013). 


\section{Identification and quantification strategies}

Due to the nature of an MSI experiment, it is not always possible to determine exact chemical structures from single-stage accurate-mass information acquired by MSI. Typically, an orthogonal analysis is required to increase both the depth of coverage and the sensitivity and allow identification of as many chemical species as possible. The presence of either isomers (structural or stereo) or near-isobaric chemicals confounds the interpretation of the spectra. Nearisobaric chemicals can be distinguished by the use of higher mass-resolving power, which at the extremes can be used to provide unambiguous identification of molecular formula by measurement of the isotopic fine structure at RP > 300,000 FWHM (Miura et al. 2010). The high mass RP required is only achieved using FT instruments, including FT-ICR and the latest Orbitrap MS instruments. However, the identification of molecular formula still does not provide absolute identification of isomeric compounds; instead, MS/ MS (de Hoffmann 1996) can be used to identify individual chemicals by fragmentation analysis, where precursor ions are fragmented using techniques including Collision-Induced Dissociation (CID) (Sleno and Volmer 2004), Higher-Energy Collisional Dissociation (HCD) (McAlister et al. 2011; Olsen et al. 2007), Electron Transfer Dissociation (ETD) (Syka et al. 2004), Electron Capture Dissociation (ECD) (Zubarev et al. 2000), or Sustained OffResonance Collision-Induced Dissociation (SORICID) (Gauthier et al. 1991). Individual compounds fragment in a unique manner, generating combinations of product ions whose relative abundances can be compared to those of an authentic standard to identify the precursor ion. Identification of individual metabolites may be difficult due to low fragment ion abundance or interfering ions. To increase sensitivity, SRM- and MRM-type experiments using instruments capable of MS/MS can be employed, but the tradeoff is an inability to monitor wide mass ranges (Barry et al. 2014). There are a number of on-line databases that include high-resolution mass spectra and also in some cases MS/MS fragmentation patterns of endogenous and exogenous molecules, making them useful for identifying metabolites, including: METLIN (https://meltlin.scripps.edu), LIPIDMAPS (www. lipidmaps.org), MassBank (www.massbank.jp), Human Metabolome Database (HMDB, www.hmdb. ca) and mzCloud (www.mzcloud.org). As most spectral databases have been generated for human systems, the total number of spectra for plant metabolites is low. Further compound databases can be searched for accurate mass and formula matches, including PubChem, ChEBI, and the In Vivo/In Silico Metabolites Database (IIMDB) (http://metabolomics.pharm. uconn.edu/iimdb/).

Quantitation and validation of analytes pixel-bypixel in MSI datasets is challenging and is severely affected by the local tissue environment or 'matrix effect', evident as ion suppression effects from the complex series of chemicals present (see Ellis et al. 2014a for a detailed review). Typically, an orthogonal or complementary approach is conducted to provide absolute quantitation (Berisha et al. 2014; Tomlinson et al. 2014). There have been several approaches to quantitation, including the generation of external standard curves by doping of tissue homogenates or direct application of a dilution series onto the tissue section. This approach is most suitable for exogenous materials, including drugs and contaminants; endogenous metabolite quantitation is a more challenging problem and requires the use of labelled internal standards. The commercial software Quantinetix ${ }^{\mathrm{TM}}$ (ImaBiotech, Lille, France) is available to conduct quantitative MSI experiments and has seen extensive use for studying drug distribution, pharmacokinetics and toxicology. For LA-ICP-MS systems, a quantitative approach has been demonstrated for the imaging of metal ions in tissues using a single-point calibration (Sussulini et al. 2013).

\section{Analytical software and data analysis techniques}

Due to the sheer volume and complexity of the data generated in MSI experiments, there is a requirement for advanced software and computational data analysis techniques to extract meaningful results from the data. Originally, data analysis of MSI datasets was largely limited to manual identification and mapping of individual ions; analysis software had not yet incorporated advanced clustering and comparative visualization tools allowing spatial segmentation, identification and comparison of multiple ions. The need for advanced software to analyze MSI datasets drove the generation of a number of software packages, and over the past 3 years there has been 
significant development and improvement in the range of software. This includes BioMap (Novartis, Basel, Switzerland), Datacube Explorer (FOM-AMOLF, Amsterdam, Netherlands) (Klinkert et al. 2014), FlexImaging and ClinProTools (Bruker Daltonik, Bremen, Germany), HDI (high-definition MALDI MS imaging) coupled to MassLynx and MarkerLynx (Waters, Manchester UK), ImageQuest (Thermo Scientific, Waltham, MA, USA), MALDIVision (PREMIER Biosoft), Metabolite Imager (University of Texas) (Horn and Chapman 2013), MIRION (Justus Liebig University) (Paschke et al. 2013), MSiReader (North Carolina State University) (Robichaud et al. 2013), OpenMSI (Lawrence Berkeley National Lab, CA, USA, http://openmsi.nersc.gov) (Rübel et al. 2013), SCiLS Lab (SCiLS Bremen, Germany) and TissueView (AB Sciex, based on BioMap). The website maldi-msi.org, operated by a consortium of European MSI users, provides a number of free software tools for download. Many researchers still rely on "in-house" data analysis methods, and the use of MATLAB tools is common. Very recent adoption of the common imzML data format standard (www. imzml.org) (Schramm et al. 2012) by instrument vendors and incorporation into a variety of tools or directly into the vendor software (such as FlexImaging) has allowed export of instrument-specific data into a common format, which has aided the development of vendor-independent tools for data analysis and application of advanced statistical techniques to identify underlying metabolite distributions and colocalizations. Many of the current packages for MS image analysis have been developed incorporating only visualization and simple clustering techniques such as Hierarchical Cluster Analysis (HCA) and Principal Component Analysis (PCA).

Due to the inherent heterogeneity of MSI data, preprocessing and spectral "de-noising" is recommended to obtain better results (Alexandrov 2012; Alexandrov et al. 2013; Norris et al. 2007). Pre-processing includes steps for baseline subtraction and smoothing, peak alignment and mass recalibration across the entire dataset, normalization of signal intensity, peak-picking and data reduction steps. A number of publications have provided detailed analysis pathways and suitable tools to examine MSI data (Alexandrov 2012; Rübel et al. 2013). Once pre-processing steps are complete, there are three types of unsupervised approaches to identify hidden patterns and spatial distributions of metabolites: Component Analysis, Spatial Segmentation and Self-Organizing Maps. The first, component analysis, has been dominated by the use of Principal Component Analysis (PCA), although other methods have been used to uncover the variation in MALDI-MSI data, including non-negative matrix factorization, maximum auto-correlation factorization and latent semantic analysis [see review by Alexandrov (2012) for further details]. PCA represents the spatial patterns of molecules in terms of the set of score images, but PCA has a number of limitations including negative values (which are not present in the data) and difficulty in determining co-localized ion images for identified patterns of distribution. Spatial segmentation is a robust approach to examine MSI data where a segmentation map displays different regions in the tissues with distinct molecular composition (Alexandrov 2012). A common approach is to use Hierarchical Cluster Analysis (HCA), which is directly incorporated into FlexImaging. More recently, advanced spatial segmentation clustering techniques have been developed that cluster $\mathrm{m} / \mathrm{z}$ values with distinct regions of the tissue (Alexandrov et al. 2013; Krasny et al. 2015) and are incorporated directly into the commercial software SCiLS Lab. The third area is an emerging data analysis technique that makes use of unsupervised Self-Organizing Maps (SOM) (Fonville et al. 2013; Franceschi and Wehrens 2014) and Growing Self-Organizing Maps (Wijetunge et al. 2014) that reduce the dimensionality of the data and allow identification of hidden patterns within the data.

Three-Dimensional Mass Spectrometry Imaging (3D-MSI) has been reported (Andersson et al. 2008) and reviewed previously (Seeley and Caprioli 2012). 3D-MSI is conducted using one of two approaches: (1) depth profiling on the same tissues by conducting sequential rastering events (Seeley and Caprioli 2012), which is common for SIMS (Fletcher et al. 2011a, b) but has also been reported for LAESI which was used to depth profile plant leaf tissue (Nemes et al. 2009); or (2) by combining multiple two-dimensional MSI measurements conducted on serial tissue sections from a single sample. Individual datasets are computationally re-assembled to generate 3D volume reconstructions of individual ion distributions; for this purpose, researchers have used software such as Amira (www.fei.com), Image $\mathbf{J}$ (http://imagej.nih. gov/ij), MATLAB (www.mathworks.com) and more recently SCiLS Lab (scils.de) to generate 3D images. 


\section{Common reporting standards and repository}

Recent guidelines for the reporting of MSI datasets have been published (McDonnell et al. 2015). The article outlines the detailed metadata and contextualizing of information that is required to fully describe a MSI dataset, and it provides eight specific reportable areas: (1) Tissue Samples, including the type and how the tissue was sampled; (2) Tissue Preparation, including methods such as washing and matrix application steps; (3) Optical Image, detailing information about the corresponding optical images used for MSI analysis; (4) Data Acquisition, detailing the instrument and parameters used to acquire the data; (5) Mass Spectra Pre-processing, detailing the parameters used to baseline subtract, to smooth and align spectra, for intensity normalization methods, for peak picking and data reduction methods; (6) MSI Visualization, including methods for peak picking and image generation parameters; (7) Compound Identification, including all procedures used to identify individual metabolites; and (8) Data Analysis, detailing procedures, methods and software used. The reader is also reminded that there are a number of other reporting standards for identification in metabolomics experiments, including definitions for tentative, putative and confirmed identification (Creek et al. 2014). For MSI experiments, the ability to confirm identifications is all the more difficult, due to the inability to separate isobaric compounds. A common public repository has also recently been announced, where MSI datasets can be deposited for storage and later retrieval, although the repository may be more suited to biomedical and clinical datasets (Rompp et al. 2015).

\section{Applications}

The types of publications focused on plant MSI are evolving; at the beginning, subject matter tended to cover the application of a new technology to plants and the development of new techniques and methods to examine plant metabolites (see Table 3 for a complete list of plant-based MSI publications). Although there is still much technical development required, the approach has matured to a point where more advanced questions in plant biology are now being addressed. There are a number of common themes emerging that range from fundamental biology, plant structural and surface metabolites and plant responses to abiotic and biotic stresses, plant pathology and symbiont systems. The targets of analysis have typically been highly abundant plant metabolites that include natural products, structural components and their precursors, defense and energy storage molecules.

Detection and visualization of primary metabolite distributions using MSI provides insights to normal plant growth, development and reproduction processes. In a multi-omics approach including MALDIMSI, fructan metabolism of barley grain was studied at different post-pollination time points (Peukert et al. 2014). The authors reported levan- and graminan-type fructan accumulation in the endosperm before starch biosynthesis, while inulin-type fructan was more concentrated in and around the emerging endosperm cavity. Low-weight metabolites, including amino acids, small organic acids, flavonoid and flavonoid glycosides, benzoxazinoids and sulpholipids, have been imaged in corn leaf (Korte and Lee 2014), with cell-level differences in distribution across a wide range of metabolites within juvenile maize leaves determined via an oversampling method in MALDIMSI at lateral resolutions of $5 \mu \mathrm{m}$ (Korte et al. 2015) (Fig. 5). The authors found distinct differences in distributions of plant metabolites, including intermediates in central carbon metabolism, cell wall components, lipids and flavonoids. Of note, flavonoids were found asymmetrically distributed within the epidermal layers of the tissue, in particular maysin was present exclusively in the adaxial epidermis, consistent with its reported anti-herbivory (Rector et al. 2003) and UV protectant properties (Casati and Walbot 2005). The plant defense benzoxazinoids, HMBOA-Glc (2-hydroxy-7-methoxy-1,4-benzoxazin-3-one glucoside) and DIMBOA-Glc (2,4-dihydroxy-7-methoxy-1,4benzoxazin-3-one glucoside) were found to be specifically localized to select mesophyll cells between the vascular bundles. The authors also provide evidence for subcellular distribution of plant metabolites, where they observed non-overlapping localization of DIMBOA-Glc, stored in cell vacuoles, and SQDG in the chloroplast of the same cell.

In an impressive exploration of temporal biology, Seaman and colleagues (2014) investigated the nitrogen cycle, from elemental uptake and incorporation into one generation of radish plants, followed by decomposition of the leaves and release of nitrogen, then transfer of labelled nitrogen compounds and 


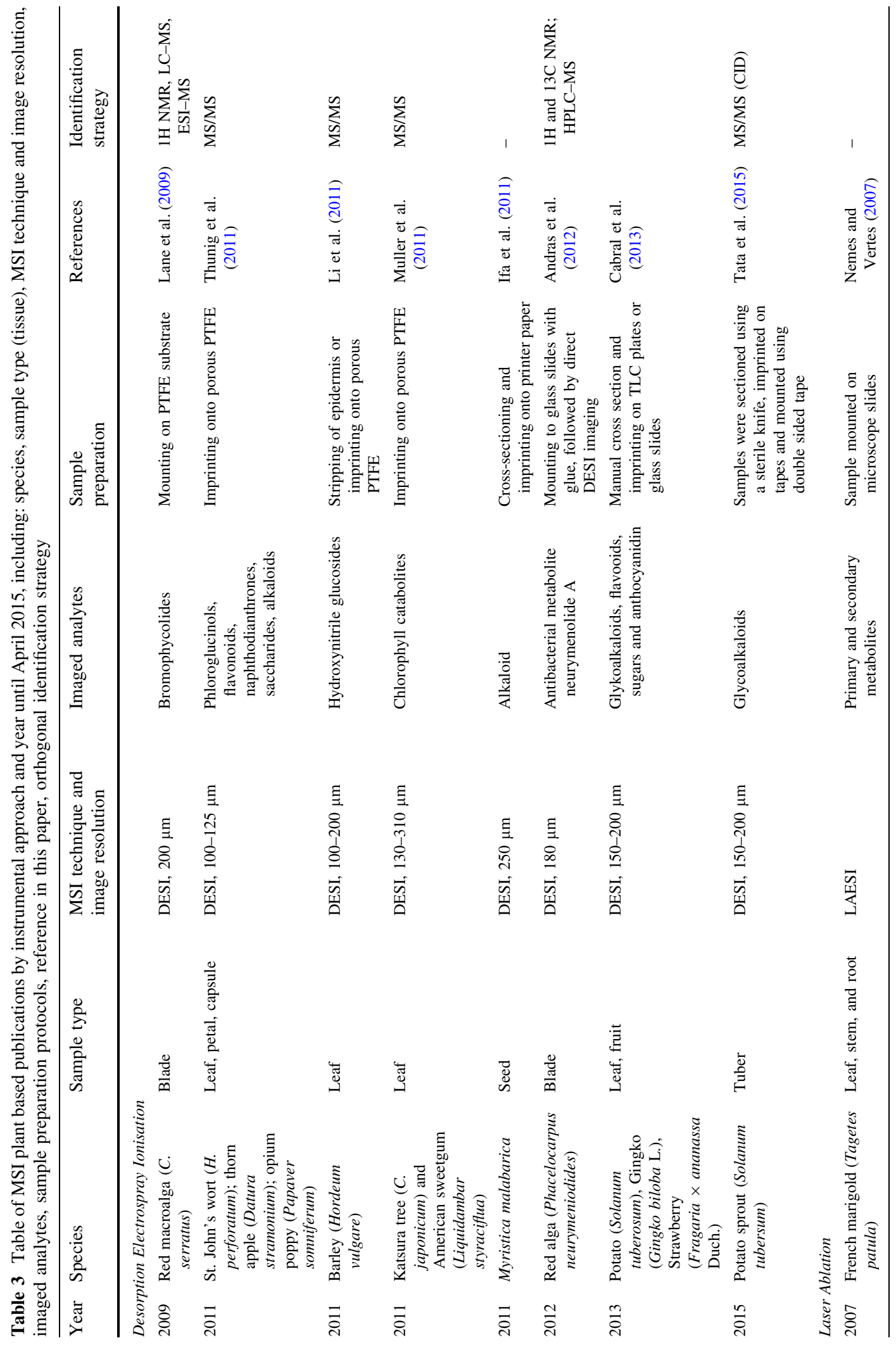




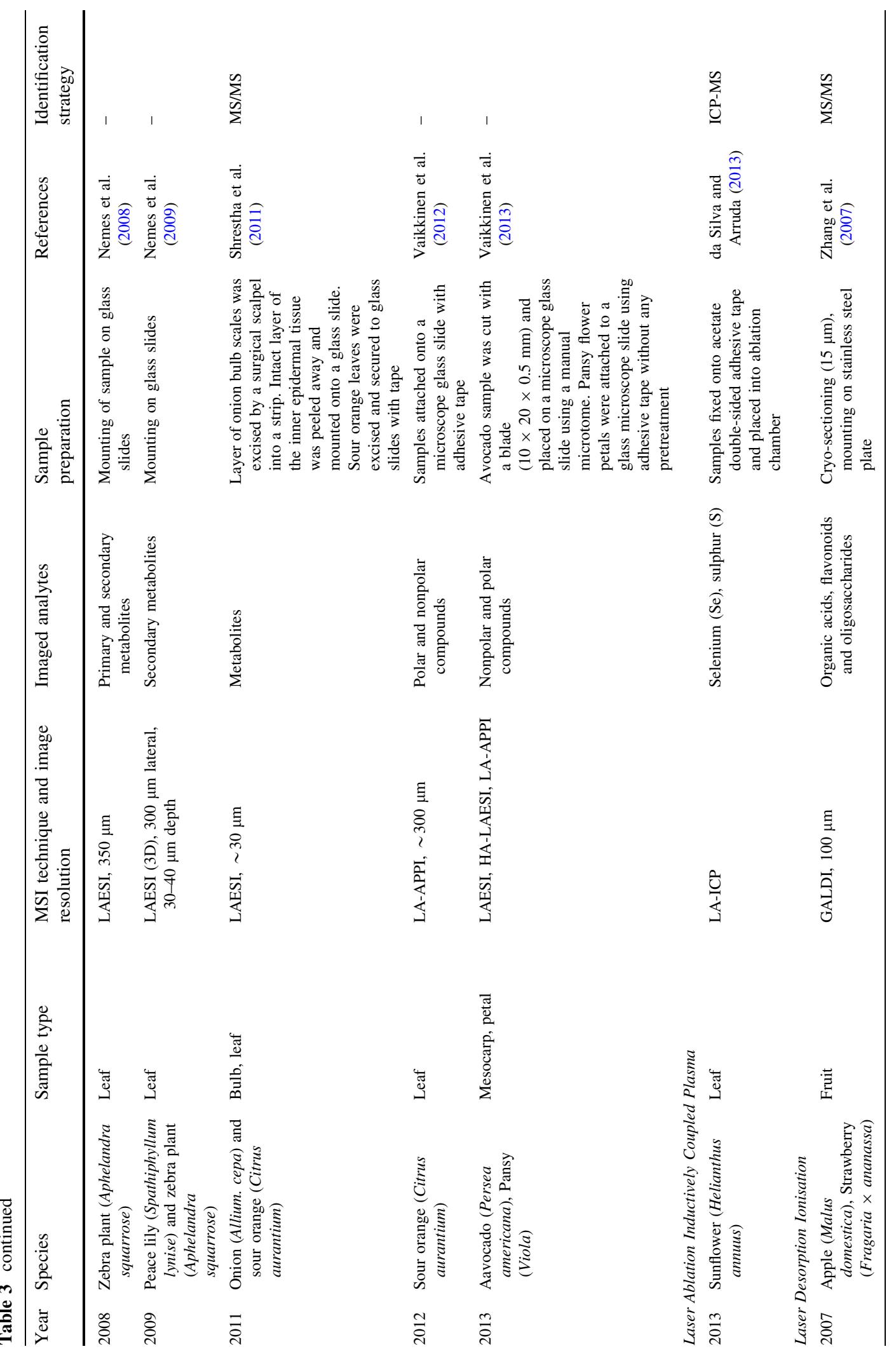




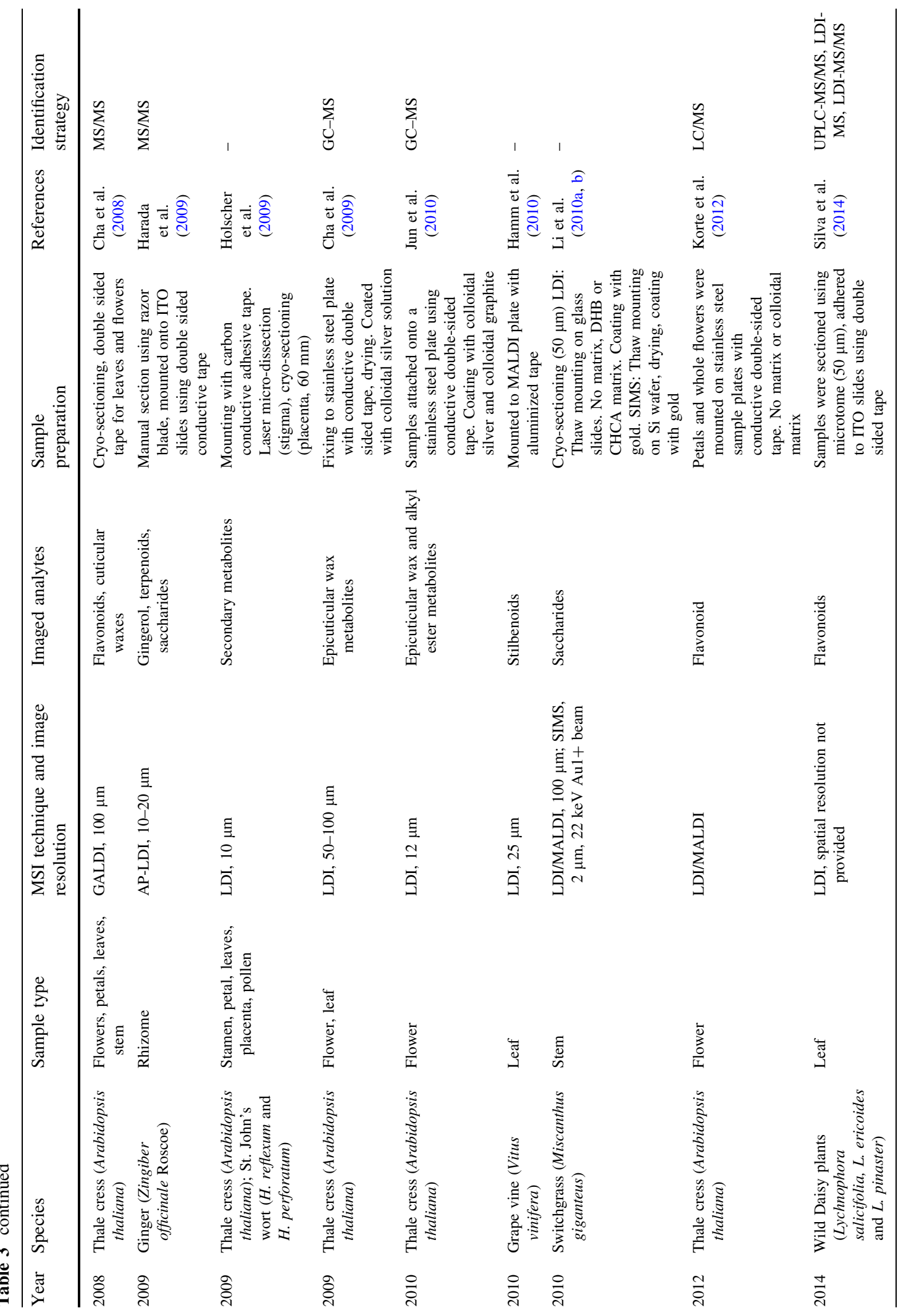




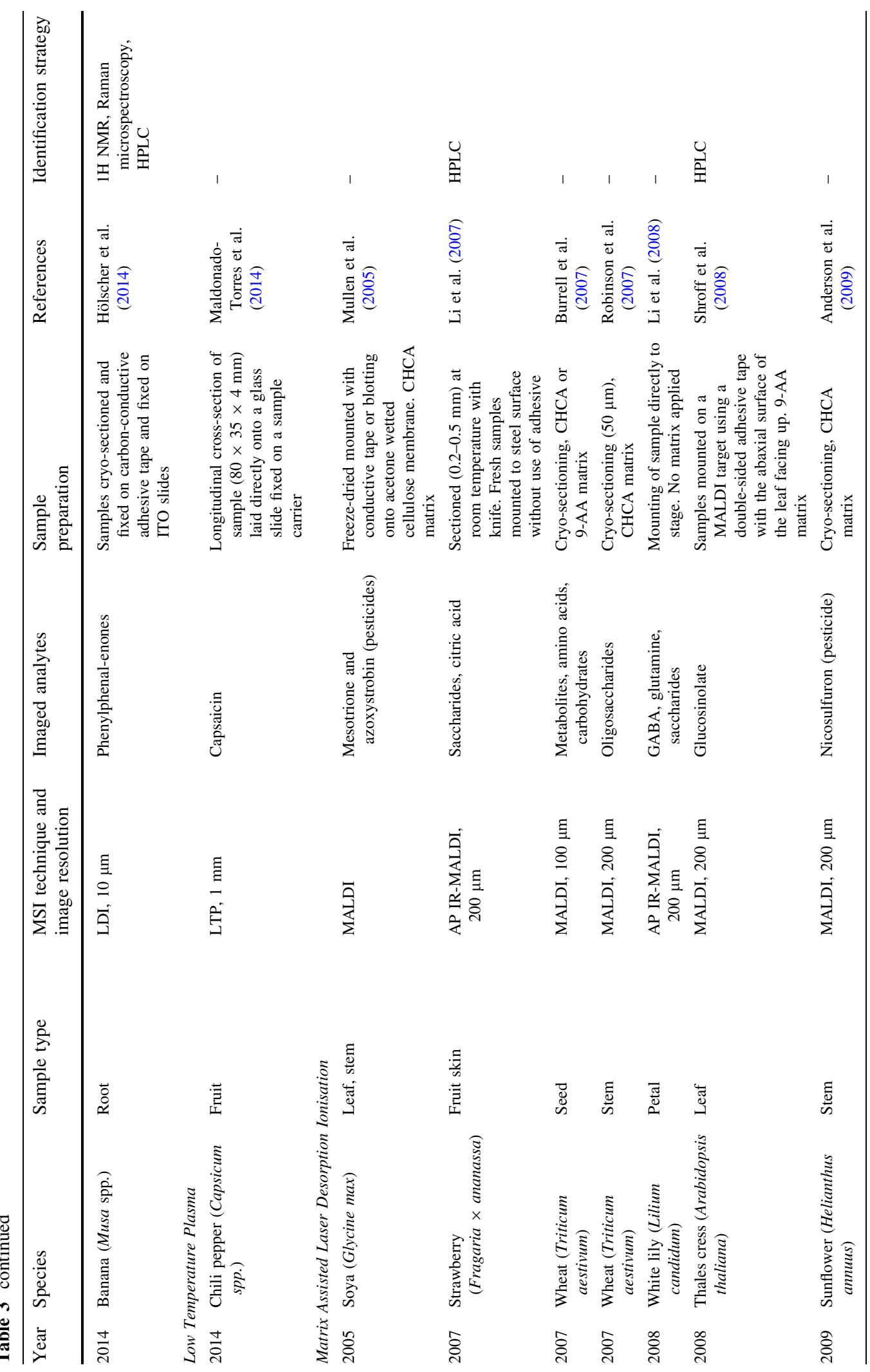




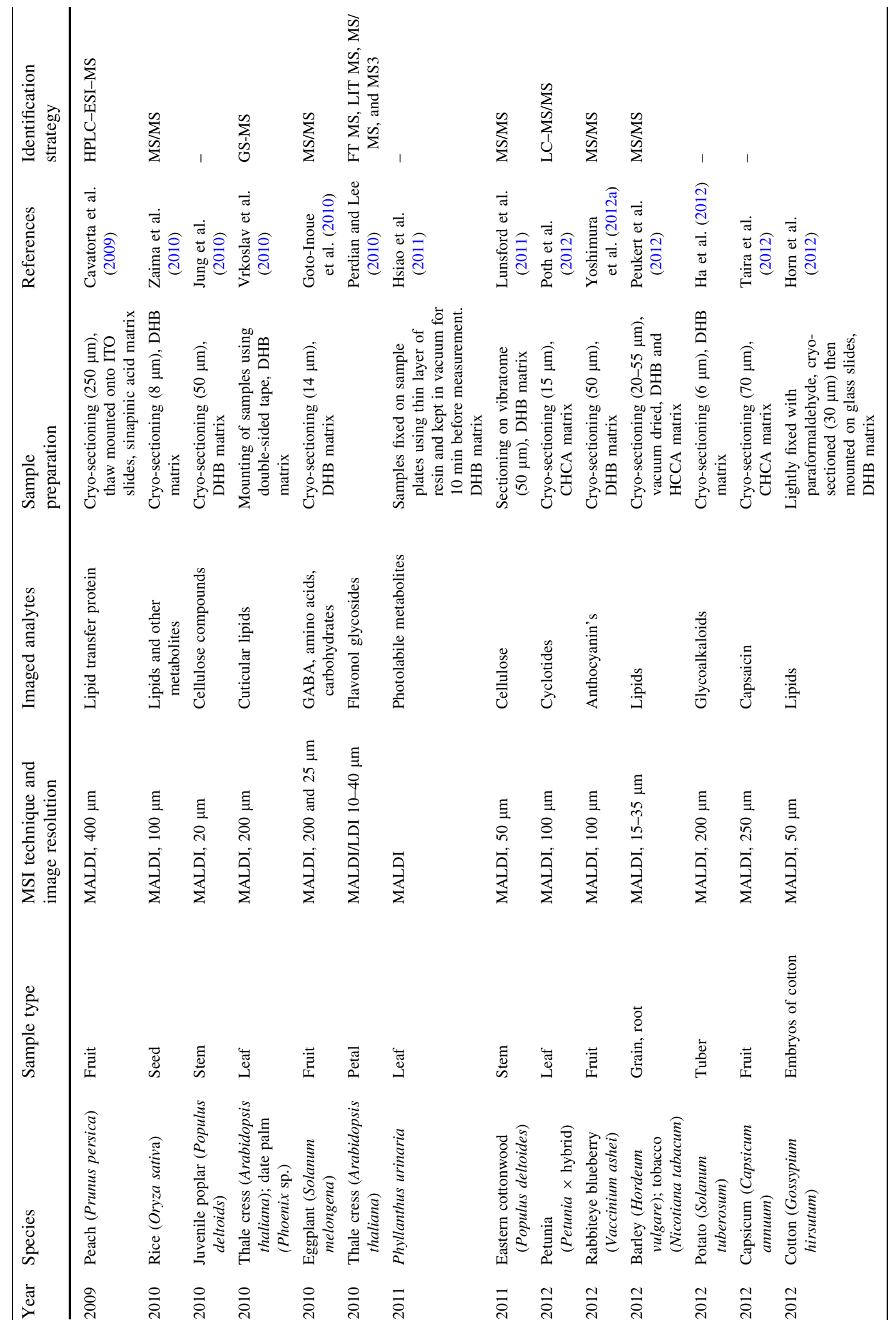




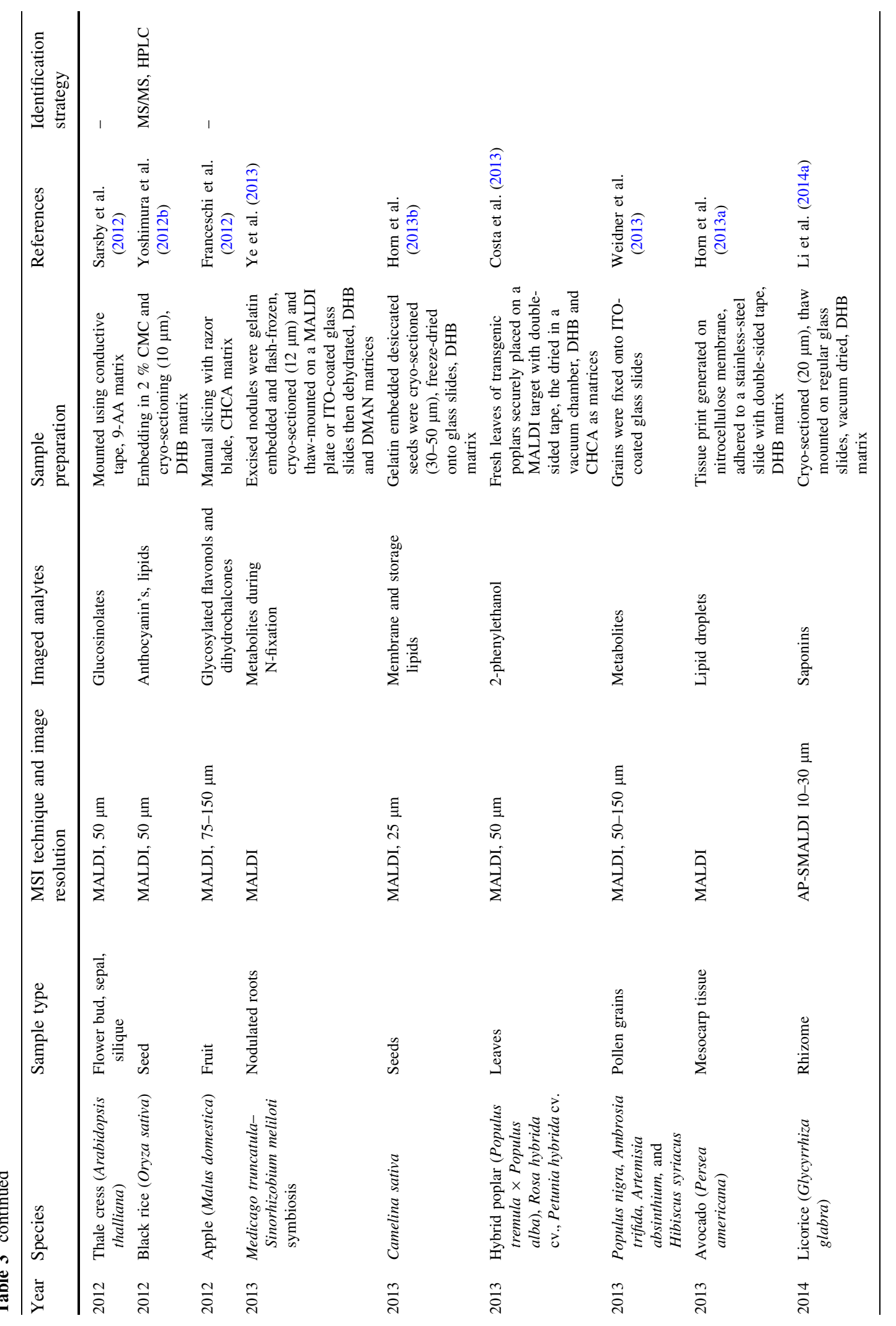




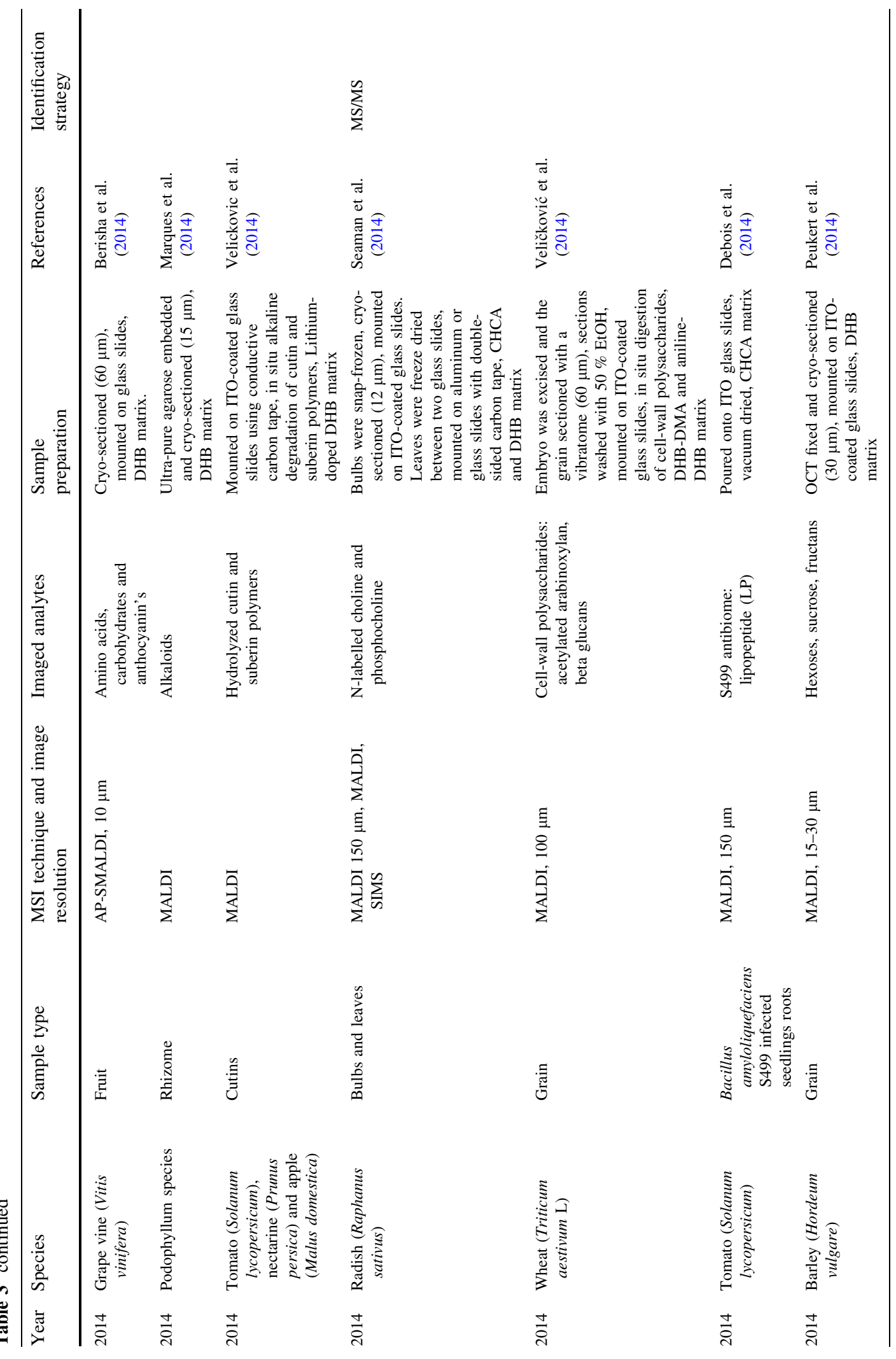




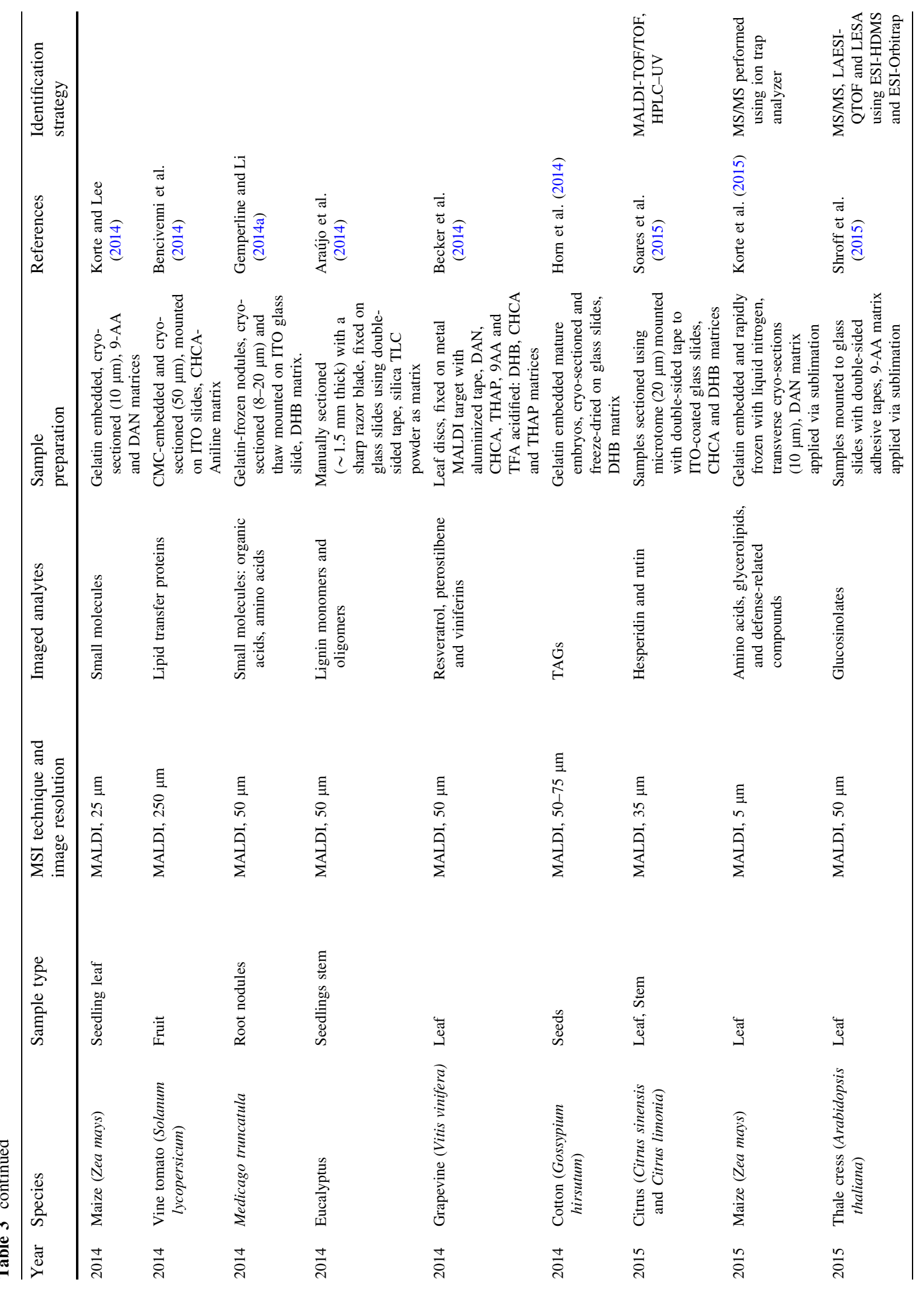




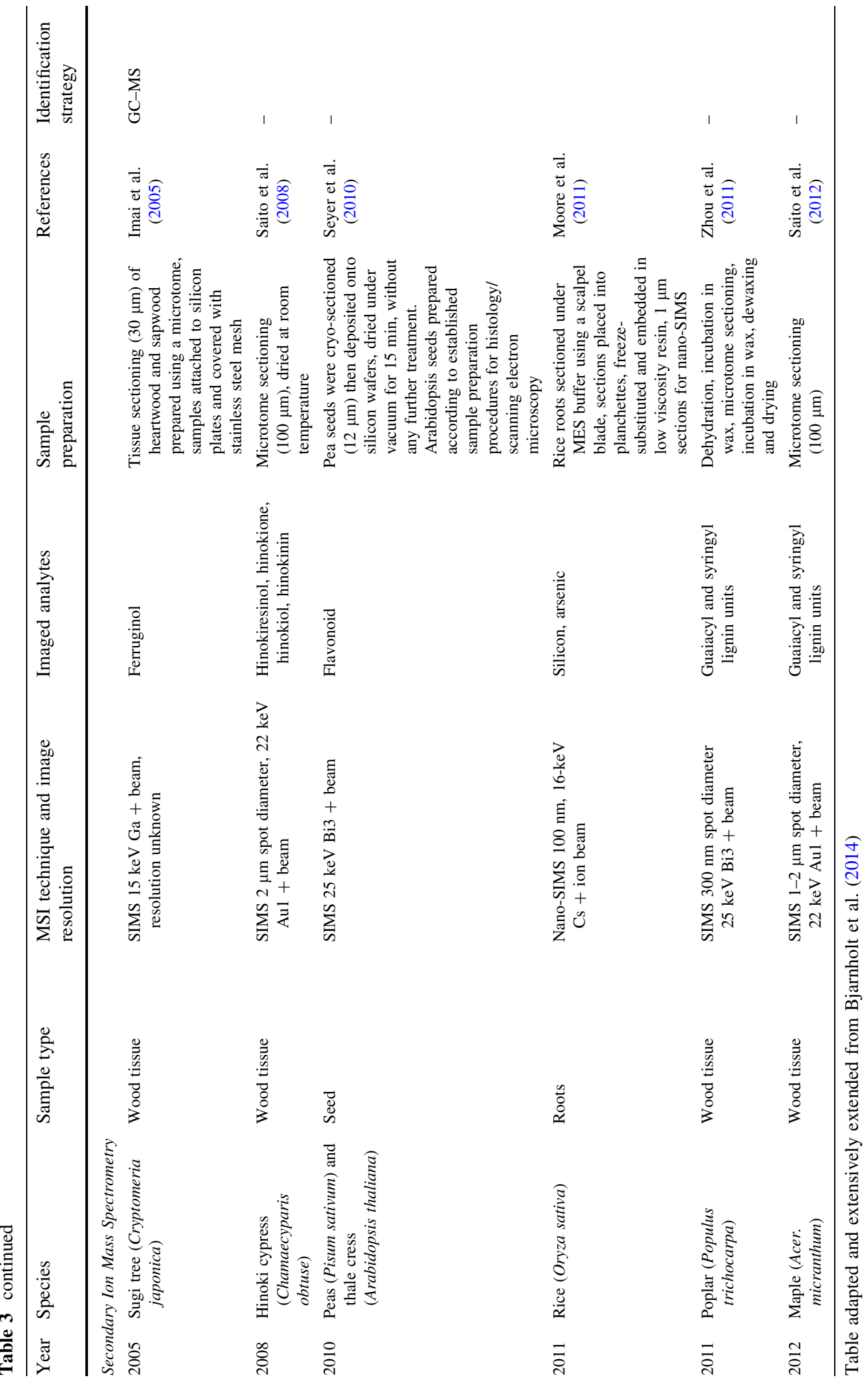


incorporation into the next generation (Fig. 6). They monitored labelled ${ }^{15} \mathrm{~N}$, which was found to be incorporated into choline and phosphocholine, using both MALDI and SIMS imaging in the so-called 'Afterlife Experiment' (Seaman et al. 2014). The experiment demonstrated the usefulness of stable isotope labelling to examine dynamic processes and the recycling of materials from dead to living organisms.

The storage of specialized metabolites in special cell types has been explored by examining the metabolite profiles of trichomes on the leaves of wild tomato, Solanum habrochaites. Metabolites were visualized using carbon-substrate-assisted laser desorption/ionization, in which acyl sugars, alkaloids, flavonoids and terpenoid acids were successfully detected at a spatial resolution of around $50 \mu \mathrm{m}(\mathrm{Li}$ et al. 2014b).

\section{Elemental distributions}

Elemental distributions within plant tissues have been investigated using LA-ICP-MS, where the distribution and quantities of the elements selenium and sulphur were mapped in sunflower plant leaves (da Silva and Arruda 2013). Sulphur is incorporated into a variety of primary metabolites but also defense glucosinolates. LA-ICP-MS has also been used to compare the distribution of iron $(\mathrm{Fe})$ concentrations in transgenic and non-transgenic soybean leaves, with differences of spatial distribution identified using LA-ICP-MS. While Fe was homogenously distributed across the whole transgenic soybean leaf, it was concentrated in the leaf mid-vein and secondary veins of non-transgenics (Oliveira and Arruda 2015). The altered distribution of $\mathrm{Fe}$ was attributed to the changes in the genome and gene products of the transgenic soy plants. Nanoscale SIMS (NanoSIMS) is a technique used to measure the nanoscale distribution $(<100 \mathrm{~nm})$ of elements and isotopes available only on a Cameca NanoSIMS 50 instrument. Using NanoSIMS, the distribution of toxic depositions of arsenic (As) in rice grains and roots has been investigated; As is a severe health threat to rice consumers, and it is important to understand how the rice plant takes up As and distributes it within its tissues (Moore et al. 2013). The authors found a difference of As distribution between high 2-deoxymugineic acid (DMA) grains and wild-type rice grains treated with inorganics. For the former, they found high concentrations in the sub- aleurone region, while for the latter, As was found in the multilayered aleurone layer near the ovular vascular trace (Moore et al. 2013).

\section{Plant structural components}

The composition of plant structural components is of interest to biologists, however most structural components are far too large to measure using MSI approaches. Typically, it is much easier to measure the precursor monomeric units that are directly incorporated into larger structural components. In an example of measuring the spatial distribution of monomeric precursors, syringyl and guaiacyl lignin units have been reported in Eucalyptus species, using MALDIMSI and silica particles as a novel matrix. Examination of differential distribution of monomeric units provides some insight for the purpose of biofuel production from lignocellulosic materials (Araújo et al. 2014). Another strategy to examine the compositional variation in structural units uses enzymatic hydrolysis and tissue pre-treatments to degrade structural components into smaller units which are more amenable to measurement. The localization and quantity of arabinoxylans and beta-glucans in developing wheat grain cell walls was investigated using this approach, where initial in situ enzymatic digestion of large polysaccharides and MALDI-MSI analysis demonstrated an intense endogenous acetylation of arabinoxylans in young grains, as well as feruloylation of arabinoxylans and a variety of structural features of beta-glucans (Veličković et al. 2014). The approach proved effective to measure plant polysaccharide segregation and enabled in situ polysaccharide structural characterization.

\section{Plant surface metabolites}

Mapping of surface-bound metabolites on plant leaves and flowers is another popular area of research, and DESI-MSI provides an exemplary method for directly sampling plant surfaces. It has been used on especially delicate plant surfaces such as flower petals and thin leaves, where it has been extensively used to examine metabolic changes during growth and stress responses (Cabral et al. 2013; Hemalatha and Pradeep 2013; Li et al. 2011, 2013b; Muller et al. 2011). MSI techniques are often hard to apply to non-flat and irregular plant surfaces such as petals, leaves or fruits, because the 


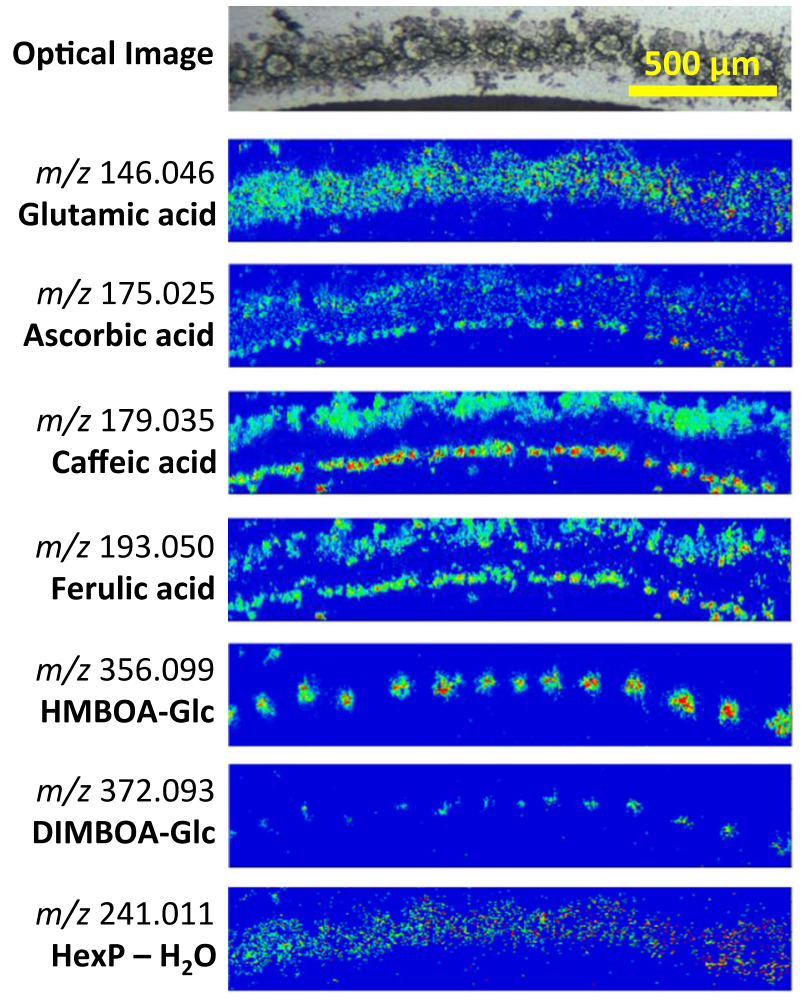

Fig. 5 Optical image and MS images of various metabolites in a maize leaf cross-section obtained at $5 \mu \mathrm{m}$ spatial resolution. Images are oriented such that the upward-facing (adaxial) surface of the leaf is at the top. HMBOA-Glc 2-hydroxy-7-methoxy-1,4benzoxazin-3-one glucoside; DIMBOA-Glc 2,4-dihydroxy-7methoxy-1,4-benzoxazin-3-one glucoside; $H$ exP hexose phosphate; $H_{2} x_{2}$ hexose disaccharide; $P G$ phosphatidylglycerol; $S Q D G$ sulfoquinovosyl diacylglycerol. Glutamic acid and HexP are found throughout the tissues with disaccharides concentrated within the vasculature. Ferulic and caffeic acid are found predominantly within the epidermal layers. Flavonoids are found asymmetrically distributed within the epidermal layers of the tissue. Notably, Maysin is found exclusively in the adaxial epidermis consistent with anti-herbivory and UV protectant properties. PG(34:2) was

preparation of the plant sample becomes time-consuming and frequently requires the use of a cryostat. However, such morphological problems may be overcome by using DESI-MSI. This technique allows preserving the relationship between the spatial distribution and the relative intensity of the chemical compounds. Also, the soft tissues of leaves and petals have been examined using a similar DESI approach by employing a ternary solvent system that enabled the direct imaging of Very-Long-Chain Fatty Acids (VLCFAs) and other secondary metabolites in the
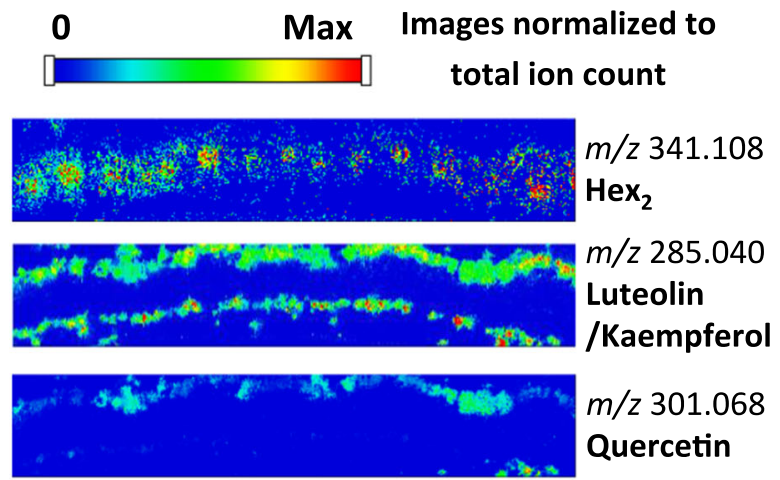

$\mathrm{m} / \mathrm{z} 301.068$

Quercetin

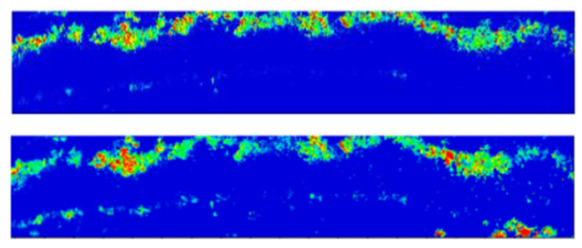

$m / z 575.144$

Maysin

$m / z 609.146$

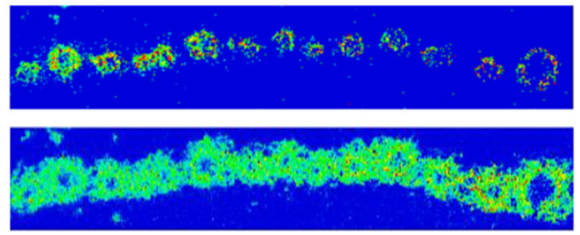

$m / z 745.502$

PG (34:2)

$m / z 815.499$ SQDG (34:3)

found exclusively in the bundle sheath cells, SQDG found distributed in bundle sheath and mesophyll cells. HMBOA-Glc and DIMBOA-Glc found to be specifically distributed to select mesophyll cells between the vascular bundles. Signals are normalized to TIC on each pixel. Maximum values for generating images are as follows. Glutamic acid: $1 \times 10^{-2}$. Ascorbic acid: $8 \times 10^{-3}$. Caffeic acid: $3.5 \times 10^{-2}$. Ferulic acid: $8 \times 10^{-3}$. HMBOA-Glc: $3 \times 10^{-2}$. DIMBOA-Glc: $1 \times 10^{-2}$. HexP- $\mathrm{H}_{2} \mathrm{O}$ : $4 \times 10^{-3}$. $\mathrm{Hex}_{2}: 6 \times 10^{-3}$. Luteolin/kaempferol: $5 \times 10^{-2}$. Quercetin: $4.5 \times 10^{-2}$. Maysin: $5 \times 10^{-2}$. Rutin: $2 \times 10^{-2}$. PG (34:2): $5 \times 10^{-3}$. SQDG (34:3): $3 \times 10^{-2}$.Reproduced with kind permission from Springer Science and Business Media, Anal. Bioanal. Chem., (Korte et al., 2015), 407(8):2301-2309, Copyright (C) 2015

cuticle ( $\mathrm{Li}$ et al. 2013a). By employing a ternary solvent system, the cuticle was not removed from the sample and, as a result, VLCFAs were preserved for MSI. Surface heterogeneity of other plant lipid polymers such as cutin and suberin were determined in tomato, apple and nectarine fruits using MALDIMSI coupled with in situ alkaline depolymerization (Velickovic et al. 2014). This overcame the limitation to analyze structural features of plant surface lipid polymers that would be otherwise difficult to access by dissection and chemical analysis. 


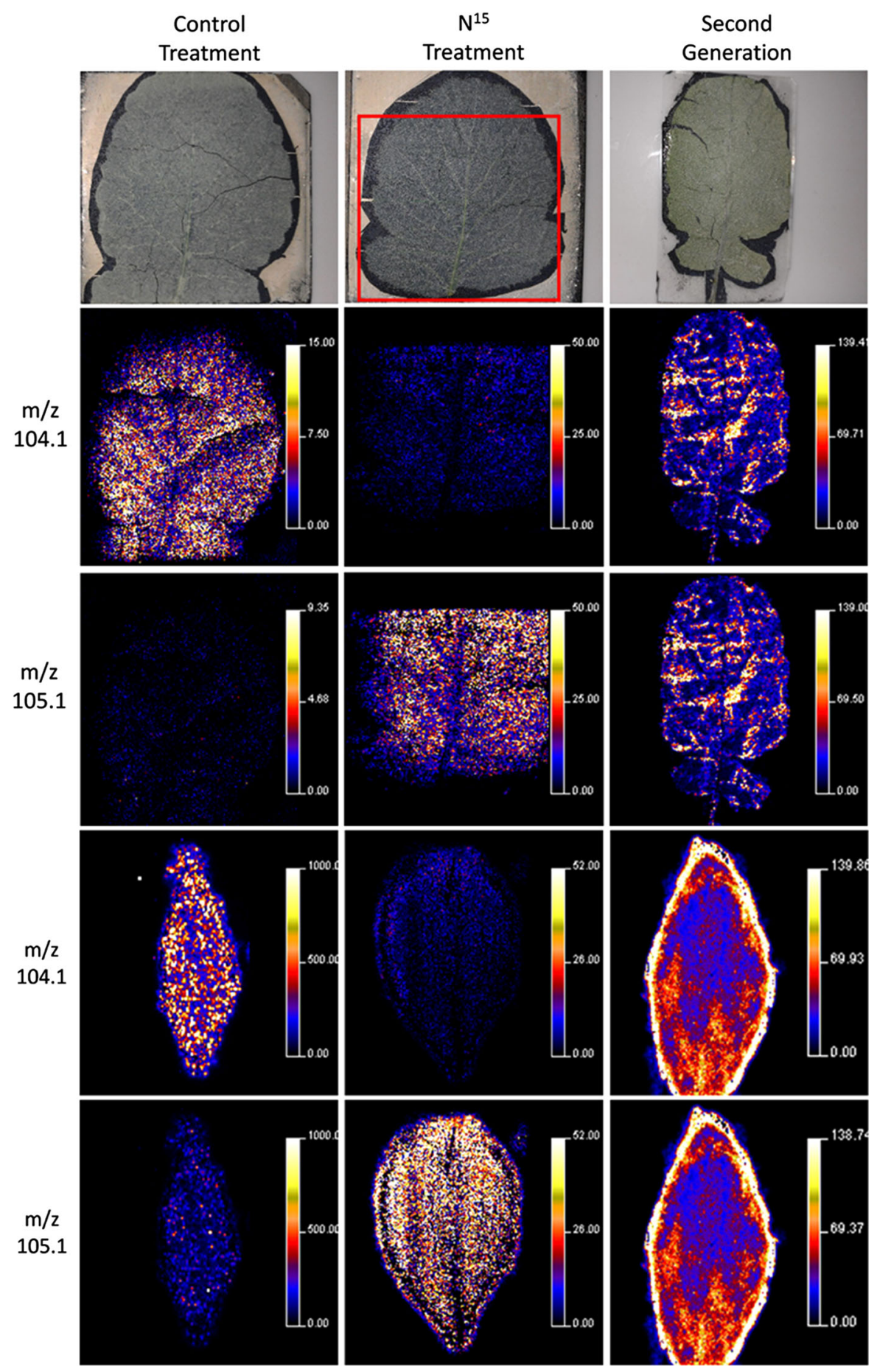

Fig. 6 MALDI-MS images showing the distribution of choline at $\mathrm{m} / \mathrm{z} 104$ and 105 within the leaf and the bulb of the radish (normalized against TIC) Reprinted with permission from
Anal.Chem. (Seaman et al., 2014), 86, 10071-7. Copyright (C) American Chemical Society 
Plant lipids

Lipids, including triacylglycerols (TAGs), glycerophospholipids and sterols, are of particular interest for the generation of high-lipid-content species. MALDI-MSI has been particularly suited to lipid imaging and has been employed in plant-based MSI research. The chemical distribution of the major and minor storage and membrane lipids on mature cotton embryo tissues was examined, and a heterogeneous distribution of TAGs and phosphatidylcholines (PCs) was observed at the cellular level (Horn et al. 2012). MALDI-MSI revealed an altered accumulation of TAG species in cotton embryos expressing a nonfunctional allele of a Brassica napus delta-12 desaturase gene, particularly within cotyledon tissues (Horn et al. 2014). The authors concluded that genetic modifications of cottonseed fatty acid composition are associated with changes in dominant molecular species of TAGs and their spatial distributions within embryo tissues, indicating the possibility of tissuespecific differences in TAG biosynthesis pathways within cotton embryos (Horn et al. 2014). In a truly multi-omics research program combining lipidomics, proteomics and transcriptomics, two new lipid droplet-associated proteins (LDAP1 and LDAP2) were discovered (Horn et al. 2013a). In other species, MALDI-MSI has been employed to map the spatial differences in TAG deposition in lipid bodies present in Avocado mesocarps (Horn et al. 2013a). In an example of multi-modal imaging, they utilized MRI and MSI to examine the distribution of TAGs and their glycerophospholipid precursors within cotyledons and the hypocotyl/radical axis in embryos of Camelina sativa, a crop targeted for future biofuel production (Horn et al. 2013b). Both TAGs and glycerophospholipid precursors were distributed differently within the tissues. Transgenic manipulation of seed lipid composition by modification of enzyme expression resulted in altered patterns of distribution of seed storage lipids, thus highlighting the importance of spatial analysis to identify plant biochemical pathways.

\section{Plant-symbiont systems}

Information on the extent of metabolite changes in plant roots is highly valuable, and plant-symbiont associations, such as nitrogen fixation and defense mechanisms, are of significant importance. While untargeted metabolites can be spatially determined in the model legume plant Medicago truncatula roots and nodules during nitrogen fixation via MALDI-MSI (Gemperline and Li 2014a), a combination of this method with MS/MS metabolite fragmentation in Medicago root nodules and its symbiotic nitrogenfixing bacteria Sinorhizobium meliloti revealed spatial metabolite distributions between Medicago roots, nitrogen-fixing root nodules and non-nitrogen-fixing root nodules (Ye et al. 2013). The studies pave the way for understanding the complex relationship between the plant and its symbiont. MSI studies of other plantsymbiont systems also shed light into understanding the distribution of vital compounds involved in these processes within plant roots. Spatio-temporal distribution of bacterial antibiome/antibiotic biofilms on plant roots that confers resistance against phytopathogens were explored using MALDI-MSI (Debois et al. 2013, 2014). In addition, the spatio-temporal distribution of the plant immunity elicitor surfactin was revealed in different quantities and time intervals. Complementary MS/MS was able to identify new variants of plant surfactins that are vital for protection against pathogen infection (Debois et al. 2014).

Plant responses to abiotic stress

Metabolic changes occur when plants are exposed to external stress, and plants respond in both localized and global manners. MSI has provided a unique tool to explore the spatio-temporal distributions of plant stress metabolites (e.g. phytoalexins, flavonoids etc.) within different cell types. The distribution of glycosylated flavonols and dihydrochalcones in Golden Delicious apples was determined using MALDI-MSI (Franceschi et al. 2012). Glycosides were found to be differentially distributed, with a quercetin-hexoside found in higher abundance directly beneath the cuticle, whereas quercetin-rhamnoside and phloretinhexoside were found throughout the apple pericarp but with glycosides more concentrated directly underneath the cuticle (Franceschi et al. 2012). The results from this study suggest highly localized, tissuespecific biosynthesis of different flavonoid glycosides. Separately, MSI imaging of transverse sections of Lychnophora salicifolia leaves using Tandem MS to distinguish different flavonoids via unique fragmentation patterns revealed a conserved accumulation of 
the flavonoid vicenin-2 in the top layers of the leaves. Vicenin-2 is believed to protect the plants from extreme sunlight, and the highly specific localization to the top of the epidermis supports this hypothesis (Silva et al. 2014).

Plant responses to biotic stress

Plants possess a wide range of defense mechanisms that include structural, chemical and protein-based strategies to cope with biotic stresses. Upon exposure to pathogens and/or herbivores, changes in levels of plant defense compounds, mostly secondary metabolites such as alkaloids, hydroxynitrile glucosides, glucosinolates, phenolics and terpenes are observed (Bennett and Wallsgrove 1994). Localization and distribution of a number of these metabolites has been intensively studied using MSI, with an aim to better understand their roles in plants. MSI has been used to monitor changes in glycoalkaloid toxins produced by plants in response to microbial infection using both DESI and MALDI approaches (Cabral et al. 2013; Ha et al. 2012; Tata et al. 2015). Examination of toxins in food products is important both to guarantee food supply but also to examine the underlying biology of plant-pathogen response. The DESI approach was used to examine fluctuation of toxic glycoalkaloids, $\alpha$ chaconine and $\alpha$-solanine, in sprouted potatoes infected by the phytopathogen Pythium ultimum, at different time intervals and with minimal sample preparation (Tata et al. 2015). Results demonstrate distinct differences in the spatial distribution of specific plant metabolites throughout the tissue and the accumulation of aglycon and glycoalkaloid precursors, including solanidine, solasodine, $\gamma / \beta$-chaconine, $\gamma / \beta$-solanine and others, around the site of infection. At later time points, decreases in these metabolites around the infection demonstrated the ability of the pathogen to metabolize toxic glycoalkaloids to less toxic intermediates, by partial or complete hydrolysis of sugar units. Other glycoalkaloids including saponins have also been examined in Glycyrrhiza glabra (licorice) using AP-MALDI-MS/MS at high mass and spatial resolution $(10 \mu \mathrm{m})$. The results provided unique information, localizing biosynthetic pathways for glycoalkaloid production to the rhizomes, which are the primary source of compounds with medicinal value ( $\mathrm{Li}$ et al. 2014a). In addition, MALDI-MSI was also able to confirm the presence of the mycotoxin deoxynivalenol on a fungus-infected wheat seed surface (Berisha et al. 2014), as well as illustrate high levels of hesperidin distributed at infection sites of Xylella fastidiosa on citrus leaves and stems (Soares et al. 2015). The antifungal secondary metabolites hordatine and its derivatives were also spatially mapped in barley embryo tissues using MALDI-MSI, where specific glycosylation patterns as well as tissue-specific hordatine derivatives were revealed (Gorzolka et al. 2014).

Other plant defense molecules, including the highly toxic hydroxynitrile glucosides (cyanogenic glucosides) have been detected in the plant leaf epidermis using DESI-MSI (Li et al. 2011, 2013b) (Fig. 7). The herbivory response was simulated in Lotus japonicas applying mechanical stress to the leaf by crushing. Mechanical stress releases stores of hydroxynitrile glucosides and allows interaction with $\beta$-glycosidases and lyases, leading to enzymatic hydrolysis and release of hydrogen cyanide. The reaction is observed as local decreases in hydroxynitrile signal and a corresponding increase of glucose as one of the hydrolysis products in the tissues. MALDI-MSI has been used to determine spatio-temporal distribution and quantities of glucosinolates in Arabidopsis leaves, where the glucosinolate profile and overall concentration not only attracts but also affects feeding preferences of lepidopterans (Sarsby et al. 2012; Shroff et al. 2008, 2015). The authors established a robust, quantitative imaging approach to determine the concentrations of glucosinolates on the leaf surface (Shroff et al. 2015). Banana-specific nematostatic and nematicidal phytoalexins, phenylphenalenones, were examined using a multi-modal approach, involving a combination of LDI-MSI, ${ }^{1} \mathrm{H}$ NMR spectroscopy and Raman microspectroscopy, to determine the distribution of phenylphenalenones around nematode-caused lesions on banana plants; and their ingestion and localization within nematodes (Hölscher et al. 2014). The results demonstrated that the higher concentration of the phenylphenalenone anigorufone, produced by resistant cultivars, is the reason for differences in cultivar resistance to nematode infection.

\section{Future outlook}

Ongoing technological improvements promise to surpass the limitations of current instruments, for 
instance where spatially resolved detection using the Timepix detector enables a rapid analysis of larger areas, leading to faster acquisition times for MSI experiments (Soltwisch et al. 2014; Syed et al. 2015). However, the technology is not in common use and is limited to TOF detectors but offers significant promise for profiling- and screening-type MSI approaches where ultra-high mass accuracy is not needed. Continual development of older MSI technologies to bypass current limitations will provide new capabilities; a recent example is SIMS, where development of 'soft ionization' techniques using water cluster beams has enabled measurement of the molecular ions of individual lipids without fragmentation to lateral resolutions of less than $10 \mu \mathrm{m}$ (Berrueta Razo et al. 2014; Sheraz nee Rabbani et al. 2015). The development of new types of sources, including the vast array of ambient pressure sources that could be employed in MSI will reduce necessary sample preparation steps and allow examination of a wider range of surfaces (Monge et al. 2013; Wu et al. 2013). Modification of developed sources, such as addition of a second postionization laser to generate the MALDI-2-MS source (Soltwisch et al. 2015), offers much promise to increase the sensitivity towards plant metabolites. New combination approaches that take advantage of complementary technologies on a single instrument provide an enormous advantage where, for example, small molecules may be mapped quickly with MALDI to high lateral resolution, and then metabolite and protein distributions can determined by nano-ESILESA (Tomlinson et al. 2014).

A single MSI experiment provides only a static snapshot of the underlying molecular distribution, which does not allow direct determination of metabolic flux within an organism. Development of new analytical approaches to examine spatio-temporally resolved metabolite flux using Kinetic Mass Spectrometry Imaging (kMSI), through incorporation of stable isotope labelling, provides much potential to explore the dynamics of plant metabolism (Louie et al. 2013) (Fig. 8).

MSI suffers from ion suppression effects and has limitations where molecules cannot be ionized or volatilized. However, the development of 'Reactive nano-DESI', which incorporates selective and reactive chemicals (for specific metabolites or classes of metabolites) into the solvent stream, raises new possibilities (Laskin et al. 2012a). Individual classes
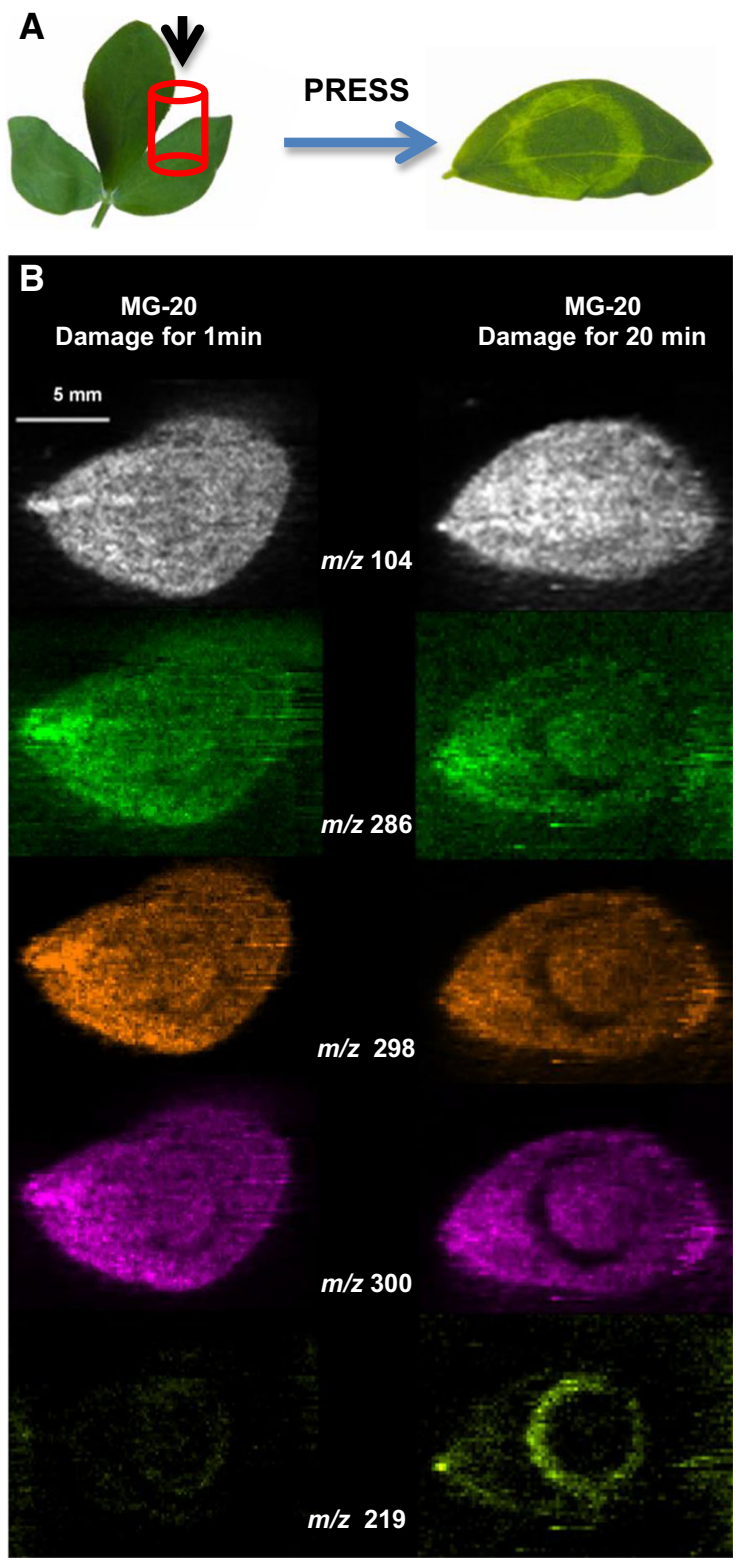

Fig. 7 Demonstrates immediate response to physical stress and degradation of hydoxynitriles (cyanogenic glucosides) in wounded Lotus japonicas MG20 leaf tissues over time. Visualization of $\beta$ glucosidase mediated hydrolysis of hydroxynitrile glucosides in wounded leaves. A The leaves were wounded by pressing with a metal pipe; $\mathbf{B}$ indirect DESI-MS images of the wounded leaves: $\mathrm{m} / \mathrm{z}$ $104[\gamma \text {-aminobutyric acid }+\mathrm{H}]^{+}, 286[\text { linamarin }+\mathrm{K}]^{+}, 298$

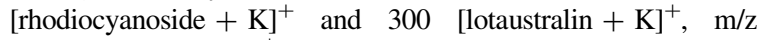
$219=[\text { glucose }+\mathrm{K}]^{+}$. Reproduced with kind permission from John Wiley and Sons Ltd, The Plant Journal, (Li et al., 2013b), 74:1059-1071, Copyright (C) 2013

of chemicals may be targeted, chemically modified to enhance ionization or provide a specific chemical probe that may allow quantification directly off the 
A

\section{${ }^{2} \mathrm{H}_{2} \mathrm{O}$-administration}

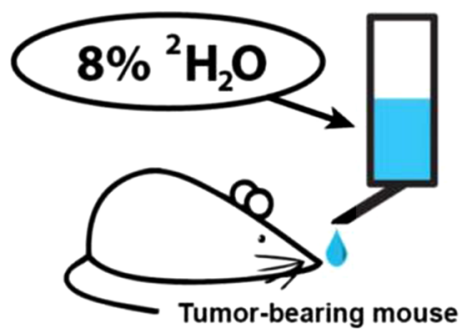

C

Histology of serial section

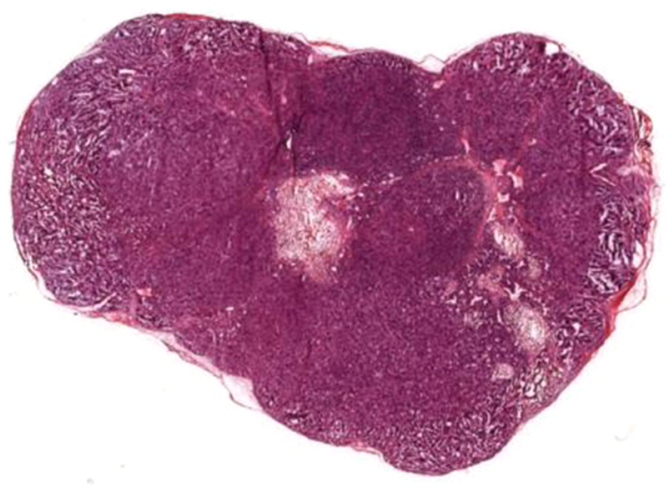

B

D

\section{NIMS imaging of tumor section}
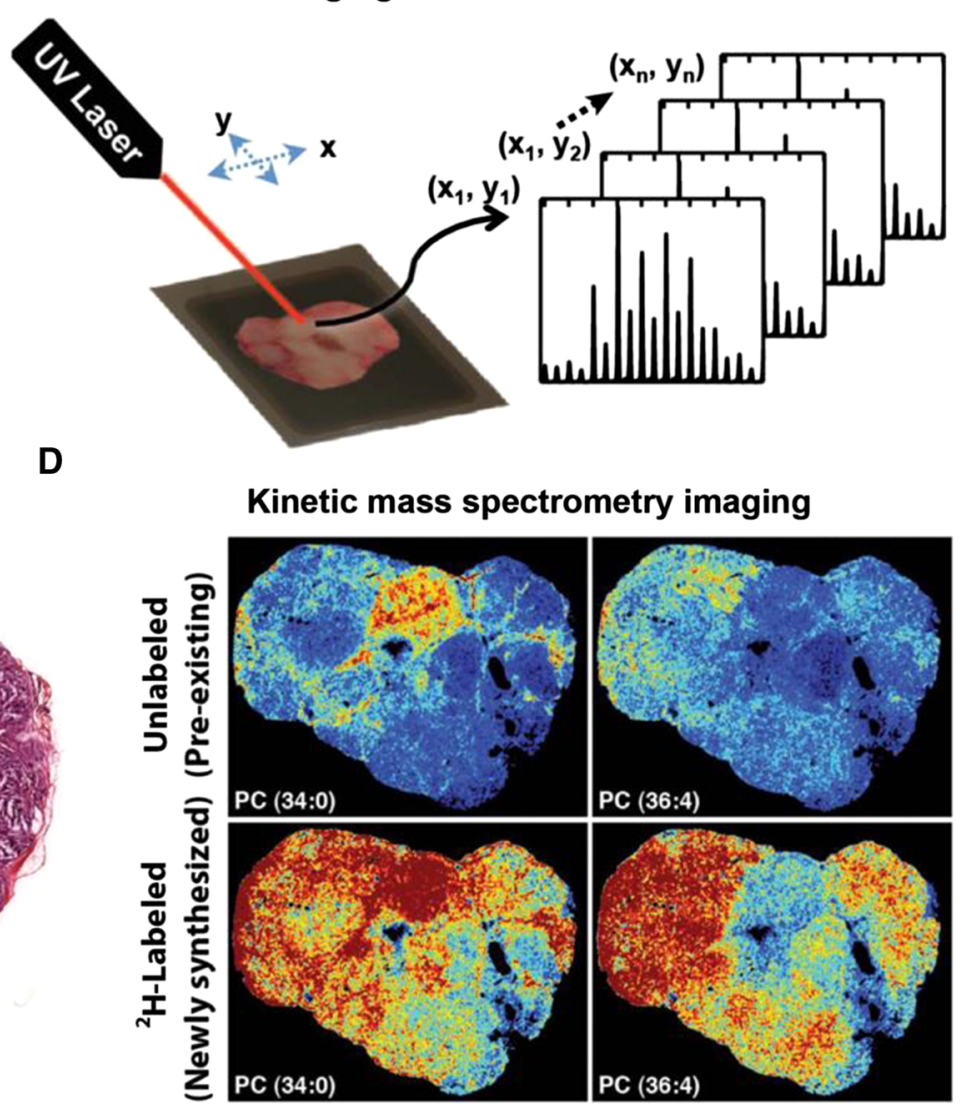

Fig. 8 Example of kinetic mass spectrometric imaging - experimental workflow for using kMSI to define spatial heterogeneity of lipid composition and biosynthesis. A A tumor-bearing mouse is administered ${ }^{2} \mathrm{H}_{2} \mathrm{O}$-enriched water to incorporate deuterium into tissue as a result of active metabolism. B The deuterium-enriched tumor is excised, sectioned and imaged using NIMS. An individual mass spectrum is generated for each pixel every $50 \mu \mathrm{m}$, with spectra comprised of isotopologues from both ${ }^{2} \mathrm{H}$ -

tissue, providing another level of chemical specificity and a selective tool for the analytical scientist.

Data analysis remains a bottleneck, however, emerging MSI data analysis techniques that enable analysis of ultra-high resolution MSI data and incorporate spatial segmentation will enhance discovery of spatially resolved metabolism. Further development of unsupervised techniques that utilize the spatial information within a MSI dataset and statistical techniques to discover co-occurring metabolites and significant differences in regions of tissue will also help to unlock the power of MSI analysis. Further afield, integration of MSI data with gene expression and metabolomics data will allow identification of novel biosynthetic pathways labeled and unlabeled lipid molecules. C Serial sections of the tumor are used for histopathology correlation with kMSI results. D Deconvolution of spectra is performed to separate ${ }^{2} \mathrm{H}$-labeled and unlabeled lipids. Intensity images are generated to show the spatial distribution for both newly synthesized and pre-existing lipids. Reprinted by permission from Macmillan Publishers Ltd: Scientific Reports, (Louie et al., 2013) 3:1656, Copyright (C) 2013

and mechanisms, providing new avenues to explore biological function of metabolites and genes. Specifically, the integration of the transcriptome with the measured metabolome of an organism has proven to be a powerful method to interrogate production of novel phytochemicals by allowing rapid identification of the genes and gene products involved in underlying biosynthetic pathways (Hegeman 2010; Sumner et al. 2015; Zhang et al. 2004). Plant-based MSI, used as a spatial metabolomics tool, holds much promise to localize the biosynthesis of important plant metabolites and their storage sites, aiding the elucidation of specialized biosynthetic pathways and the identification of genes and gene products. Together, this has the 
potential to enhance bioengineering of crops to either produce much-needed phytochemicals or to better withstand challenging environmental conditions.

\section{Conclusion}

The MSI research that has been conducted up to this point will underpin the future development of techniques and instrumentation of chemical mapping of plant tissues. Over the past decade, plant MSI has developed rapidly from a boutique technique employed by analytical chemists to a robust technique that is rapidly growing. Plant scientists across a diverse range of research fields are employing MSI to examine fundamental plant biology. Technical developments have overcome many past difficulties, and emerging data analysis methods promise to unleash the full potential of MSI for spatial analysis.

Acknowledgments The authors are grateful to Metabolomics Australia (MA) at The University of Melbourne, a member of Bioplatforms Australia Pty Ltd which is funded through the National Collaborative Research Infrastructure Strategy (NCRIS), 5.1 Biomolecular Platforms and Informatics and coinvestments from the Victorian Government.

\section{Compliance with ethical standards}

Conflicts of interest The authors state no conflict of interest and have received no payment for the preparation of this manuscript.

Open Access This article is distributed under the terms of the Creative Commons Attribution 4.0 International License (http:// creativecommons.org/licenses/by/4.0/), which permits unrestricted use, distribution, and reproduction in any medium, provided you give appropriate credit to the original author(s) and the source, provide a link to the Creative Commons license, and indicate if changes were made.

\section{References}

Addie RD, Balluff B, Bovee JV, Morreau H, McDonnell LA (2015) Current state and future challenges of mass spectrometry imaging for clinical research. Anal Chem 87:6426

Aichler M, Walch A (2015) MALDI Imaging mass spectrometry: current frontiers and perspectives in pathology research and practice. Lab Invest 95:422-431

Alexandrov T (2012) MALDI imaging mass spectrometry: statistical data analysis and current computational challenges. BMC Bioinform 13(Suppl 16):S11

Alexandrov T, Chernyavsky I, Becker M, von Eggeling F, Nikolenko S (2013) Analysis and interpretation of imaging mass spectrometry data by clustering mass-to-charge images according to their spatial similarity. Anal Chem 85:11189-11195

Amstalden van Hove ER, Blackwell TR, Klinkert I, Eijkel GB, Heeren RMA, Glunde K (2010) Multimodal mass spectrometric imaging of small molecules reveals distinct spatio-molecular signatures in differentially metastatic breast tumor models. Cancer Res 70:9012-9021

Anderson DM, Carolan VA, Crosland S, Sharples KR, Clench MR (2009) Examination of the distribution of nicosulfuron in sunflower plants by matrix-assisted laser desorption/ ionisation mass spectrometry imaging. Rapid Commun Mass Spectrom 23:1321-1327

Anderson DM, Floyd KA, Barnes S, Clark JM, Clark JI, McHaourab H, Schey KL (2015) A method to prevent protein delocalization in imaging mass spectrometry of non-adherent tissues: application to small vertebrate lens imaging. Anal Bioanal Chem 407:2311-2320

Andersson M, Groseclose MR, Deutch AY, Caprioli RM (2008) Imaging mass spectrometry of proteins and peptides: 3D volume reconstruction. Nat Methods 5:101-108

Andras TD, Alexander TS, Gahlena A, Parry RM, Fernandez FM, Kubanek J, Wang MD, Hay ME (2012) Seaweed allelopathy against coral: surface distribution of a seaweed secondary metabolite by imaging mass spectrometry. J Chem Ecol 38:1203-1214

Angel PM, Spraggins JM, Baldwin HS, Caprioli R (2012) Enhanced sensitivity for high spatial resolution lipid analysis by negative ion mode matrix assisted laser desorption ionization imaging mass spectrometry. Anal Chem 84:1557-1564

Araújo P, Ferreira MS, de Oliveira DN, Pereira L, Sawaya ACHF, Catharino RR, Mazzafera P (2014) Mass spectrometry imaging: an expeditious and powerful technique for fast in situ lignin assessment in eucalyptus. Anal Chem 86:3415-3419

Baluya DL, Garrett TJ, Yost RA (2007) Automated MALDI matrix deposition method with inkjet printing for imaging mass spectrometry. Anal Chem 79:6862-6867

Barry JA, Robichaud G, Bokhart MT, Thompson C, Sykes C, Kashuba AD, Muddiman DC (2014) Mapping antiretroviral drugs in tissue by IR-MALDESI MSI coupled to the Q Exactive and comparison with LC-MS/MS SRM assay. J Am Soc Mass Spectrom 25:2038-2047

Becker JS (2013) Imaging of metals in biological tissue by laser ablation inductively coupled plasma mass spectrometry (LA-ICP-MS): state of the art and future developments. J Mass Spectrom 48:255-268

Becker L, Carre V, Poutaraud A, Merdinoglu D, Chaimbault P (2014) MALDI mass spectrometry imaging for the simultaneous location of resveratrol, pterostilbene and viniferins on grapevine leaves. Molecules 19:10587-10600

Bencivenni M, Faccini A, Zecchi R, Boscaro F, Moneti G, Dossena A, Sforza S (2014) Electrospray MS and MALDI imaging show that non-specific lipid-transfer proteins (LTPs) in tomato are present as several isoforms and are concentrated in seeds. J Mass Spectrom 49:1264-1271

Bennett RN, Wallsgrove RM (1994) Secondary metabolites in plant defence mechanisms. New Phytol 127:617-633 
Berisha A, Dold S, Guenther S, Desbenoit N, Takats Z, Spengler B, Römpp A (2014) A comprehensive high-resolution mass spectrometry approach for characterization of metabolites by combination of ambient ionization, chromatography and imaging methods. Rapid Commun Mass Spectrom 28:1779-1791

Berrueta Razo I, Sheraz S, Henderson A, Lockyer NP, Vickerman JC (2014) Comparing C60+ and (H2O)n+ clusters for mouse brain tissue analysis. Surf Interface Anal 46:136-139

Bjarnholt N, Li B, D’Alvise J, Janfelt C (2014) Mass spectrometry imaging of plant metabolites-principles and possibilities. Nat Prod Rep 31:818-837

Burrell M, Earnshaw C, Clench M (2007) Imaging matrix assisted laser desorption ionization mass spectrometry: a technique to map plant metabolites within tissues at high spatial resolution. J Exp Bot 58:757-763

Cabral EC, Mirabelli MF, Perez CJ, Ifa DR (2013) Blotting assisted by heating and solvent extraction for DESI-MS imaging. J Am Soc Mass Spectrom 24:956-965

Caprioli RM, Farmer TB, Gile J (1997) Molecular imaging of biological samples: localization of peptides and proteins using MALDI-TOF MS. Anal Chem 69:4751-4760

Casati P, Walbot V (2005) Differential accumulation of maysin and rhamnosylisoorientin in leaves of high-altitude landraces of maize after UV-B exposure. Plant Cell Environ 28:788-799

Castaing R, Slodzian G (1962) Microanalyse par emission ionique secondaire. J Microsc 1:395-410

Cavatorta V, Sforza S, Mastrobuoni G, Pieraccini G, Francese S, Moneti G, Dossena A, Pastorello EA, Marchelli R (2009) Unambiguous characterization and tissue localization of Pru P 3 peach allergen by electrospray mass spectrometry and MALDI imaging. J Mass Spectrom 44:891-897

Cha S, Yeung ES (2007) Colloidal graphite-assisted laser desorption/ionization mass spectrometry and MSn of small molecules. 1. Imaging of cerebrosides directly from rat brain tissue. Anal Chem 79:2373-2385

Cha S, Zhang H, Ilarslan HI, Wurtele ES, Brachova L, Nikolau BJ, Yeung ES (2008) Direct profiling and imaging of plant metabolites in intact tissues by using colloidal graphiteassisted laser desorption ionization mass spectrometry. Plant J 55:348-360

Cha S, Song Z, Nikolau BJ, Yeung ES (2009) Direct profiling and imaging of epicuticular waxes on arabidopsis thaliana by laser desorption/ionization mass spectrometry using silver colloid as a matrix. Anal Chem 81:2991-3000

Chaurand P (2012) Imaging mass spectrometry of thin tissue sections: a decade of collective efforts. J Proteomics 75:4883-4892

Chughtai K, Heeren RM (2010) Mass spectrometric imaging for biomedical tissue analysis. Chem Rev 110:3237-3277

Chughtai S, Chughtai K, Cillero-Pastor B, Kiss A, Agrawal P, MacAleese L, Heeren RMA (2012) A multimodal mass spectrometry imaging approach for the study of musculoskeletal tissues. Int J Mass Spectrom 325-327:150-160

Claros MG, Bautista R, Guerrero-Fernandez D, Benzerki H, Seoane P, Fernandez-Pozo N (2012) Why assembling plant genome sequences is so challenging. Biology 1:439-459

Costa MA, Marques JV, Dalisay DS, Herman B, Bedgar DL, Davin LB, Lewis NG (2013) Transgenic hybrid poplar for sustainable and scalable production of the commodity/ specialty chemical, 2-phenylethanol. PLoS ONE 8:e83169

Creek DJ, Dunn WB, Fiehn O, Griffin JL, Hall RD, Lei Z, Mistrik R, Neumann S, Schymanski EL, Sumner LW, Trengove R, Wolfender J-L (2014) Metabolite identification: are you sure? And how do your peers gauge your confidence? Metabolomics 10:350-353

da Silva MA, Arruda MA (2013) Laser ablation (imaging) for mapping and determining $\mathrm{Se}$ and $\mathrm{S}$ in sunflower leaves. Metallomics 5:62-67

de Hoffmann E (1996) Tandem mass spectrometry: a primer. J Mass Spectrom 31:129-137

Debois D, Ongena M, Cawoy H, De Pauw E (2013) MALDIFTICR MS imaging as a powerful tool to identify Paenibacillus antibiotics involved in the inhibition of plant pathogens. J Am Soc Mass Spectrom 24:1202-1213

Debois D, Jourdan E, Smargiasso N, Thonart P, De Pauw E, Ongena M (2014) Spatiotemporal monitoring of the antibiome secreted by bacillus biofilms on plant roots using MALDI mass spectrometry imaging. Anal Chem $86: 4431-4438$

Dreisewerd K (2003) The desorption process in MALDI. Chem Rev 103:395-426

Dufresne M, Thomas A, Breault-Turcot J, Masson J-F, Chaurand $P$ (2013) Silver-assisted laser desorption ionization for high spatial resolution imaging mass spectrometry of olefins from thin tissue sections. Anal Chem 85:3318-3324

Eikel D, Vavrek M, Smith S, Bason C, Yeh S, Korfmacher WA, Henion JD (2011) Liquid extraction surface analysis mass spectrometry (LESA-MS) as a novel profiling tool for drug distribution and metabolism analysis: the terfenadine example. Rapid Commun Mass Spectrom 25:3587-3596

Ellis SR, Bruinen AL, Heeren RM (2014a) A critical evaluation of the current state-of-the-art in quantitative imaging mass spectrometry. Anal Bioanal Chem 406:1275-1289

Ellis SR, Soltwisch J, Heeren RM (2014b) Time-resolved imaging of the MALDI linear-TOF ion cloud: direct visualization and exploitation of ion optical phenomena using a position- and time-sensitive detector. J Am Soc Mass Spectrom 25:809-819

Fiehn O (2002) Metabolomics- the link between genotypes and phenotypes. Plant Mol Biol 48:155-171

Fletcher JS, Lockyer NP, Vickerman JC (2011a) Developments in molecular SIMS depth profiling and 3D imaging of biological systems using polyatomic primary ions. Mass Spectrom Rev 30:142-174

Fletcher JS, Vickerman JC, Winograd N (2011b) Label free biochemical 2D and 3D imaging using secondary ion mass spectrometry. Curr Opin Chem Biol 15:733-740

Fonville JM, Carter CL, Pizarro L, Steven RT, Palmer AD, Griffiths RL, Lalor PF, Lindon JC, Nicholson JK, Holmes E, Bunch J (2013) Hyperspectral visualization of mass spectrometry imaging data. Anal Chem 85:1415-1423

Franceschi P, Wehrens R (2014) Self-organizing maps: a versatile tool for the automatic analysis of untargeted imaging datasets. Proteomics 14:853-861

Franceschi P, Dong Y, Strupat K, Vrhovsek U, Mattivi F (2012) Combining intensity correlation analysis and MALDI imaging to study the distribution of flavonols and dihydrochalcones in Golden Delicious apples. J Exp Bot 63:1123-1133 
Fraser PD, Enfissi EM, Goodfellow M, Eguchi T, Bramley PM (2007) Metabolite profiling of plant carotenoids using the matrix-assisted laser desorption ionization time-of-flight mass spectrometry. Plant J 49:552-564

Fujimura Y, Miura D (2014) MALDI mass spectrometry imaging for visualizing in situ metabolism of endogenous metabolites and dietary phytochemicals. Metabolites 4:319-346

Galle P (1970) Sur une nouvelle methode d'analyse cellulaire utilisant le phenomene d'emission ionique secondaire. Ann Phys Biol Med 42:84-94

Gauthier JW, Trautman TR, Jacobson DB (1991) Sustained offresonance irradiation for collision-activated dissociation involving Fourier transform mass spectrometry. Collisionactivated dissociation technique that emulates infrared multiphoton dissociation. Anal Chim Acta 246:211-225

Gemperline E, Li L (2014a) MALDI-mass spectrometric imaging for the investigation of metabolites in Medicago truncatula root nodules. J Vis Exp 85:e51434

Gemperline E, Li L (2014b) MALDI-mass spectrometric imaging of endogenous metabolites in biological systems. eLS, Wiley. doi:10.1002/9780470015902.a0023207

Gode D, Volmer DA (2013) Lipid imaging by mass spectrometry-a review. Analyst 138:1289-1315

Goodwin RJ, Dungworth JC, Cobb SR, Pitt AR (2008) Timedependent evolution of tissue markers by MALDI-MS imaging. Proteomics 8:3801-3808

Goodwin RJ, Lang AM, Allingham H, Boren M, Pitt AR (2010) Stopping the clock on proteomic degradation by heat treatment at the point of tissue excision. Proteomics 10:1751-1761

Goodwin RJ, Iverson SL, Andren PE (2012) The significance of ambient-temperature on pharmaceutical and endogenous compound abundance and distribution in tissues sections when analyzed by matrix-assisted laser desorption/ionization mass spectrometry imaging. Rapid Commun Mass Spectrom 26:494-498

Gorzolka K, Bednarz H, Niehaus K (2014) Detection and localization of novel hordatine-like compounds and glycosylated derivates of hordatines by imaging mass spectrometry of barley seeds. Planta 239:1321-1335

Goto-Inoue N, Setou M, Zaima N (2010) Visualization of spatial distribution of $\gamma$-aminobutyric acid in eggplant (Solanum melongena) by matrix-assisted laser desorption/ionization imaging mass spectrometry. Anal Sci 26:821-825

Ha M, Kwak JH, Kim Y, Zee OP (2012) Direct analysis for the distribution of toxic glycoalkaloids in potato tuber tissue using matrix-assisted laser desorption/ionization mass spectrometric imaging. Food Chem 133:1155-1162

Hamm G, Carre V, Poutaraud A, Maunit B, Frache G, Merdinoglu D, Muller JF (2010) Determination and imaging of metabolites from Vitis vinifera leaves by laser desorption/ ionisation time-of-flight mass spectrometry. Rapid Commun Mass Spectrom 24:335-342

Hankin JA, Barkley RM, Murphy RC (2007) Sublimation as a method of matrix application for mass spectrometric imaging. J Am Soc Mass Spectrom 18:1646-1652

Hanrieder J, Karlsson O, Brittebo EB, Malmberg P, Ewing AG (2014) Probing the lipid chemistry of neurotoxin-induced hippocampal lesions using multimodal imaging mass spectrometry. Surf Interface Anal 46:375-378
Harada T, Yuba-Kubo A, Sugiura Y, Zaima N, Hayasaka T, Goto-Inoue N, Wakui M, Suematsu M, Takeshita K, Ogawa K, Yoshida Y, Setou M (2009) Visualization of volatile substances in different organelles with an atmosphericpressure mass microscope. Anal Chem 81:9153-9157

Hegeman AD (2010) Plant metabolomics-meeting the analytical challenges of comprehensive metabolite analysis. Brief Funct Genomics 9:139-148

Hemalatha RG, Pradeep T (2013) Understanding the molecular signatures in leaves and flowers by desorption electrospray ionization mass spectrometry (DESI MS) imaging. J Agric Food Chem 61:7477-7487

Holscher D, Shroff R, Knop K, Gottschaldt M, Crecelius A, Schneider B, Heckel DG, Schubert US, Svatos A (2009) Matrix-free UV-laser desorption/ionization (LDI) mass spectrometric imaging at the single-cell level: distribution of secondary metabolites of Arabidopsis thaliana and Hypericum species. Plant J 60:907-918

Hölscher D, Dhakshinamoorthy S, Alexandrov T, Becker M, Bretschneider T, Buerkert A, Crecelius AC, De Waele D, Elsen A, Heckel DG, Heklau H, Hertweck C, Kai M, Knop K, Krafft C, Maddula RK, Matthäus C, Popp J, Schneider B, Schubert US, Sikora RA, Svatoš A, Swennen RL (2014) Phenalenone-type phytoalexins mediate resistance of banana plants (Musa spp.) to the burrowing nematode Radopholus similis. Proc Natl Acad Sci 111:105-110

Horn PJ, Chapman KD (2013) Metabolite Imager: customized spatial analysis of metabolite distributions in mass spectrometry imaging. Metabolomics 10:337-348

Horn PJ, Chapman KD (2014) Lipidomics in situ: insights into plant lipid metabolism from high resolution spatial maps of metabolites. Prog Lipid Res 54:32-52

Horn PJ, Korte AR, Neogi PB, Love E, Fuchs J, Strupat K, Borisjuk L, Shulaev V, Lee YJ, Chapman KD (2012) Spatial mapping of lipids at cellular resolution in embryos of cotton. Plant Cell 24:622-636

Horn PJ, James CN, Gidda SK, Kilaru A, Dyer JM, Mullen RT, Ohlrogge JB, Chapman KD (2013a) Identification of a new class of lipid droplet-associated proteins in plants. Plant Physiol 162:1926-1936

Horn PJ, Silva JE, Anderson D, Fuchs J, Borisjuk L, Nazarenus TJ, Shulaev V, Cahoon EB, Chapman KD (2013b) Imaging heterogeneity of membrane and storage lipids in transgenic Camelina sativa seeds with altered fatty acid profiles. Plant J 76:138-150

Horn PJ, Sturtevant D, Chapman KD (2014) Modified oleic cottonseeds show altered content, composition and tissuespecific distribution of triacylglycerol molecular species. Biochimie 96:28-36

Hsiao CH, Hong CW, Liu BH, Chen CW, Wu CC, Wang YS (2011) Comprehensive molecular imaging of photolabile surface samples with synchronized dual-polarity time-offlight mass spectrometry. Rapid Commun Mass Spectrom 25:834-842

Ifa DR, Wiseman JM, Song Q, Cooks RG (2007) Development of capabilities for imaging mass spectrometry under ambient conditions with desorption electrospray ionization (DESI). Int J Mass Spectrom 259:8-15

Ifa DR, Srimany A, Eberlin LS, Naik HR, Bhat V, Cooks RG, Pradeep T (2011) Tissue imprint imaging by desorption 
electrospray ionization mass spectrometry. Anal Methods 3:1910

Imai T, Tanabe K, Kato T, Fukushima K (2005) Localization of ferruginol, a diterpene phenol, in Cryptomeria japonica heartwood by time-of-flight secondary ion mass spectrometry. Planta 221:549-556

Jackson SN, Ugarov M, Egan T, Post JD, Langlais D, Albert Schultz J, Woods AS (2007) MALDI-ion mobilityTOFMS imaging of lipids in rat brain tissue. J Mass Spectrom 42:1093-1098

Jackson SN, Baldwin K, Muller L, Womack VM, Schultz JA, Balaban C, Woods AS (2014a) Imaging of lipids in rat heart by MALDI-MS with silver nanoparticles. Anal Bioanal Chem 406:1377-1386

Jackson SN, Barbacci D, Egan T, Lewis EK, Schultz JA, Woods AS (2014b) MALDI-ion mobility mass spectrometry of lipids in negative ion mode. Anal Methods 6:5001-5007

Jun JH, Song Z, Liu Z, Nikolau BJ, Yeung ES, Lee YJ (2010) High-spatial and high-mass resolution imaging of surface metabolites of arabidopsis thaliana by laser desorptionionization mass spectrometry using colloidal silver. Anal Chem 82:3255-3265

Jung S, Chen Y, Sullards MC, Ragauskas AJ (2010) Direct analysis of cellulose in poplar stem by matrix-assisted laser desorption/ionization imaging mass spectrometry. Rapid Commun Mass Spectrom 24:3230-3236

Jungmann JH, Heeren RM (2012) Emerging technologies in mass spectrometry imaging. J Proteomics 75:5077-5092

Kaspar S, Peukert M, Svatos A, Matros A, Mock H-P (2011) MALDI-imaging mass spectrometry-an emerging technique in plant biology. Proteomics 11:1840-1850

Kertesz V, Van Berkel GJ (2010) Fully automated liquid extraction-based surface sampling and ionization using a chip-based robotic nanoelectrospray platform. J Mass Spectrom 45:252-260

Klein AT, Yagnik GB, Hohenstein JD, Ji Z, Zi J, Reichert MD, MacIntosh GC, Yang B, Peters RJ, Vela J, Lee YJ (2015) Investigation of the chemical interface in the soybeanaphid and rice-bacteria interactions using MALDI-mass spectrometry imaging. Anal Chem 87:5294-5301

Klinkert I, Chughtai K, Ellis SR, Heeren RMA (2014) Methods for full resolution data exploration and visualization for large $2 \mathrm{D}$ and $3 \mathrm{D}$ mass spectrometry imaging datasets. Int $\mathrm{J}$ Mass Spectrom 362:40-47

Koestler M, Kirsch D, Hester A, Leisner A, Guenther S, Spengler B (2008) A high-resolution scanning microprobe matrix-assisted laser desorption/ionization ion source for imaging analysis on an ion trap/Fourier transform ion cyclotron resonance mass spectrometer. Rapid Commun Mass Spectrom 22:3275-3285

Korte A, Farlow A (2013) The advantages and limitations of trait analysis with GWAS: a review. Plant Methods 9:29

Korte AR, Lee YJ (2014) MALDI-MS analysis and imaging of small molecule metabolites with 1,5-diaminonaphthalene (DAN). J Mass Spectrom 49:737-741

Korte AR, Song Z, Nikolau BJ, Lee YJ (2012) Mass spectrometric imaging as a high-spatial resolution tool for functional genomics: tissue-specific gene expression of TT7 inferred from heterogeneous distribution of metabolites in Arabidopsis flowers. Anal Methods 4:474-481
Korte AR, Yandeau-Nelson MD, Nikolau BJ, Lee YJ (2015) Subcellular-level resolution MALDI-MS imaging of maize leaf metabolites by MALDI-linear ion trap-orbitrap mass spectrometer. Anal Bioanal Chem 407:2301-2309

Krasny L, Hoffmann F, Ernst G, Trede D, Alexandrov T, Havlicek V, Guntinas-Lichius O, von Eggeling F, Crecelius AC (2015) Spatial segmentation of MALDI FT-ICR MSI data: a powerful tool to explore the head and neck tumor in situ lipidome. J Am Soc Mass Spectrom 26:36-43

Lane AL, Nyadong L, Galhena AS, Shearer TL, Stout EP, Parry RM, Kwasnik M, Wang MD, Hay ME, Fernandez FM, Kubanek J (2009) Desorption electrospray ionization mass spectrometry reveals surface-mediated antifungal chemical defense of a tropical seaweed. Proc Natl Acad Sci USA 106:7314-7319

Lanekoff I, Burnum-Johnson K, Thomas M, Short J, Carson JP, Cha J, Dey SK, Yang P, Prieto Conaway MC, Laskin J (2013) High-speed tandem mass spectrometric in situ imaging by nanospray desorption electrospray ionization mass spectrometry. Anal Chem 85:9596-9603

Lanni E, Dunham SB, Nemes P, Rubakhin S, Sweedler J (2014) Biomolecular imaging with a C60-SIMS/MALDI dual ion source hybrid mass spectrometer: instrumentation, matrix enhancement, and single cell analysis. J Am Soc Mass Spectrom 25:1897-1907

Laskin J, Eckert PA, Roach PJ, Heath BS, Nizkorodov SA, Laskin A (2012a) Chemical analysis of complex organic mixtures using reactive nanospray desorption electrospray ionization mass spectrometry. Anal Chem 84:7179-7187

Laskin J, Heath BS, Roach PJ, Cazares L, Semmes OJ (2012b) Tissue imaging using nanospray desorption electrospray ionization mass spectrometry. Anal Chem 84:141-148

Lefevre R (1975) Microanalyse et microscopie ioniques des tissus calcifies humains., Academie de Paris, vol. PhD. Universite Rene Descartes, Paris

Li Y, Shrestha B, Vertes A (2007) Atmospheric pressure molecular imaging by infrared MALDI mass spectrometry. Anal Chem 79:523-532

Li Y, Shrestha B, Vertes A (2008) Atmospheric pressure infrared MALDI imaging mass spectrometry for plant metabolomics. Anal Chem 80:407-420

Li Z, Bohn PW, Sweedler JV (2010a) Comparison of sample pre-treatments for laser desorption ionization and secondary ion mass spectrometry imaging of Miscanthus $\times$ giganteus. Bioresour Technol 101:5578-5585

Li Z, Chu L-Q, Sweedler JV, Bohn PW (2010b) Spatial correlation of confocal raman scattering and secondary ion mass spectrometric molecular images of lignocellulosic materials. Anal Chem 82:2608-2611

Li B, Bjarnholt N, Hansen SH, Janfelt C (2011) Characterization of barley leaf tissue using direct and indirect desorption electrospray ionization imaging mass spectrometry. J Mass Spectrom 46:1241-1246

Li B, Hansen SH, Janfelt C (2013a) Direct imaging of plant metabolites in leaves and petals by desorption electrospray ionization mass spectrometry. Int $\mathrm{J}$ Mass Spectrom 348:15-22

Li B, Knudsen C, Hansen NK, Jorgensen K, Kannangara R, Bak S, Takos A, Rook F, Hansen SH, Moller BL, Janfelt C, Bjarnholt N (2013b) Visualizing metabolite distribution 
and enzymatic conversion in plant tissues by desorption electrospray ionization mass spectrometry imaging. Plant $\mathbf{J}$ 74:1059-1071

Li B, Bhandari DR, Janfelt C, Rompp A, Spengler B (2014a) Natural products in Glycyrrhiza glabra (licorice) rhizome imaged at the cellular level by atmospheric pressure matrix-assisted laser desorption/ionization tandem mass spectrometry imaging. Plant J 80:161-171

Li C, Wang Z, Jones AD (2014b) Chemical imaging of trichome specialized metabolites using contact printing and laser desorption/ionization mass spectrometry. Anal Bioanal Chem 406:171-182

Lorenz M, Ovchinnikova OS, Kertesz V, Van Berkel GJ (2013) Laser microdissection and atmospheric pressure chemical ionization mass spectrometry coupled for multimodal imaging. Rapid Commun Mass Spectrom 27:1429-1436

Louie KB, Bowen BP, McAlhany S, Huang Y, Price JC, Mao JH, Hellerstein M, Northen TR (2013) Mass spectrometry imaging for in situ kinetic histochemistry. Sci Rep 3:1656

Lunsford KA, Peter GF, Yost RA (2011) Direct matrix-assisted laser desorption/ionization mass spectrometric imaging of cellulose and hemicellulose in populus tissue. Anal Chem 83:6722-6730

Maldonado-Torres M, Lopez-Hernandez JF, Jimenez-Sandoval P, Winkler R (2014) 'Plug and Play' assembly of a lowtemperature plasma ionization mass spectrometry imaging (LTP-MSI) system. J Proteomics 102:60-65

Marques JV, Dalisay DS, Yang H, Lee C, Davin LB, Lewis NG (2014) A multi-omics strategy resolves the elusive nature of alkaloids in Podophyllum species. Mol BioSyst 10:2838-2849

McAlister GC, Phanstiel DH, Brumbaugh J, Westphall MS, Coon JJ (2011) Higher-energy collision-activated dissociation without a dedicated collision cell. MCP 10(O111):009456

McDonnell LA, Rompp A, Balluff B, Heeren RM, Albar JP, Andren PE, Corthals GL, Walch A, Stoeckli M (2015) Discussion point: reporting guidelines for mass spectrometry imaging. Anal Bioanal Chem 407:2035-2045

Meriaux C, Franck J, Wisztorski M, Salzet M, Fournier I (2010) Liquid ionic matrixes for MALDI mass spectrometry imaging of lipids. J Proteomics 73:1204-1218

Miura D, Tsuji Y, Takahashi K, Wariishi H, Saito K (2010) A strategy for the determination of the elemental composition by fourier transform ion cyclotron resonance mass spectrometry based on isotopic peak ratios. Anal Chem 82:5887-5891

Miura D, Fujimura Y, Wariishi H (2012) In situ metabolomic mass spectrometry imaging: recent advances and difficulties. J Proteomics 75:5052-5060

Molin L, Seraglia R, Dani FR, Moneti G, Traldi P (2011) The double nature of 1,5-diaminonaphthalene as matrix-assisted laser desorption/ionization matrix: some experimental evidence of the protonation and reduction mechanisms. Rapid Commun Mass Spectrom 25:3091-3096

Monge ME, Harris GA, Dwivedi P, Fernandez FM (2013) Mass spectrometry: recent advances in direct open air surface sampling/ionization. Chem Rev 113:2269-2308

Moore KL, Schröder M, Wu Z, Martin BGH, Hawes CR, McGrath SP, Hawkesford MJ, Feng Ma J, Zhao F-J, Grovenor CRM (2011) High-resolution secondary ion mass spectrometry reveals the contrasting subcellular distribution of arsenic and silicon in rice roots. Plant Physiol 156:913-924

Moore KL, Hawes CR, McGrath SP, Zhao F-J, Grovenor CRM (2013) High resolution SIMS analysis of arsenic in rice. Surf Interface Anal 45:309-311

Morrison GH, Slodzian G (1975) Ion microscopy. Anal Chem 47:932A-943A

Mullen AK, Clench MR, Crosland S, Sharples KR (2005) Determination of agrochemical compounds in soya plants by imaging matrix-assisted laser desorption/ionisation mass spectrometry. Rapid Commun Mass Spectrom 19:2507-2516

Muller T, Oradu S, Ifa DR, Cooks RG, Krautler B (2011) Direct plant tissue analysis and imprint imaging by desorption electrospray ionization mass spectrometry. Anal Chem 83:5754-5761

Muller L, Kailas A, Jackson SN, Roux A, Barbacci DC, Schultz JA, Balaban CD, Woods AS (2015) Lipid imaging within the normal rat kidney using silver nanoparticles by matrixassisted laser desorption/ionization mass spectrometry. Kidney Int 88:162-192

Nemes P, Vertes A (2007) Laser ablation electrospray ionization for atmospheric pressure, in vivo, and imaging mass spectrometry. Anal Chem 79:8098-8106

Nemes P, Barton AA, Li Y, Vertes A (2008) Ambient molecular imaging and depth profiling of live tissue by infrared laser ablation electrospray ionization mass spectrometry. Anal Chem 80:4575-4582

Nemes P, Barton AA, Vertes A (2009) Three-dimensional imaging of metabolites in tissues under ambient conditions by laser ablation electrospray ionization mass spectrometry. Anal Chem 81:6668-6675

Norris JL, Caprioli RM (2013) Analysis of tissue specimens by matrix-assisted laser desorption/ionization imaging mass spectrometry in biological and clinical research. Chem Rev 113:2309-2342

Norris JL, Cornett DS, Mobley JA, Andersson M, Seeley EH, Chaurand P, Caprioli RM (2007) Processing MALDI mass spectra to improve mass spectral direct tissue analysis. Int J Mass Spectrom 260:212-221

Ogrinc Potočnik N, Škrášková K, Flinders B, Pelicon P, Heeren RMA (2014) Gold sputtered fiducial markers for combined secondary ion mass spectrometry and MALDI imaging of tissue samples. Anal Chem 86:6781-6785

Oliveira SR, Arruda MAZ (2015) Application of laser ablation (imaging) inductively coupled plasma mass spectrometry for mapping and quantifying $\mathrm{Fe}$ in transgenic and nontransgenic soybean leaves. J Anal At Spectrom 30:389-395

Olsen JV, Macek B, Lange O, Makarov A, Horning S, Mann M (2007) Higher-energy C-trap dissociation for peptide modification analysis. Nat Methods 4:709-712

Park SG, Murray KK (2012) Infrared laser ablation sample transfer for MALDI imaging. Anal Chem 84:3240-3245

Paschke C, Leisner A, Hester A, Maass K, Guenther S, Bouschen W, Spengler B (2013) Mirion-a software package for automatic processing of mass spectrometric images. J Am Soc Mass Spectrom 24:1296-1306

Patterson NH, Thomas A, Chaurand P (2014) Monitoring timedependent degradation of phospholipids in sectioned tissues by MALDI imaging mass spectrometry. J Mass Spectrom 49:622-627 
Perdian DC, Lee YJ (2010) Imaging MS methodology for more chemical information in less data acquisition time utilizing a hybrid linear ion trap-orbitrap mass spectrometer. Anal Chem 82:9393-9400

Peukert M, Matros A, Lattanzio G, Kaspar S, Abadia J, Mock HP (2012) Spatially resolved analysis of small molecules by matrix-assisted laser desorption/ionization mass spectrometric imaging (MALDI-MSI). New Phytol 193:806-815

Peukert M, Thiel J, Peshev D, Weschke W, Van den Ende W, Mock HP, Matros A (2014) Spatio-temporal dynamics of fructan metabolism in developing barley grains. Plant Cell 26:3728-3744

Poth AG, Mylne JS, Grassl J, Lyons RE, Millar AH, Colgrave ML, Craik DJ (2012) Cyclotides associate with leaf vasculature and are the products of a novel precursor in petunia (Solanaceae). J Biol Chem 287:27033-27046

Powers TW, Neely BA, Shao Y, Tang H, Troyer DA, Mehta AS, Haab BB, Drake RR (2014) MALDI imaging mass spectrometry profiling of $\mathrm{N}$-glycans in formalin-fixed paraffin embedded clinical tissue blocks and tissue microarrays. PLoS ONE 9:e106255

Rector BG, Liang G, Guo Y (2003) Effect of maysin on wildtype, deltamethrin-resistant, and Bt-resistant Helicoverpa armigera (Lepidoptera: Noctuidae). J Econ Entomol 96:909-913

Roach PJ, Laskin J, Laskin A (2010) Nanospray desorption electrospray ionization: an ambient method for liquid-extraction surface sampling in mass spectrometry. Analyst 135:2233-2236

Robichaud G, Garrard KP, Barry JA, Muddiman DC (2013) MSiReader: an open-source interface to view and analyze high resolving power MS imaging files on Matlab platform. J Am Soc Mass Spectrom 24:718-721

Robichaud G, Barry J, Muddiman D (2014) IR-MALDESI mass spectrometry imaging of biological tissue sections using ice as a matrix. J Am Soc Mass Spectrom 25:319-328

Robinson S, Warburton K, Seymour M, Clench M, ThomasOates J (2007) Localization of water-soluble carbohydrates in wheat stems using imaging matrix-assisted laser desorption ionization mass spectrometry. New Phytol 173:438-444

Rompp A, Spengler B (2013) Mass spectrometry imaging with high resolution in mass and space. Histochem Cell Biol 139:759-783

Rompp A, Wang R, Albar JP, Urbani A, Hermjakob H, Spengler B, Vizcaino JA (2015) A public repository for mass spectrometry imaging data. Anal Bioanal Chem 407:2027-2033

Rübel O, Greiner A, Cholia S, Louie K, Bethel EW, Northen TR, Bowen BP (2013) OpenMSI: a high-performance webbased platform for mass spectrometry imaging. Anal Chem 85:10354-10361

Saito K, Mitsutani T, Imai T, Matsushita Y, Fukushima K (2008) Discriminating the indistinguishable sapwood from heartwood in discolored ancient wood by direct molecular mapping of specific extractives using time-of-flight secondary ion mass spectrometry. Anal Chem 80:1552-1557

Saito K, Watanabe Y, Shirakawa M, Matsushita Y, Imai T, Koike T, Sano Y, Funada R, Fukazawa K, Fukushima K (2012) Direct mapping of morphological distribution of syringyl and guaiacyl lignin in the xylem of maple by time- of-flight secondary ion mass spectrometry. Plant J 69:542-552

Sarsby J, Towers MW, Stain C, Cramer R, Koroleva OA (2012) Mass spectrometry imaging of glucosinolates in Arabidopsis flowers and siliques. Phytochemistry 77:110-118

Schramm T, Hester A, Klinkert I, Both JP, Heeren RM, Brunelle A, Laprevote O, Desbenoit N, Robbe MF, Stoeckli M, Spengler B, Rompp A (2012) imzML—a common data format for the flexible exchange and processing of mass spectrometry imaging data. J Proteomics 75:5106-5110

Schwartz SA, Reyzer ML, Caprioli RM (2003) Direct tissue analysis using matrix-assisted laser desorption/ionization mass spectrometry: practical aspects of sample preparation. J Mass Spectrom 38:699-708

Seaman C, Flinders B, Eijkel G, Heeren RM, Bricklebank N, Clench MR (2014) "Afterlife experiment": use of MALDI-MS and SIMS imaging for the study of the nitrogen cycle within plants. Anal Chem 86:10071-10077

Seeley EH, Caprioli RM (2012) 3D imaging by mass spectrometry: a new frontier. Anal Chem 84:2105-2110

Seeley EH, Oppenheimer SR, Mi D, Chaurand P, Caprioli RM (2008) Enhancement of protein sensitivity for MALDI imaging mass spectrometry after chemical treatment of tissue sections. J Am Soc Mass Spectrom 19:1069-1077

Seyer A, Einhorn J, Brunelle A, Laprévote O (2010) Localization of flavonoids in seeds by cluster time-of-flight secondary ion mass spectrometry imaging. Anal Chem 82:2326-2333

Shariatgorji M, Svenningsson P, Andren PE (2014) Mass spectrometry imaging, an emerging technology in neuropsychopharmacology. Neuropsychopharmacology 39:34-49

Sheraz nee Rabbani S, Razo IB, Kohn T, Lockyer NP, Vickerman JC (2015) Enhancing ion yields in time-of-flightsecondary ion mass spectrometry: a comparative study of argon and water cluster primary beams. Anal Chem $87: 2367-2374$

Shrestha B, Patt JM, Vertes A (2011) In situ cell-by-cell imaging and analysis of small cell populations by mass spectrometry. Anal Chem 83:2947-2955

Shroff R, Vergara F, Muck A, Svatos A, Gershenzon J (2008) Nonuniform distribution of glucosinolates in Arabidopsis thaliana leaves has important consequences for plant defense. Proc Natl Acad Sci USA 105:6196-6201

Shroff R, Schramm K, Jeschke V, Nemes P, Vertes A, Gershenzon J, Svatos A (2015) Quantification of plant surface metabolites by matrix-assisted laser desorption-ionization mass spectrometry imaging: glucosinolates on Arabidopsis thaliana leaves. Plant J 81:961-972

Silva DB, Turatti ICC, Gouveia DR, Ernst M, Teixeira SP, Lopes NP (2014) Mass spectrometry of flavonoid vicenin2, based sunlight barriers in Lychnophora species. Sci Rep 4:4309

Sleno L, Volmer DA (2004) Ion activation methods for tandem mass spectrometry. J Mass Spectrom 39:1091-1112

Soares MS, da Silva DF, Forim MR, da Silva MF, Fernandes JB, Vieira PC, Silva DB, Lopes NP, de Carvalho SA, de Souza AA, Machado MA (2015) Quantification and localization of hesperidin and rutin in Citrus sinensis grafted on $C$. limonia after Xylella fastidiosa infection by HPLC-UV and MALDI imaging mass spectrometry. Phytochemistry 115:161-170 
Soltwisch J, Göritz G, Jungmann JH, Kiss A, Smith DF, Ellis SR, Heeren RMA (2014) MALDI mass spectrometry imaging in microscope mode with infrared lasers: bypassing the diffraction limits. Anal Chem 86:321-325

Soltwisch J, Kettling H, Vens-Cappell S, Wiegelmann M, Muthing J, Dreisewerd K (2015) Mass spectrometry imaging with laser-induced postionization. Science 348:211-215

Sparvero LJ, Amoscato AA, Dixon CE, Long JB, Kochanek PM, Pitt BR, Bayır H, Kagan VE (2012) Mapping of phospholipids by MALDI imaging (MALDI-MSI): realities and expectations. Chem Phys Lipids 165:545-562

Spengler B (2015) Mass spectrometry imaging of biomolecular information. Anal Chem 87:64-82

Spengler B, Kaufmann MHR (1994) Development of a new scanning UV-laser microprobe for ion imaging and confocal microscopy. In: Proceedings of the 42nd ASMS conference on mass spectrometry and allied topics, May 29-June 3, 1994, Chicago, Illinois. ASMS

Stauber J, MacAleese L, Franck J, Claude E, Snel M, Kaletas BK, Wiel IM, Wisztorski M, Fournier I, Heeren RM (2010) On-tissue protein identification and imaging by MALDIion mobility mass spectrometry. J Am Soc Mass Spectrom 21:338-347

Sumner LW, Lei Z, Nikolau BJ, Saito K (2015) Modern plant metabolomics: advanced natural product gene discoveries, improved technologies, and future prospects. Nat Prod Rep 32:212-229

Sussulini A, Wiener E, Marnitz T, Wu B, Muller B, Hamm B, Sabine Becker J (2013) Quantitative imaging of the tissue contrast agent [Gd(DTPA)](2)(-) in articular cartilage by laser ablation inductively coupled plasma mass spectrometry. Contrast Media Mol Imaging 8:204-209

Svatoš A (2010) Mass spectrometric imaging of small molecules. Trends Biotechnol 28:425-434

Syed SU, Eijkel GB, Maher S, Kistemaker P, Taylor S, Heeren RM (2015) A micropixelated ion-imaging detector for mass resolution enhancement of a QMS instrument. Anal Bioanal Chem 407:2055-2062

Syka JEP, Coon JJ, Schroeder MJ, Shabanowitz J, Hunt DF (2004) Peptide and protein sequence analysis by electron transfer dissociation mass spectrometry. Proc Natl Acad Sci USA 101:9528-9533

Taira S, Sugiura Y, Moritake S, Shimma S, Ichiyanagi Y, Setou M (2008) Nanoparticle-assisted laser desorption/ionization based mass imaging with cellular resolution. Anal Chem 80:4761-4766

Taira S, Shimma S, Osaka I, Kaneko D, Ichiyanagi Y, Ikeda R, Konishi-Kawamura Y, Zhu S, Tsuneyama K, Komatsu K (2012) Mass spectrometry imaging of the capsaicin localization in the Capsicum fruits. Int J Biotechnol Wellness Ind 1:61-65

Tata A, Montemurro C, Porcari AM, Silva KC, Lopes de Faria JB, Eberlin MN (2014) Spatial distribution of theobromine-a low MW drug-in tissues via matrixfree NALDI-MS imaging. Drug Test Anal 6:949-952

Tata A, Perez C, Hamid T, Bayfield M, Ifa D (2015) Analysis of metabolic changes in plant pathosystems by imprint imaging DESI-MS. J Am Soc Mass Spectrom 26:641-648

Thiery-Lavenant G, Zavalin AI, Caprioli RM (2013) Targeted multiplex imaging mass spectrometry in transmission geometry for subcellular spatial resolution. J Am Soc Mass Spectrom 24:609-614

Thunig J, Hansen SH, Janfelt C (2011) Analysis of secondary plant metabolites by indirect desorption electrospray ionization imaging mass spectrometry. Anal Chem $83: 3256-3259$

Tomlinson L, Fuchser J, Futterer A, Baumert M, Hassall DG, West A, Marshall PS (2014) Using a single, high mass resolution mass spectrometry platform to investigate ion suppression effects observed during tissue imaging. Rapid Commun Mass Spectrom 28:995-1003

Vaikkinen A, Shrestha B, Kauppila TJ, Vertes A, Kostiainen R (2012) Infrared laser ablation atmospheric pressure photoionization mass spectrometry. Anal Chem 84:1630-1636

Vaikkinen A, Shrestha B, Nazarian J, Kostiainen R, Vertes A, Kauppila TJ (2013) Simultaneous detection of nonpolar and polar compounds by heat-assisted laser ablation electrospray ionization mass spectrometry. Anal Chem 85:177-184

Van de Plas R, Yang J, Spraggins J, Caprioli RM (2015) Image fusion of mass spectrometry and microscopy: a multimodality paradigm for molecular tissue mapping. Nat Methods 12:366-372

van Hove ER, Smith DF, Fornai L, Glunde K, Heeren RM (2011) An alternative paper based tissue washing method for mass spectrometry imaging: localized washing and fragile tissue analysis. J Am Soc Mass Spectrom 22:1885-1890

Velickovic D, Herdier H, Philippe G, Marion D, Rogniaux H, Bakan B (2014) Matrix-assisted laser desorption/ionization mass spectrometry imaging: a powerful tool for probing the molecular topology of plant cutin polymer. Plant J 80:926-935

Veličković D, Ropartz D, Guillon F, Saulnier L, Rogniaux H (2014) New insights into the structural and spatial variability of cell-wall polysaccharides during wheat grain development, as revealed through MALDI mass spectrometry imaging. J Exp Bot 65:2079-2091

Vrkoslav V, Muck A, Cvacka J, Svatos A (2010) MALDI imaging of neutral cuticular lipids in insects and plants. J Am Soc Mass Spectrom 21:220-231

Wang X, Han J, Chou A, Yang J, Pan J, Borchers CH (2013) Hydroxyflavones as a new family of matrices for MALDI tissue imaging. Anal Chem 85:7566-7573

Weidner S, Schultze RD, Enthaler B (2013) Matrix-assisted laser desorption/ionization imaging mass spectrometry of pollen grains and their mixtures. Rapid Commun Mass Spectrom 27:896-903

Wijetunge CD, Saeed I, Halgamuge SK, Boughton B, Roessner U (2014) Unsupervised learning for exploring MALDI imaging mass spectrometry 'omics' data. In: 2014 7th international conference on information and automation for sustainability (ICIAfS), pp 1-6

Wiseman JM, Ifa DR, Song Q, Cooks RG (2006) Tissue imaging at atmospheric pressure using desorption electrospray ionization (DESI) mass spectrometry. Angew Chem Int Ed Engl 45:7188-7192

Woo H-K, Northen TR, Yanes O, Siuzdak G (2008) Nanostructure-initiator mass spectrometry: a protocol for preparing and applying NIMS surfaces for high-sensitivity mass analysis. Nat Protocols 3:1341-1349 
Wu HP, Yu CJ, Lin CY, Lin YH, Tseng WL (2009) Gold nanoparticles as assisted matrices for the detection of biomolecules in a high-salt solution through laser desorption/ionization mass spectrometry. J Am Soc Mass Spectrom 20:875-882

Wu C, Dill AL, Eberlin LS, Cooks RG, Ifa DR (2013) Mass spectrometry imaging under ambient conditions. Mass Spectrom Rev 32:218-243

Yang H, Liu N, Qiu X, Liu S (2009) A new method for analysis of disulfide-containing proteins by matrix-assisted laser desorption ionization (MALDI) mass spectrometry. J Am Soc Mass Spectrom 20:2284-2293

Ye H, Gemperline E, Venkateshwaran M, Chen R, Delaux PM, Howes-Podoll M, Ane JM, Li L (2013) MALDI mass spectrometry-assisted molecular imaging of metabolites during nitrogen fixation in the Medicago truncatula-Sinorhizobium meliloti symbiosis. Plant J 75:130-145

Yoshimura Y, Enomoto H, Moriyama T, Kawamura Y, Setou M, Zaima N (2012a) Visualization of anthocyanin species in rabbiteye blueberry Vaccinium ashei by matrix-assisted laser desorption/ionization imaging mass spectrometry. Anal Bioanal Chem 403:1885-1895

Yoshimura Y, Zaima N, Moriyama T, Kawamura Y (2012b) Different localization patterns of anthocyanin species in the pericarp of black rice revealed by imaging mass spectrometry. PLoS ONE 7:e31285
Zaima N, Goto-Inoue N, Hayasaka T, Setou M (2010) Application of imaging mass spectrometry for the analysis of Oryza sativa rice. Rapid Commun Mass Spectrom 24:2723-2729

Zhang W, Franco C, Curtin C, Conn S (2004) To stretch the boundary of secondary metabolite production in plant cellbased bioprocessing: anthocyanin as a case study. J Biomed Biotechnol 2004:264-271

Zhang H, Cha S, Yeung ES (2007) Colloidal graphite-assisted laser desorption/ionization MS and MSn of small molecules. 2. Direct profiling and MS imaging of small metabolites from fruits. Anal Chem 79:6575-6584

Zhou C, Li Q, Chiang VL, Lucia LA, Griffis DP (2011) Chemical and spatial differentiation of syringyl and guaiacyl lignins in poplar wood via time-of-flight secondary ion mass spectrometry. Anal Chem 83:7020-7026

Zoltán T, Wiseman JM, Gologan B, Cooks RG (2004) Mass spectrometry sampling under ambient conditions with desorption electrospray ionization. Science 306:471-473

Zubarev RA, Horn DM, Fridriksson EK, Kelleher NL, Kruger NA, Lewis MA, Carpenter BK, McLafferty FW (2000) Electron capture dissociation for structural characterization of multiply charged protein cations. Anal Chem 72:563-573 